INCREASING SELF-EFFICACY IN

RISK ASSESSMENT AND MANAGEMENT OF SUICIDAL CLIENTS:

TRAINING PERSPECTIVES FROM MENTAL HEALTH PROVIDERS

A Dissertation presented to the Faculty of the Graduate School

University of Missouri

In Partial Fulfillment

of the Requirements for the Degree

Doctor of Philosophy

by

REBEKAH A. FREESE

Dr. Mansoo Yu, Dissertation Chair

JULY 2019 
The undersigned, appointed by the dean of the Graduate School of the University of Missouri-Columbia, have examined the dissertation entitled

\section{INCREASING SELF-EFFICACY IN}

RISK ASSESSMENT AND MANAGEMENT OF SUICIDAL CLIENTS: TRAINING PERSPECTIVES FROM MENTAL HEALTH PROVIDERS

presented by Rebekah A. Freese, a candidate for the degree of doctor of philosophy, and hereby certify that, in their opinion, it is worthy of acceptance.

Professor Mansoo Yu

Professor Kelli Canada

Professor Clark Peters

Professor Tina Bloom 


\section{Dedication Page}

I dedicate this to the memory of my mother, Martha L. Rowntree Brownlie. The utmost spiritual, intelligent and strongest person I have ever known. My mother taught me to be compassionate, to critically think, and most of all, to dedicate my energy to the service of others. I will continue my life journey applying her values of love, social justice, high expectations, a strong work ethic, and the unselfish sacrifice to put others' needs before my own. Thank you for your unconditional love and dedication to me, Mom. May your spirit be the shining light for all of us to see! 


\section{ACKNOWLEDGEMENTS}

First, I would like to thank my advisor and dissertation chair, Dr. Mansoo Yu. Dr. Yu has been a great support throughout this process. I appreciate his guidance and willingness to lead me through the research process, especially the statistical analysis, which allowed me to grow my skills.

Thank you to the other committee members. To Dr. Kelli Canada, I will never be able to thank you enough for your kindness, generosity, and willingness to walk me through some of the challenging moments in this process, and allowing me to step out gracefully from a position I loved, to focus on finishing this process. I am honored to be your colleague. Thank you Dr. Clark Peters and Dr. Tina Bloom for your time and energy. I realize as a member of my committee it can be a time consuming process, and your support and guidance has been appreciated.

I am grateful to the Department of Mental Health for allowing me to use their trainings for my research study. Dr. Laine Young Walker and Dr. Ronda Reitz were incredibly kind and helpful in the development of my study. I especially appreciate Dr. Ronda Reitz for assisting me on the training days and her expertise in the field of suicide research and intervention.

I want to give a big thank you to Michael Pelts, $\mathrm{PhD}$ and Ashley Givens, $\mathrm{PhD}$ who listened and allowed for me to process through my findings in the study. They have been incredible supports and I am not able to thank them enough. Other important people in my life have supported and listened intently to me. I want to express my gratitude to them, Melissa Stone Rogers, Rae Finch, and Megan Corbin. To my students, especially those within the last few years, you are an inspiration and have been a driving force in my desire to train and supervise students and young careered professionals, as well as research what factors impact a provider's 
ability to perceive strong capabilities in assessing and managing suicidal clients. I would be remiss if I did not thank Amelia Howser and Ashley for spending their Saturdays and Sundays walking with me so I could relieve tension and stress, only to get back onto the saddle again and work long hours to complete this manuscript.

Finally, I want to thank my loving husband, Darren, and son, Dyson Myles, whom I cannot imagine a life without. Darren, you have been a catalyst for our family as I spent the last six years on this dissertation journey. Your love, hugs, and genuine kindness has lifted my spirits and allowed me to finish this marathon. Without you, I would be a lost soul and I am grateful for our time together on this earth. Dyson, your humor, laughter, and silliness are precious, and in moments of enduring stress, were such a relief to me. You are a shining star and will be an incredible leader in your lifetime. Thank you both for the gift of space and time to create and complete this process. 


\section{TABLE OF CONTENTS}

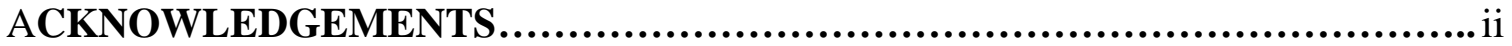

LIST OF TABLES..................................................................

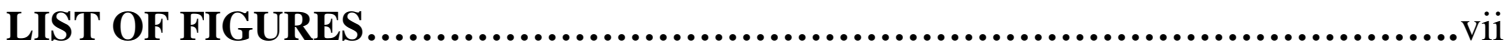

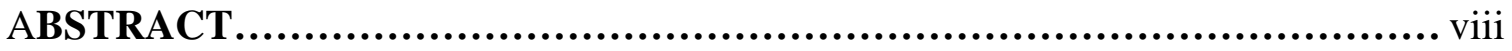

Chapter One: Introduction........................................................... 1

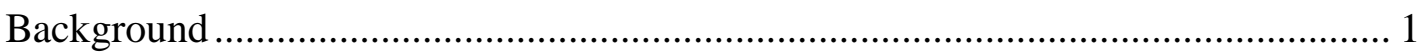

Significance of Assessing Suicide ...................................................................... 2

Significance to Social Work ........................................................................... 3

Challenges in Assessing Suicide in Practice.............................................................. 4

Characteristics of Mental Health Providers ............................................................. 6

Current Assessment Methods to Assess Suicidal Risk ............................................ 8

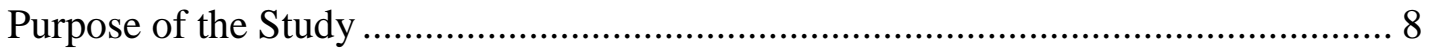

Chapter Two: Literature Review.................................................... 11

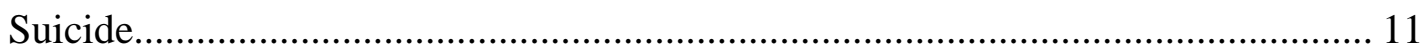

Known risk and protective factors associated with suicide ...................................... 14

Impact of Suicide Risk Assessment and Management Training ............................... 20

Proposed Training ……………………………………............................... 24

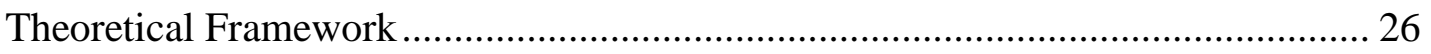

Chapter Three: Research Questions, Method \& Design................................35

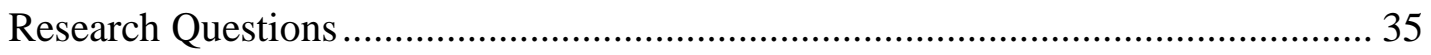

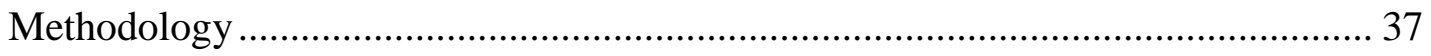




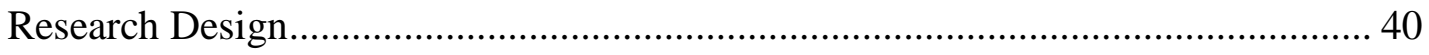

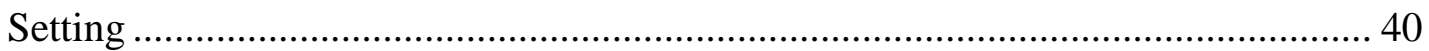

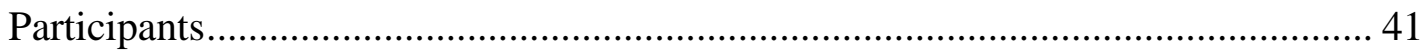

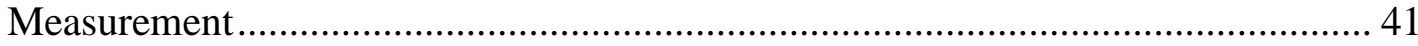

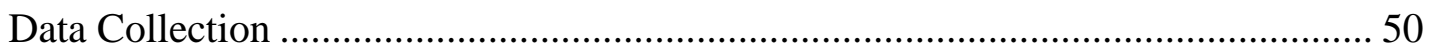

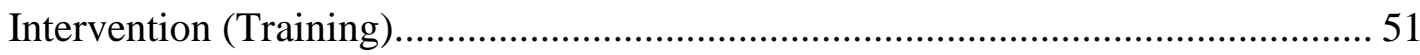

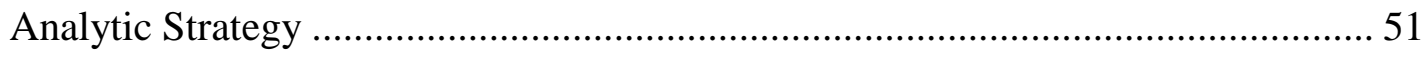

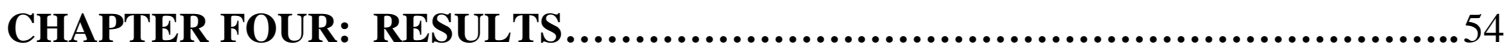

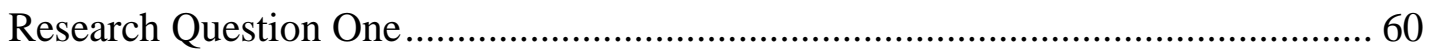

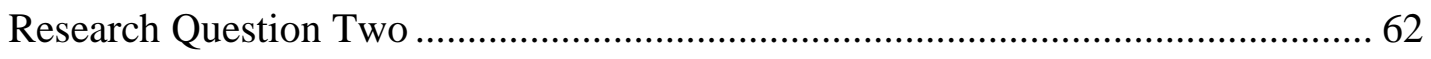

Research Question Three ...................................................................................... 66

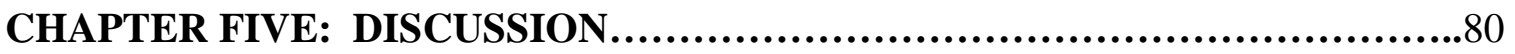

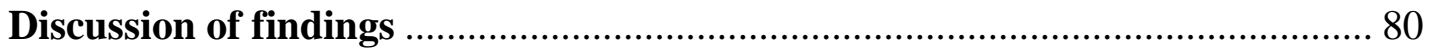

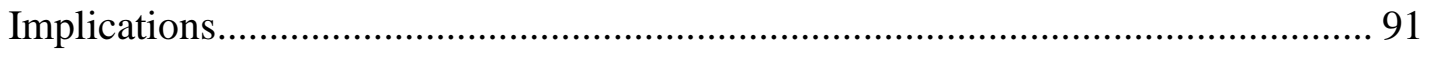

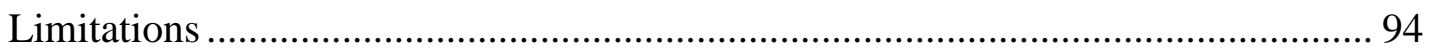

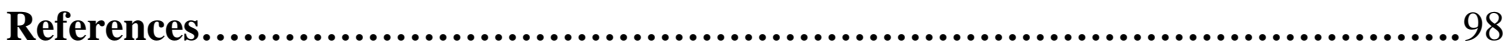

Appendix A: Recruitment Email............................................... 124

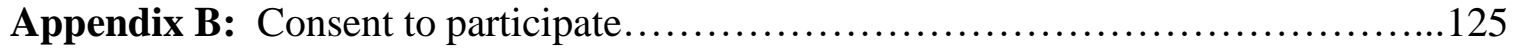

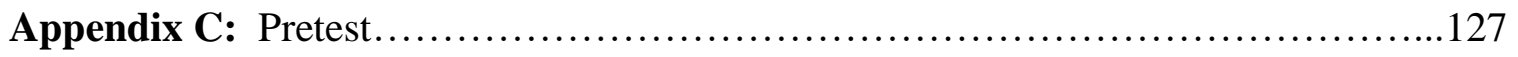

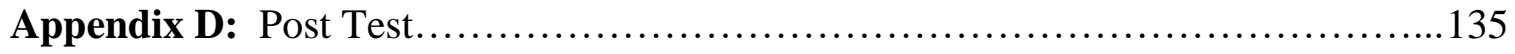

Appendix E: Training Feedback............................................. 138

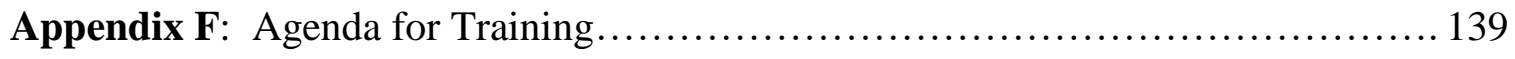

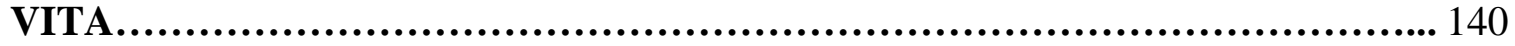




\section{LIST OF TABLES}

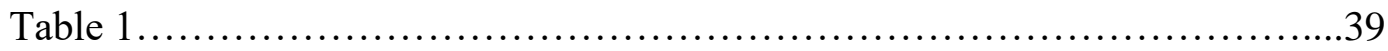

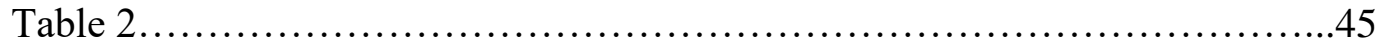

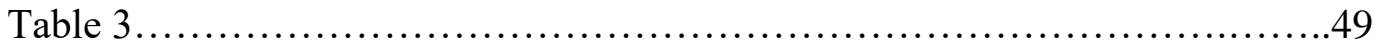

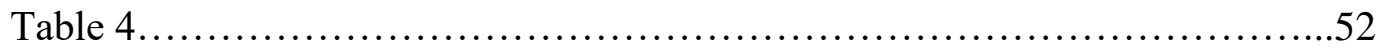

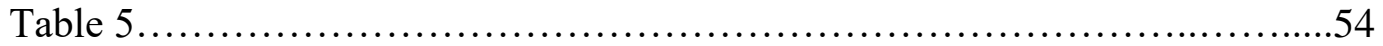

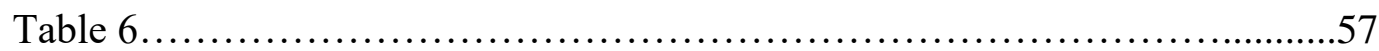

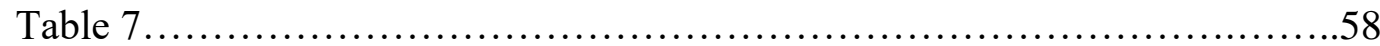

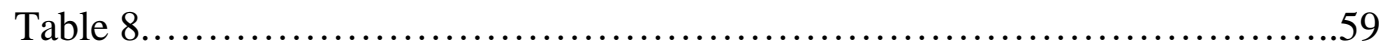

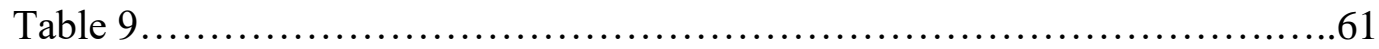

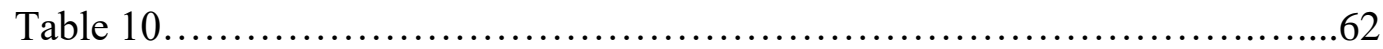

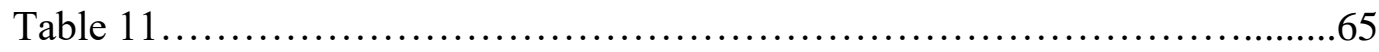

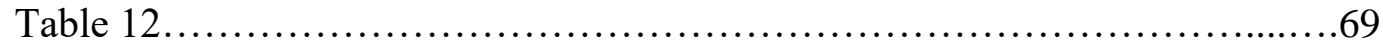

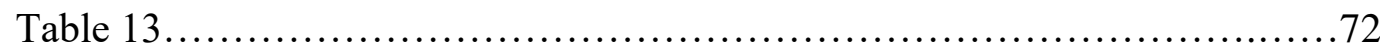

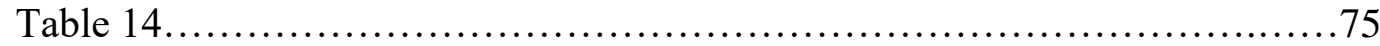

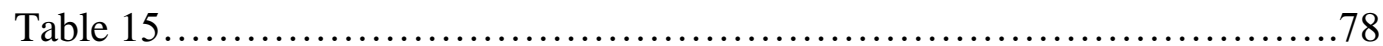




\section{LIST OF FIGURES}

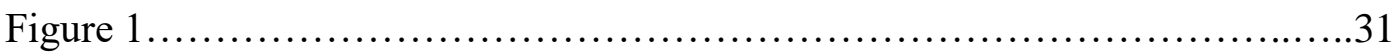

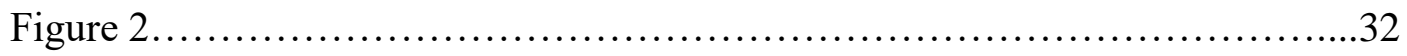

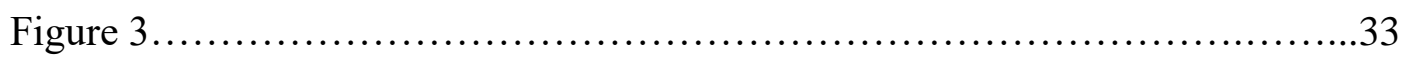

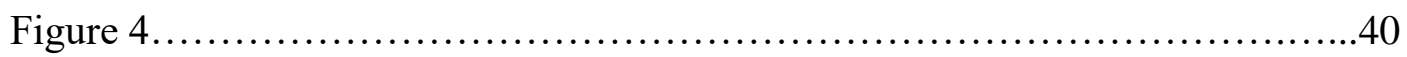




\title{
INCREASING SELF-EFFICACY IN
}

RISK ASSESSMENT AND MANAGEMENT OF SUICIDAL CLIENTS:

\section{TRAINING PERSPECTIVES FROM MENTAL HEALTH PROVIDERS}

\author{
Rebekah A. Freese \\ Dr. Mansoo Yu, Dissertation Supervisor
}

\begin{abstract}
Suicide is one of the top ten leading deaths among adults and children in the U.S. Suicidal clients are assessed using various risk assessment tools and by professionals who are trained in various theoretical and procedural frameworks. Self-Efficacy Theory (Bandura, 1996) and logic modeling (Kaplan \& Garrett, 2005; Lafferty \& Mahoney, 2003; McLaughlin \& Jordan, 1998; Millar, Simeone \& Carnevale, 2001) provided the theoretical framework for this study. This study aimed to (1) describe the characteristics of service providers working in the field, and (2) explore how service providers view their efficacy in suicide risk assessment and management of suicidal behaviors.
\end{abstract}

A sample of 340 service providers $(85.5 \%$ female) was recruited from nine different training sites across the state of Missouri. Descriptive statistics, bivariate analysis and, logistic regression analysis were employed to address three research questions and related hypotheses. Of the participants, $85.5 \%$ were female. Most of the participants $(80 \%)$ had completed education with a master's degree, and $71 \%$ were licensed professional counselors. Slightly less than half used Cognitive Behavioral Therapy (40\%) as their primary approach to practice, and over half of 
the participants had experience working with a suicidal client (88\%). Most of the participants had prior training in assessment and management of suicidal behavior (82\%). On average, participants reported they had a training 1.3 years prior this training. The posttest scores of general assessment, high-risk assessment, suicide history assessment, and management of suicidal behaviors were significantly higher than the pretest scores. Results of the regression analyses showed that ten or more years of practice experience, along with high sources of mastery and general-self efficacy, significantly predicted efficacy in suicide assessment and management after controlling for demographics. The findings provide a foundation to understanding sources of self-efficacy for providers, which can assist in developing supports, policies, and procedures to ensure quality and effective assessment and intervention for those clients who experience suicide. 


\section{Chapter One: Introduction}

\section{Background}

According to the American Foundation for Suicide Prevention (2019), approximately 129 individuals die by suicide per day. In 2016, the Center for Disease Control and Prevention (CDC) reported nearly 45,000 deaths by suicide. The World Health Organization and CDC report suicide as the $10^{\text {th }}$ leading cause of death in the US, $15^{\text {th }}$ leading cause of death worldwide, and for every death by suicide, there are 30 others who attempt. In 2018 in the United States, suicide was the $2^{\text {nd }}$ leading cause of death for ages 10 to 24 , and the $4^{\text {th }}$ leading cause among adults between ages $35-54$ (CDC, 2018). Missouri is ranked $19^{\text {th }}$ out of 50 states for deaths by suicide, with a reported 1,151 deaths by suicide in 2017 (American Association of Suicidology, 2017). The toll nationwide is higher than the total number of homicides and war-related deaths each year (World Health Organization, 2018). Each suicide attempt and death places a burden on family, friends, coworkers, and our nation in terms of emotional, economic and medical care costs, and loss of productivity (National Action Alliance, 2012).

In 2012, the U.S. Surgeon General, along with the National Action Alliance for Suicide Prevention, released the National Strategy for Suicide Prevention. This blueprint provides a guideline to health providers and organizations on how to organize efforts to prevent suicide. The goals of the 2012 National Strategy include: training personnel who are in contact with individuals with suicide risk, assessing and treating those individuals identified as at-risk for suicidal behaviors, and including suicide prevention as a core component in health care. Additionally, the National Institute of Mental Health (NIMH) (2014) points to early detection and understanding the role of risk factors as crucial to the prevention of suicide. 
Recommendations developed by these initiatives all point to risk assessment and management of suicidal behaviors as one route to prevention.

\section{Significance of Assessing Suicide}

Suicide risk assessment and management of suicide-related concerns is a task for many professionals, in particular mental health providers. Suicidal behavior is most visible to providers working in mental health services due to the correlation between mental health disorders and suicide (Feldman \& Freedenthal, 2006). Several studies have shown that one third to a half of all individuals who died by suicide received mental health services within the last month of their life (Luoma, Martin, \& Peason, 2002; Mann et al., 2005). The Joint Commission Behavioral Health Care National Patient Safety Goal 15.01.01 mandates mental health providers to continuously identify individuals who are most likely to try to die by suicide. The key tasks recommended by the Joint Commission are to conduct a risk assessment, to address the immediate safety needs, and to provide suicide prevention information if the individual leaves the care of the organization. The Commission on Accreditation of Rehabilitation (2012) calls for accredited service providers to have standards to guide clinicians in the areas of risk assessment and prevention.

The National Strategy for Suicide Prevention (2012) outlines critical goals to address deficits around risk assessment and suicide. The plan calls for "an increase in the number of licensing boards in relevant professions to require or promote competencies in depression and management of suicide prevention." The Commission on Accreditation of Rehabilitation Facilities (CARF), which oversees the accreditation of health and human service organizations, is in support of the 2012 National Strategy for Suicide Prevention. In efforts to meet this 
objective, many state licensing boards have responded by adding continuing education expectations for renewal of licensure. Trainings sponsored by reputable organizations, in each individual state, have been growing (American Psychological Association, 2018; NASW News, 2014). Organizations (e.g. hospitals, social service agencies, community mental health centers) have implemented policies and procedures for suicide risk assessment and intervention (Commission on Accreditation of Rehabilitation Facilities, 2016; Joint Commission, 2018).

Overtime studies have been conducted to readily evaluate training in educational and organizational/community settings. Schmitz et al. (2012) conducted a study to explore suicide specific training in an outpatient setting. The authors noted training is available and often accessible, yet it is not clear on how it impacts providers' behaviors. In contrast, Wachter, Morris \& Barrio Minto (2012) found licensed counselors reported in their first two years of practice receiving little to no training in suicide assessment. Pisani et al. (2011) described some concern of efficacy in continuing educational trainings (e.g. accessibility, length of training), however the authors did note effectiveness of evidenced-based trainings on knowledge and shifting of providers' attitudes on risk assessment. Findings from literature are conflicting on the overall impact of training, and limited in understanding the experiences from a provider's perspective. Awareness of what affects providers' abilities to perform suicide assessments and management of suicidal behaviors would decrease the gaps in literature.

\section{Significance to Social Work}

Social workers are the major providers in a wide range of settings, and thus have a high probability of encountering suicidal clients (Feldman, B. \& Freedenthal, S., 2006). Jacobson, Ting, Sanders \& Harrington (2004) indicate that social workers will experience at least one death 
of a client by suicide over the course of their career. According to the U.S. Department of Labor Bureau of Labor Statistics, the social work profession is rapidly growing. Approximately 650,000 individuals hold a social work degree (NASW, 2014). Given the growing population of social workers and the high likelihood of social work encounters with clients who are suicidal, additional training and awareness of suicide will likely have a significant impact.

\section{Challenges in Assessing Suicide in Practice}

The challenges in responding to suicidal individuals are not unique to any particular provider or setting. Unfortunately, it is not uncommon to overlook suicidal ideations if those thoughts are not accompanied by a previous attempt or current plan (Wolitzky-Taylor et al., 2010). A major threat to effectively manage clients experiencing suicide is inadequate training among mental health professionals (Bonger \& Harmatz, 1991; Harned, Lungu, Wilks, Linehan, 2016, Neimeyer, 2000). Any oversight of risk could potentially give rise to suicidal behaviors, attempts, and deaths. Providers who interact with suicidal clients experience various factors which impact their ability to detect risk and intervene. Some of those circumstances include: perceived capabilities of dealing effectively with a suicidal client, experience in conducting risk assessments and intervening with suicidal clients, history of losing a client to suicide, and fear of liability (Douglas \& Morris, 2015; Linehan, Comtois, Ward-Ciesielski, 2012; Rudd \& Cukrowicz, 2008). Despite those factors, the frequency with which individuals are attempting and dying by suicide points to the crucial need for mental health professionals to be prepared to assess and manage individuals at risk.

How a provider is trained in the area of suicide risk assessment and care of the suicidal individual is dependent on educational and professional training, organization policies, and 
continuing educational requirements (Betz et al., 2013; Graham et al., 2011; Mackelprang et al., 2014). Existing research on suicidal training ranges from brief suicidal screening to in-depth comprehensive risk assessment (Isaac, et al., 2009; Linehan, Comtois, \& Ward-Ciesielski, 2012; Oordt, Jobes, Fonseca, \& Schmidt, 2009; Osteen et al., 2014; Smith, Silva, Covington, \& Joiner, 2014). Research implies that almost half of our professionally trained mental health providers (psychologists, psychiatrists, social workers) receive little to no formal training from their academic institution for risk assessment and management of suicidal clients. In a few studies that reviewed postgraduate training and/or education, $42 \%$ of participants in the sample had no continuing education for risk assessment and management (Jobes, 2006). In academic institutions, training ranges from brief didactic training to none at all (Dexter, Mazza \& Freeman, 2003; Feldman, \& Freedenthal, 2006; Kleespies, Penk \& Forsyth, 1993). In a study of psychology graduate programs, Jahn et al. (2012) found that nearly 76\% of psychology graduate directors indicated a desire for more suicide specific training in their programs (as cited in Schmitz, Allen, Feldman, Gutin, Jhan, Kleespies, Quinnett and Simpson, 2012). In a study by Feldman \& Freedenthal (2006), 3,000 randomly selected social workers from the National Association of Social Workers (NASW) were asked in a web-based survey to provide information on experience and training with suicide. Out of the 457 who participated in the study, only $21.2 \%$ reported receiving formal training in their master's-level program (Feldman \& Freedenthal 2006). For those in the field of psychiatry, it appears more attempts are made to ensure proper training. In the review of the literature by Schmitz et al. (2012), a study by Ellis, Dickey and Jones (1988) indicated that $94 \%$ of directors from psychiatry reported risk assessment and intervention in their psychiatry residency programs. Evidence in research shows training, while accessible, typically only occurs at one point in time and often limited to no more 
than 16 hours in length (Betz, et al., 2013; Oordt et al., 2009; Smith et al., 2014). Research is pointing to training as an important aspect of preparing individuals for tasks in assessments. Since effectiveness and impact of training is still not fully understood, further research on impact of training will add to the literature.

Failure to accurately assess and manage suicidal behaviors appropriately is associated with negative consequences for providers (Helms \& Prinstein, 2014; Linehan, Comtois \& WardCiesielski, 2012). Liability is likely formulated by a provider's attitude, perception of the client, and lack of awareness of risk and protective factors (Linehan et al., 2012). Mental health professionals experiencing the loss of a client to suicide often report stress, fear, anger, personal inadequacy, depression, and guilt (Chemtob, Hamada, Bauer, Torigoe \& Kinney, 1988; Linehan et al., 2012; Wurst et al., 2010). Accurately identifying risk hinges on whether the provider is intuitively confident (perceived self-efficacy) and competent in his/her assessment (Douglas \& Morris, 2015, Schmitz, 2012). Additional insight into the elements that give rise to self-efficacy in assessment and management of suicidal is needed.

\section{Characteristics of Mental Health Providers}

Who are the professionals who engage with suicidal clients? Osteen and his colleagues (2014) have classified potential trained individuals that can come into contact with suicidal clients as gatekeepers and behavioral health providers. Gatekeepers are a heterogeneous group of individuals, but are not inclusive of behavioral health professionals (Isaac et al., 2009; Osteen et al., 2014). Community gatekeepers are typically professionals and para-professionals (e.g. case managers, administers, medical assistants) yet are not the "designated behavioral health professional" treating the suicidal individual. To further complicate the situation, one can 
consider the crisis line staff or primary health care providers (PCPs) as a part of the "gatekeeper" group. While gatekeepers play a crucial role in identifying suicidal clients, they often lack adequate training in facilitating a thorough risk assessment and effectively managing the suicidal clients long-term (Oordt et al., 2009; Schmitz, et al., 2012; Smith et al., 2014).

In contrast to the gatekeepers, there is an additional group of mental health professionals that are commonly referred to as Behavioral Health Providers (Osteen et al., 2014; Schmitz et al., 2012). This category of professionals includes those who work, not only with mental health issues, but those that provide substance abuse treatment as well. Psychiatrists, psychologists, nurses, social workers, and licensed professional counselors are among those considered in this provider class, most of who have been trained within higher education and adhere to licensure requirements that includes ongoing continuing education. In a national sample of social workers, $87 \%$ worked with a suicidal client (Feldman \& Freedenthal, 2006) and 99\% of pre-doctoral psychology interns indicated treating at least one suicidal client during their graduate training (Dexter-Mazza \& Freeman, 2003). Regardless of whether one is a gatekeeper or behavioral health professional, almost all those individuals working in or around health settings will encounter a client who is suicidal (Rudd \& Joiner, 1998; Schmitz et al., 2012).

Another characteristic of behavioral health providers is the theoretical lens or practice approach used in the field. A few common theoretical models, such as Cognitive Behavior Therapy (CBT), Behavior Therapy, Psychodynamic therapies, Person-Centered Therapy, Family Therapy, Motivational Interviewing (MI), and Dialectical Behavior Therapy (DBT), have been found to be used most frequently among behavioral or mental health providers (Walsh, 2010). In addition, some practice models are more conducive than others to providing training for suicide assessment and management (Linehan, 1993; Linehan. et al., 2012). For example, DBT trained 
providers are specifically trained to assess and manage suicidal behaviors prior to treating any other symptoms (Linehan, 1993). While the theoretical lens in which a provider approaches their practice does not necessarily equate to effective risk assessment and management of suicidal clients, there is a question as to whether cognitive behavioral approaches could predict higher self-efficacy in suicide risk assessment and management of suicidal behaviors.

\section{Current Assessment Methods to Assess Suicidal Risk}

To date, numerous risk assessment and management protocols of suicidal clients exist (Mann et al., 2005). Initial screening can be performed to detect risk, yet it is incredibly different than assessing and managing risk (Boudreaux \& Horowitz, 2014). Initial screenings or full risk assessments can be completed in a variety of settings (Betz et al., 2013; Graham et al., 2011; Hooper et al., 2011; Mackelprang et al., 2014). Assessment tools come in an assortment of designs (e.g. written, verbal) with an upsurge in electronic assessment for quick and easy risk formulation (e.g. AVERT ${ }^{\mathrm{tm}}$, electronic medical records). While a plethora of assessment methods are readily available, this does not mean a provider will believe in their capabilities to provide an effective assessment of suicide risk.

\section{Purpose of the Study}

To enhance our suicide prevention efforts, there are numerous national and international entities pointing toward the need for improvement in risk assessment and management of suicide (HHS, 2015; National Action Alliance [AA], 2015; WHO, 2015). Startling statistics from the American Foundation for Suicide Prevention and the CDC indicate it is futile to believe suicidal individuals will value their lives and not attempt to take their life. Advances in scientific 
research and ever changing patient demographics are the realities of healthcare practice. Mental health professionals must keep up with recommendations to continue providing quality care of suicidal individuals. Providers need to be prepared to detect risk and intervene.

Several salient factors have converged that has given rise to the routine practice of risk assessment and management of suicidal clients. To rapidly decrease suicide attempts and deaths, increasing the number of people with skills in risk assessment and management is necessary (National Action Alliance for Suicide Prevention, 2014). To improve training in this area, researchers, clinicians, and other service providers need to continue to explore and understand factors which impact providers conducting suicide risk assessment and managing suicidal behaviors. Comprehension in this area will provide significant information regarding where to focus training efforts.

Douglas \& Morris (2015) developed and tested the validity for the Counselor Suicide Assessment Efficacy Survey (CSAES). The results of this study showed four major tasks within the process of assessment where a provider's efficacy could be challenged. The authors pointed out efficacy in one area did not necessarily result in efficacy in another, therefore proposing training programs to target the four tasks of assessment to increase efficacy (Bandura, 1986; Douglas \& Morris, 2015). The purpose of this study was to further examine mental health provider perspectives on what sources of general self-efficacy give rise to higher self-efficacy in risk assessment and management of suicidal individuals. Additionally, this study investigated the relationship among demographic training variables (e.g. education, profession, practice approach, and years of experience in the field) to examine predictors of higher self-efficacy in suicide assessment tasks. The study added to the limited literature on self-efficacy as it relates to provider's perceived abilities to conduct suicide assessment tasks. 
This chapter included background on suicide, the significance of assessing suicide, a description of providers who assess and manage suicidal individuals, and what current methods are available to perform this task. The next section, Chapter 2, includes the literature review, which will further develop the topics in the Introduction. Chapter 3 will provide information on the research questions, method and design, participants, instruments, and quantitative analysis. The results will be discussed in Chapter 4. Chapter 5 will conclude the dissertation by summarizing the results, discussing the implications to practice, policy and research, and review the limitations of the study. The final section includes references and appendices. 


\section{Chapter Two: Literature Review}

The aim of this chapter is to provide a historical review of suicide literature, impact of suicide risk assessment and management training, introduce the proposed training for the study, and present the theory/model used to develop the theoretical framework for this study. Final remarks will be made to summarize the findings from the literature review.

A systematic approach was employed to identify applicable literature in the topic area. For each content area, a search was performed using PsycINFO, Medline, PubMed, and Google Scholar via the University of Missouri Library database. Electronic copies of articles were secured and those not available were requested through the inter-library loan process. The search was limited to English language articles published from 2000-2018. For historical purposes, a search for articles published in the last few centuries was also conducted. Numerous combinations of the following terms were used in the search: "suicide," "history of suicide," "risk assessment and management of suicide," "suicide risk assessment training," "self-efficacy," "sources of self-efficacy," and "suicide prevention training."

\section{Suicide}

Beginning with Durkheim's $19^{\text {th }}$ Century study of suicide, the research literature has evolved and reviewed the impact of sociological, economic, and environmental factors on suicide (Durkheim, 1951; Page, Morrell \& Taylor, 2002). Once thought as an individual problem, suicide has become a public health concern (CDC, 2018). In a 2013 report from NIMH, suicide accounts for over fifty billion of fatal injury costs in the United Sates. Equally as important, suicidal individuals can be quite complicated to clinically manage (Gaynes et al., 
2015). Various professionals, such as mental health providers, play a role in the prevention of suicide (Schmitz et al., 2012). However, it can be extremely anxiety provoking for professionals to come face to face with an individual who appears in extreme pain and voices their desire, "I want to die. I want to kill myself." When mental health professionals recognize that a substantial proportion of providers will experience the loss of a patient to suicide, anxiety and fear of suicide increases (Wurst et al., 2010). Providers working in the area of physical and mental health need to be prepared for such a crisis to occur. Responding to suicide risk requires clear communication, suicide knowledge, awareness of the impact of suicide on the provider, efficacy in assessing and managing risk, and competence in assessment (Rudd et al., 2008; Surgeon General Call to Action, 2012). Failure to meet those challenges in practice could be fatal (Surgeon General Call to Action, 2012).

Suicide terminology. The first time suicide was found in print was in 1651 by the Oxford English Dictionary. Since the appearance of the term suicide in the dictionary, suicide has changed in its definition and use in research (Palmer, 2008). Gathering data on suicide behaviors started in 1949 with the CDC. Terminology has continued to change considerably over the years.

In February of 2011, the CDC published the "Self-Directed Violence Surveillance Uniform Definitions and Recommended Data Elements." The CDC publication proposed the following surveillance definitions to clearly define the phenomenon.

\section{Self-directed violence definitions.}

1. Self-directed violence - behavior that is self-directed and deliberately results in injury or the potential for injury to oneself. This can be categorized into the following: Nonsuicidal, Suicidal. 
2. Non-suicidal self-directed violence - behavior that is self-directed and deliberately results in injury or the potential for injury to oneself. There is no evidence, whether implicit or explicit, of suicidal intent.

3. Suicidal self-directed violence - behavior that is self-directed and deliberately results in injury or the potential for injury to oneself. There is evidence, whether implicit or explicit, of suicidal intent.

4. Undetermined self-directed violence - behavior that is self-directed and deliberately results in injury or potential injury to oneself. Suicidal intent is unclear based on available evidence.

5. Suicide attempt - a non-fatal self-directed potentially injurious behavior with any intent to die as a result of the behavior. A suicide attempt may or may not result in an injury.

Subsequently in 2012, The World Mental Health Surveys defined the terms succinctly. The following are the WHO terms and definitions:

\section{World Mental Health Survey definitions.}

1. Suicide - the act of intentionally ending one's life.

2. Suicide ideation - thoughts of engaging in behavior intended to end one's life.

3. Suicide plan - formulation of a specific method through which a person intends to die.

4. Suicide attempt - engagement in potentially self-injurious behavior in which there is at least some intent to die.

The premise of proposing firm definitions is to be able to use concrete terminology when documenting suicide risk formulation. The intervention, or training, proposed in this study will 
use a combination of the two sets of terms. Documentation, using clinical terminology, encompasses one of the key components of competent risk assessment and management of suicidal behaviors (SPRC, 2006; Surgeon General Call to Action, 2012).

Known risk and protective factors associated with suicide. Suicide risk factors are characteristics, not necessarily the direct cause. Suicide prevention and research institutions encourage mental health providers to include risk factors in assessment as an opportunity to depict the intensity of the individual's potential to complete suicide. Furthermore, assessment of the known risk factors can alert providers to the heightened imminent risk of suicide.

Risk factors associated with suicide. Frankly, everyone is at risk of suicide. It is a decision any person could make. Research suggests that there are risk factors that lend one more susceptible to suicide. Risk factors can be placed in four broad categories: mental health, biological and genetics, stressful life events, and socio-environmental factors.

Mental health risk factors. Mood disorders, impulse control issues, alcohol/substance abuse or use, psychotic disorders, and personality disorders appear in literature as the most frequent and highest risk for suicide (AAS, 2014; CDC, 2014; Mann et al., 2005; Schaffer et al., 2008). In the systematic review by Cavanagh et al. (2003), it was reported that $90 \%$ of individuals who die by suicide have a diagnosable disorder. Careful attention has been given to psychological issues among high-risk populations (WHO, 2014). In particular, recent research has begun to examine what constructs explain why psychiatric disorders are associated with suicide. Some of those constructs are hopelessness, anhedonia, and high emotional reactivity (WHO, 2012). While many believe that a history of major depression is the strongest predictor of suicide, it is actually most highly associated with thoughts of burdensomeness and thwarted belongingness (Van Orden, Cukrowicz, Braithwaite, Self, \& Joiner, 2010). Other disorders 
characterized by intense trauma (e.g. PTSD), conduct disorder, and substance disorders are among some who experience suicide ideation, which is yet another predictor of suicide intention (Nock, Hwang, Sampson, \& Kessler, 2010; Nock et al., 2013). Important to note is the association between past attempts and current suicidal behavior. Harris \& Barraclough (1997) found that individuals who have attempted suicide are 40 times more likely to attempt again. Poor mental health generally is associated with suicidal behaviors (e.g. ideation, looking for means to kill oneself, withdrawing or feeling isolated) and increased risk of dying by suicide.

Biological and genetic risk factors. Another growing area of research is biological and genetic risk factors (Agerbo, Nordentoft, \& Mortensen, 2002; Chang, Wen, Tsai, Lawlor, Yang, \& Gunnell, 2011; Petersen, Sorensen, Andersen, Mortensen, \& Hawton, 2014). Gureje et al. (2011) tested the associations between a range of parental disorders and distinct forms of suicidal behaviors. The results from their study point towards distinctive elements of an individual's genetic makeup as potential routes to suicide. Yet another study found familial transmission of sexual abuse or impulsive aggression as a potential mediator to the transmission of suicidal behavior (Brent et al., 2001; Brent et al., 2002). In 2002, Brent et al. conducted a high-risk family study on the offspring of two mood-disorder groups (suicide attempters and nonattempters). The participants were recruited from two individual sites with 81 attempters, 55 non-attempters, and their respective 183 and 116 offspring. Results indicated that the offspring of attempters had an increased risk of suicide attempts in comparison to offspring of nonattempters (Brent et al., 2002). In a large Australian twin survey, the heritability of serious suicide attempts was 55\% (Statham et al., 1998). Results also indicate that there is greater concordance for monozygotic compared to dizygotic twins for suicide completions and attempts (Roy, Segal, Centerwall \& Robinett, 1991; Roy, Segal \& Sarchiapone, 1995). While there have 
been interesting findings in this area, the research on biology and genetics continues to be limited.

Stressful life event risk factors. Exposure to adverse life events increases the vulnerability to suicide. Studies have shown that interpersonal stressful life events, in particular, are a common type of life occurrence that precedes suicide among individuals, especially those who use alcohol (Duberstein, Conwell \& Caine, 1993). Severe stressful life events, such as military training and military practice, potentially relates to an increase in the recent suicide among soldiers (Nock et al., 2013). Current data and other studies have shown that partnerrelationship separations are common stressful life events preceding suicidal behaviors in individuals with alcohol use disorders (Connor et al., 2012; Duberstein et al., 1993). Parental separation or divorce (Andrews and Lewinsohn, 1992; Fergusson, Woodward \& Horwood, 2000), parental discord (Taylor \& Stansfeld, 1984), physical or sexual abuse in childhood (Beautrais, Joyce \& Mulder, 1996; Fergusson et al., 2000; Molnar, Berkman \& Buka, 2001) or impaired neglectful parenting (Lewinsohn, Rohde \& Seeley, 1993; Brent et al., 2002) are all stressful life events linked to completed or attempted suicides. The extent to which a stressful life event is a triggering factor is still unknown (Bagge, Glenn \& Lee, 2012). However stressful life events as well as other environmental factors are common factors in those who complete or attempt suicide.

Socio-environmental risk factors. Socio-environmental factors are associated with heightened suicide risk. Limited resources and living in areas with higher prevalence rates of income inequality are among the few known socio-environmental factors (Kaslow et al., 2005). Other factors such as country of birth (Burvill, 1998; Westman, Sundquist, J., Johansson, L., Johansson, S., \& Sundquist K., 2006), governmental policies (Page, Morrell \& Taylor, 2002; 
Shaw, Dorling \& Smith, 2002) and absence of available interventions for suicidal individuals have been associated with an increase in suicide (Qi, Tong \& Hu, 2009). In a systematic review by Too, Milner, Bugeja and McClure (2014), the researchers set out to examine socioenvironmental determinants of railway suicide. The findings were inconclusive, yet the impact of inappropriate media coverage being associated with risk of railway suicide was promising (Too et al., 2014). Luoma et al. (2002) reviewed evidence of contact with mental health and primary care providers before suicide. In their review, they examined 40 studies for which rates of contact were available. The inclusion criteria for the review focused on studies where data was collected on those individuals who had completed suicide. The findings from this study indicated that only one third of individuals who completed suicide had contact with a mental health provider. This association may be due to a shortage of mental health resources or insufficient coverage of mental health conditions through health insurance (Unutzer, Schoenbaum, Druss \& Katon, 2006). Socio-environmental factors related to suicide have not been studied as heavily as a few of the previous categories, yet they are important to the overall risk of suicide. Other key factors, such as demographics (e.g. sex, race/ethnicity and age), have a strong association with suicide risk (Nock et al., 2015). Through many of these studies, awareness for what creates protection against a person from suicide has evolved.

Protective factors associated with suicide. Protective factors play a key role in overall individual prevention of suicide (Nock et al., 2013). Seen as a buffer for individuals, protective factors are not researched as extensively as risk factors (U.S. Public Health Service, 1999). Protective factors are not simply the opposite of risk factors or the absence of risk factors, rather they are empirically identified features that lead to the development of preventative interventions 
to decrease suicide (Moody \& Smith, 2013). Protection against suicide can be broadly categorized as individual and environmental factors.

Individual protective factors. Protective factors can change with an individual's circumstance. For instance, family could be a protective factor, yet for others it can heighten risk (American Association of Suicidology, 2017). Enhancement of identified protective factors can promote resilience and be utilized in the management plan of the suicidal behavior (Fraser, Geoffroy, Chachamovich, \& Kirmayer, 2015; Lapierre et al., 2011; Taliiaferro \& Muehlenkamp, 2013). Research suggests that coping skills are a form of protection against suicidal behavior (McLean, Maxwell, Platt, Harris, \& Jepson, 2008). Strategies such as mindfulness, emotion regulation, effective communication, and distress tolerance have been heavily researched and proven effective in the reduction of suicidal thinking, planning, and action (Linehan et al., 2015; McMain, Guimond, Barnhart, Habinski, Streiner, 2016). Familial support, religious affiliation (Dervic et al., 2004), beliefs of responsibility to family, and pregnancy have shown promise to protect against suicide (Nock et al., 2013). A sense of belonging to a group (e.g. peer group) has also shown to protect individuals against suicide (Rudd, Joiner, \& Rajad, 1996). Chandy, Blum and Resnick (1997) conducted a case study with a sample of boys $(n=740)$ reported to have been sexually abused and explored the protective factors that assisted in overcoming the vulnerability to suicide. Findings from this study indicated perception of parents who cared about them and maternal education were the most prevailing protective factors. The World Health Organization (2015) finds individuals who can easily problem solve, handle disputes non-violently, and have learned conflict resolution are less likely to attempt. While individual factors are necessary in the protection against suicide, environmental factors are another key component in the prevention of suicide. 
Environmental protective factors. Identified by the AAS, the CDC, and the WHO, protective environmental factors have been correlated with a reduction in suicide. The WHO (2015) broadly suggests one prevention strategy is to have access to a variety of interventions and support for individuals contemplating suicide. Environmental interventions include access to phone or internet based crisis lines, physical health and fitness resources, and treatment specializing in suicide, such as Dialectical Behavior Therapy (Linehan, 1993; Nock et al., 2013). McLean, Maxwell, Platt, Harris \& Jepson (2008), in their systematic literature review, explored data on protective factors for suicide. Conclusions from their review upheld what many organizations and the Surgeon General have asserted protects adolescents from suicide: a supportive school environment and access to health care professionals at school (Mclean et al., 2008). The CDC notes that support from an ongoing medical or mental health professional has shown promise of protection against suicide (2015). Unfortunately, there is a shortage of literature on protective factors, which leaves a gap in the prevention efforts against suicide.

Despite a need for more comprehensive understanding of protective factors, we do know accessible intervention, family and community support, and coping skills are protective. The Surgeon General urges providers to be proficient in these factors in order to build them into safety planning. Training in suicide risk assessment and management should focus discussion on the aforementioned risk and protective factors in order to increase the competency of the mental health provider (Cramer, Johnson, McLaughlin, Rausch, \& Conroy, 2013; Pisani et al., 2011).

However, the interplay between the number of risk and protective factors are different for each individual, suggesting that comprehension of those factors is not enough to thoroughly manage an individual at risk. Therefore, suicide risk assessment and management specific training needs to go beyond the scope of understanding and include an increase in provider self- 
efficacy as a part of the gold standard of competence. The intervention (training) in this study will include a discussion on suicide statistics and terminology, and introduce an assessment tool, which captures known risk and protective factors, as well as sets up a management plan for the suicidal client.

\section{Impact of Suicide Risk Assessment and Management Training}

Several organizations, Suicide Prevention Resource Center (SPRC), American Association of Suicidology, and the National Action Alliance for Suicide Prevention, provide guidelines for developing effective suicide risk assessment and management protocols for health and mental health agencies and providers. Trainings have developed out of those guidelines to provide continuing education to health and mental health providers. However, research on suicide risk assessment and management training continues to be scarce (Douglas \& Morris, 2015; Feldman \& Freedenthal, 2006; Schmitz et al., 2012). Despite limited exploration there are studies which highlight the impact of training for mental health providers, as well as provide insight into the deficits of training.

Guidelines. The SPRC in 2006 published the "core competencies" in assessment and management of suicide risk (Appendix G). The core competencies cover numerous clinical skill sets. The skills include: attitudes of suicide, provider's approach to suicide, understanding suicide, collecting accurate data, formulation of risk, development of a treatment plan, managing care, and comprehension of legal issues as they relate to suicidality (Rudd et al., 2008). The development of the core competencies was an outcome of the SPRC's work with communities to implement suicide prevention programs, and the realization that many of the programs shared similar characteristics. In 2011, Pisani et al. conducted a systematic review of all the 
workshops/trainings that focused on clinical competence in risk assessment or management of suicide risk. A rigorous criterion including components from the SPRC's definition of core competencies was utilized. From the database search, the researchers yielded 12 workshops meeting the inclusion criterion. An online survey was sent to the developers resulting in a $100 \%$ response rate. The survey contained 18 closed and 4 open-ended items examining areas such as workshop objectives, methods of training, and any relevant publications (Pisani et al., 2011). A key result of this systematic review suggests the importance of earnestly evaluating the influence of training on competency and client outcomes (Pisani et al., 2011). Regardless of whether a training includes all or some of the core competencies mentioned in the SPRC's publication, the expectation in suicide prevention efforts is to provide mental health providers with the assurance of quality and competent training in the area of risk assessment and management of suicide.

Impact. Clinician wisdom and attitudes have shown to increase as a result of training in the area of suicide risk assessment and management (Cramer et al.; 2013; de Beurs et al., 2015; Fallucco et al., 2012; Pisani et al., 2011; Rudd et al., 2008). In a study by Fenwick, Vassilas, Carter and Haque (2004), the researchers examined two types of training (e.g. full-day workshops with actors role-playing clients \& half-day lectures). The study included 109 participants from a wide range of disciplines. Improvements in assessment knowledge were noted in both forms of training in the two-month follow-up. In their systematic review, Pisani et al. (2011) found clinical competence in a variety of trainings centered on risk assessment and management of suicide. To this researcher's knowledge, this is the only study to date that has examined in-person workshops that focus on competent suicide assessment and management. The findings of the study specify the workshops had "strong" face validity (Pisani et al., 2011). Other significant results included: (1) the mental health professional's interview skills improve in 
the short term, and (2) brief trainings or one day trainings provide a means for enhancing knowledge in suicide risk assessment and management of suicidal behaviors.

While increased suicide knowledge and skill in suicide assessment and management have been favorable training results, providers still may experience particularly low efficacy in suicide risk assessment and management of suicidal behaviors (Douglas \& Morris, 2015). Recently, scientific literature has begun to demonstrate continued training can impact provider confidence in risk assessment and management of suicidal clients (Schmitz et al., 2012) Provider self-report data suggest that training enhances confidence in the accuracy of risk and management planning (Fenwick et al., 2004; Oordt et al., 2009). Other studies, such as Fallucco et al. (2012), demonstrated significance in increased confidence and knowledge immediately after the intervention (workshop) and up to 10 months post intervention. While their study was focused on primary care physicians $(n=104)$, the primary goal was to determine effects of the 60 -minute seminar plus 60-minute standardized practice sessions on confidence and knowledge. The results from this study indicated that the PCPs in the intervention group reported significant improvements in the area of assessment of risk. According to the authors, these findings are consistent with previous work focused on increasing confidence and provider skill in intervention with suicidal clients (Fallucco et al., 2012; Lustig et al., 2001; Ozer et al., 2005).

In an effort to understand confidence in suicide risk assessment and management of suicidal behaviors, Douglas \& Morris (2015) developed a measure to identify efficacy in four main tasks of suicide assessment and management of suicidal behaviors. According to the authors, counselor self-efficacy is an important area to study, as self-efficacy influences the decision making process for the provider when faced with a suicidal client (Douglas \& Morris, 2015, Schmitz et al., 2012). The four main tasks identified by those authors were: general suicide 
assessment, assessment of personal characteristics (high risk), assessment of suicide history and suicide intervention (management). The study by Douglas \& Morris (2015) demonstrated selfefficacy as it relates to suicide risk assessment and management of suicidal behaviors is complex, and providers who lack self-efficacy in one task does not readily equate to a decrease in another. This suggests it may be important to further understand self-efficacy as it relates to suicide risk assessment and management of suicidal behaviors.

Deficits. Despite evidence indicating the effectiveness of training, there are deficits. Existing data indicates that improvements for training are on a continuum, suggesting the need for further research and follow-up (Rutz, von Knorring \& Walinder, 1989; Szanto, Kalmar, Hendin, Rihmer, \& Mann, 2007). Some deficits simply are limitations of the research studies, such as the available sample size. Various studies indicated the smaller sample size limited the ability to extract valid findings as it related to suicide risk assessment training (Fallucco et al., 2011; Mackelprang et al., 2014; Oordt et al., 2009). Other researchers posit some people believe suicide assessment and management skill acquisition can be acquired in clinical practice, therefore limiting training in higher education prior to graduation (Feldman \& Freedenthal 2006; Hung et al., 2012). Bongar and Harmatz (1989) studied suicide training in graduate programs in clinical psychology. Half of the programs did not offer formal education of suicide. Many of the responders thought that clinical psychologists should receive training through the following: $22.8 \%$ graduate work, $43.5 \%$ practicum, $37 \%$ internship, and $9.8 \%$ post-doctoral experience. Similar trends were found in social work. Only $29 \%$ of master's-level social work programs offered formal training (Feldman \& Freedenthal, 2006; Levin, 1994).

In general, little systematic research has studied the effects or impact of training on selfefficacy in risk assessment and management of suicide over time (McNiel et al., 2008; Oordt et 
al., 2009). As literature has suggested further evidence is needed to determine the overall provider impact as it relates to suicide risk assessment and management of suicidal behaviors (Douglass \& Morris, 2015, Graham, Rudd, \& Bryan, 2011; Oordt et al., 2009; Schmitz et al., 2012).

\section{Proposed Training}

London (1986) advocates that counselors appraise the terminology and empirical evidence for current practice in order to improve risk assessment readiness. Literature argues that the awareness of risk and capability to respond effectively are two distinct areas of clinical competence (Jobes \& Berman, 1983; Inman, Bascue, Khan \& Shaw, 1984). Therefore, it is essential that training in the area of risk assessment and management of suicidal behaviors includes knowledge building and practice by including the use of clinical role playing and follow-up of clinical practice to assess for continued self-efficacy and competence (Cramer et al., 2013, Pisani et al., 20011, Rudd et al., 2008).

One approach for mental health providers to utilize in practice is the Linehan Risk Assessment and Management Protocol (LRAMP) developed by Linehan (2009). This particular approach is a protocol for assessing suicide risk and managing suicide in the form of a checklist. Since the development of the LRAMP, Linehan and other developers created the Linehan Suicide Safety Net (LSSN), which is a web-based multimedia tool, designed for providers (Harned, et al. 2017). In 2017, Harned et al. evaluated the use of this multimedia tool for usability and effectiveness. In their sample of forty-four mental health professionals, the participants reported high usability and an increase in self-efficacy in assessing and managing suicide over the three month evaluative period (Harned, et al. 2017). The results of this study 
appeared promising and the authors encouraged continue evaluation of the Linehan Risk Assessment Protocol.

The LRAMP applies an assortment of theoretical paradigms, including behavioral, cognitive and social learning to understand the suicidal client. Linehan (2012) and others identify suicidality as an avenue of coping or problem solving (Coombs et al., 2013; Woltzky-Taylor, 2010). Using an empathetic and non-judgmental approach, the mental health professional using the LRAMP can assist the client in identifying suicide as a maladaptive coping strategy when facing a difficult life problem, form a therapeutic alliance, and move to manage the individual's suicidal behaviors by assisting in developing solutions to the problems they face.

The LRAMP involves several key steps in the assessment and management of suicide risk. The first step is to determine the reason for the completion of the assessment (e.g. history of suicide, new report of suicide ideation, threating suicide). By collecting this specific information, a provider captures the current potential risk of suicide for the individual. After defining the reason for completion, the provider illustrates the specific incident that has occurred. The next step in the process is to complete the structured formal assessment of current suicide risk. The checklist includes risk factors that have been determined in the literature to indicate imminent suicide risk. In step three, the provider explores the protective factors to prevent suicide. After the thorough examination of the risk and protective factors, the mental health provider shifts to suicide risk management. Within this section of the assessment, the provider will determine, based on the previous exploration of risk and protective factors, whether the client is at imminent risk. Based on this determination, the LRAMP guides the provider through several other tasks to develop a plan that will manage the suicide risk as evidenced by the assessment. The last step in the process is to complete the final disposition or documentation of what the provider and client 
have collaboratively determined will prevent the current suicide plan or terminate the current suicide ideation. Adequate documentation is required as part of the core competencies in suicide prevention (SPRC, Surgeon General Call of Action for Suicide Prevention, 2012). The LRAMP has been designed to generate the necessary documentation according to the expectations set forth by the National Strategy Suicide Prevention Strategy and the core competencies (Linehan et al., 2012, SPRC, Surgeon General Call of Action for Suicide Prevention, 2012). For this study, the training facilitator used the paper format of the LRAMP.

\section{Theoretical Framework}

The training in this study is characterized as a suicide risk assessment and management training program. The focus of the study is to provide mental health professionals with the tools to effectively assess suicide risk, thus enhancing their self-efficacy in decision making and management of the suicidal client/behaviors. While literature supports the concepts of selfefficacy and competence as interrelated (Bandura, 1986), they are unique and assess different constructs (Sherer et al., 1982). Tschannen-Moran, Hoy \& Hoy (1998) point out self-efficacy has to do with perception, not actual competence. Individuals often will over or under estimate actual ability, which may have consequences in the decision making process, or the efforts someone puts into a task (Bandura, 1986, Moran et al., 1998). This study remained focused on self-efficacy. To illustrate the proposed theoretical framework of this study, Self-Efficacy Theory, and a logic modeling will be used to guide the research (Kaplan \& Garrett, 2005; Lafferty \& Mahoney, 2003; McLaughlin \& Jordan, 1998; Millar, Simeone \& Carnevale, 2001).

Bandura's (1977) ideology on self-efficacy, also known as self-confidence, has covered numerous domains of psychosocial functioning (Lent et al., 2009). Findings from Orlinsky \& 
Howard (1986) relate therapist self-confidence to client outcome. Self-efficacy principles play an important role in how well people effectively use their skills (Chen, Gully \& Eden, 2001; Gist \& Mitchell, 1992; Lent et al., 2009). A study by Tang et al. (2004), unveiled internship hours and prior related counseling experiences increased a student's self-efficacy in counseling activities.

For this study, the literature search focused on self-efficacy as it relates to risk assessment and management of suicide. Jacobson, Osteen, Sharpe and Pastoor (2012) conducted a randomized trial with social work students on the use of gatekeeper training. Gatekeeper training is a 1 to 2 hour education workshop designed to teach professionals on warning signs of suicide and how to respond. Included in the measures of efficacy was the ability to execute the gatekeeper role (Jacobson et al., 2012). The researchers selected master's level social work students $(n=112)$ at random out of a student body population $(n=417)$. Thirty-eight of those students were randomly assigned to a control group and 35 to an intervention group. The intervention for the study was a 90-minute training using the Question, Persuade, and Referral (QPR) suicide gatekeeper training module. The researchers used the Efficacy to Perform Gatekeeper Role scale as their measurement instrument. On average, the study reported that student trainees scored .47 higher on the efficacy scale than students with no training (Jacobson et al., 2012).

Research focused on experienced or seasoned providers is limited in the area of selfefficacy as it relates to suicide risk assessment. One pre/post/post survey study (Oordt et al., 2009) identified training outcomes on confidence and beliefs regarding suicide care of active duty Air Force mental health professionals $(n=82)$. The study was comprised of males $(n=52)$ and females $(n=30)$ with experience in mental health care ranging from six months to twentyseven years $(\mathrm{x}=8.2$ years). Approximately half were psychologists, $27 \%$ were social workers, 
and $13 \%$ were psychiatrists. The data in this study showed that confidence did not increase immediately following the training, yet it did show a significant change in the 6-month follow-up (Oordt et al., 2009). This may in part be due to lack of time to practice skills within the field or relate to other unknown barriers. To understand self-efficacy as it relates to suicide assessment, studies suggest that confidence (self-efficacy) should be further evaluated (Cramer et al., 2013; Pisani et al., 2012; Rudd et al., 2006). Therefore, insight into provider self-efficacy potentially could assist in the development of improved trainings and supports (environmental and/or interpersonal) required in the management of suicidal clients.

Self-efficacy theory. In 1977, Bandura reported the first step in the process of effectively accomplishing a task is to perceive capability in executing the action. This regards self-efficacy as a pivotal point in determining what roles or challenges one will take. The theory posits how much effort one will expend on a particular task, or how likely one will face failures, depends on the efficacy beliefs of the individual (Bandura, 1986). Self-efficacy is subjective in that individuals can possess a strong talent and skill in a particular area, yet not see themselves as capable (Petrovich, 2004). Bandura (1986) describes four sources of experience that contribute to efficacy: mastery, vicarious experience, social persuasion, and physiological/emotional factors. The degree of one's self-efficacy is partly due to the variability in those determinants (van der Bijl \& Shortridge-Baggett, 2001). Clinical determination of imminent risk requires a mental health provider to confidently integrate various data received to make a final decision on how to manage the individuals' suicidal behaviors. Self-efficacy reflects the confidence in the ability to make those determinations (Bandura, 1986). As such, it is important to recognize those determinants separately as constructs, which will influence the increase in overall confidence of the provider. A particular hierarchy exists among the four sources of efficacy (van der Bijl \& 
Shortridge-Baggett, 2001) which are discussed in order of importance: mastery, vicarious experience, social persuasion, and physiological/emotional arousal.

Sources of efficacy. In 1977, Bandura defined the term self-efficacy as "the conviction that one can successfully execute the behavior required to produce the outcomes" (Bandura, 1977, p. 193). Commonly referenced as perceived self-efficacy, the theory emphasizes that selfefficacy is not the ability to perform. Rather, self-efficacy is the perception of the ability to perform any given task (perceived mastery). Success will raise mastery expectations and strong self-efficacy will occur through repeated successes (Bandura, 1977). Mastery of all four determinants is the most potent of all the sources of efficacy (Strecher, Devellis, Becker \& Rosenstock, 1986). Successive mastery requires experience and repetition of the task to refine skills (Bandura, 1977; Strecher, Devellis, Becker \& Rosenstock, 1986).

Vicarious experience, the second determinant of self-efficacy, is influenced by one's observation of events or other people. Multiple studies point to evidence that vicarious experiences play a role in the development of self-efficacy (Bandura, 1986; Bandura \& Jourden, 1991; Wagler, 2011)) Seen as the second most effective way to develop self-efficacy (Chowdhury et al., 2002; Wise \& Trunnell, 2001) vicarious experience derives performance expectations for an individual (Bandura, 1977). In order for this to have a positive outcome, the observed event or person must be perceived as overcoming difficulties (Strecher et al., 1986). According to Bandura (1977), an observer who sees others perform threating activities without consequences will increase the likelihood they too can perform those tasks.

In order to influence human behavior in a particular way, social persuasion is often used. The theory suggests people who are regularly encouraged to perform a particular task often will begin to perceive they can be successful with whatever task they may face. Bandura (1977) 
hypothesizes people who are persuaded or told they are capable to master difficult situations are more likely to put forth greater effort to complete the task. However, the theory does take into consideration any stressful situation that may elicit a negative physiological/ emotional arousal, which could debilitate performance (Bandura, 1977). Self-efficacy influences human behavior in numerous ways: cognitively, motivationally, and emotionally (Bandura, 2001). Individuals rely on physiological/emotional factors, such as anxiety, to determine vulnerability to stressful situation (Bandura, 1977). Fear, a physiological/emotional factor, can further heighten anxiety that far exceeds the potential stress. Fear of liability (Linehan et al., 2012) and the threat of losing a patient (Pope \& Tabachnik, 1993) are two common physiological factors that impede competently completing a risk assessment and managing risk effectively. Therefore, simply acquiring a skill will not equate to successful task execution; rather the individual's confidence or beliefs in their abilities is more significant.

The constructs of this theory (Figure 1) are crucial to the outcomes of this study on whether the individual will ultimately perceive efficacy in suicide risk assessment tasks and therefore increase the likelihood of effective assessment and management of the suicidal client. The unassuming knowledge of risk and protective factors would not be enough in order to produce competent risk assessment and management of suicidal behaviors according to this theory. Rather, the beliefs of one's ability to generally assess for suicide, assess high risk and history of suicide, as well as manage the suicidal behaviors, are what will influence the provider's ability to conduct assessments. Self-Efficacy Theory argues that someone can have a high self-efficacy in some areas, yet low in others. Self-efficacy is an important motivational construct that influences an individual's choices, emotional reactions, effort and persistence (Gist 
$\&$ Mitchell, 1992). For this study, self-efficacy will play an integral role in determining the outcomes for this study.

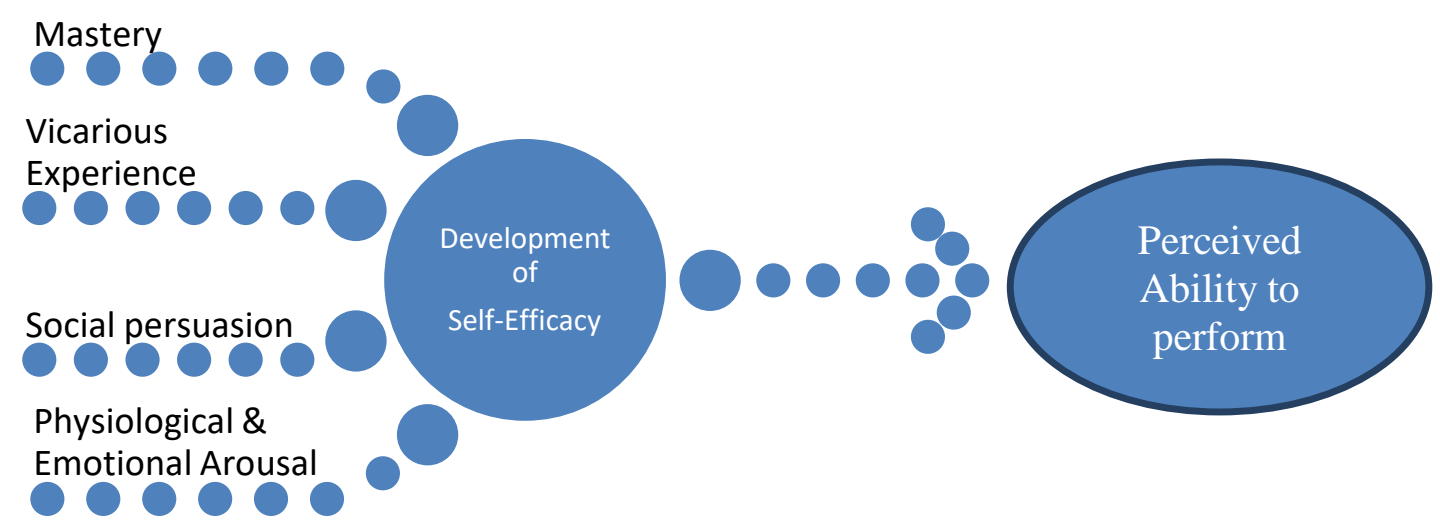

Figure 1. Self-efficacy Theory (Bandura, 1977)

Basic logic model. A logic model will be used as the framework for this study. A basic logic model (Figure 2) clearly shows the components and objectives of a program, so assessment can be thorough and meaningful to participants and stakeholders. Programs or organizations can use a logic model to assess whether practices match the theoretical assumptions or outcomes and impacts of the program. The logic modeling guide by W.K. Kellogg Foundation (2004) was used to develop the logic model for this study. The guide defines a logic model as "a picture of how your organization does its work - the theory and assumptions underlying the program" (2004, p. III). The model links outcomes with "program activities and the theoretical underpinnings of the program" (Kellogg Foundation, 2004, p. III). Similar definitions have been provided by various other researchers (Goodstadt, 2005; Kaplan \& Garrett, 2004). Goodstadt (2005) notes that research commonly refers to a "conceptual framework" as the guide, yet both logic models and conceptual frameworks are concerned with the "theoretical" foundation of the interventions and expected outcomes (Goodstadt, 2005, p. 2). McLaughlin \& Jordan (1999) describe the use of logic models as "the basis for a convincing story of the programs expected performance" 
(McLaughlin \& Jordan, 1999, p. 66). To be more scientific, the logic model permits the researcher to directly test hypotheses to the project evaluation (Kaplan \& Garrett, 2005). However defined, logic models can be beneficial to the multiple layers of program development, implementation, and delivery (Lafferty \& Mahoney, 2003, Schalock \& Bonham 2003). The W.K. Kellogg Foundation logic model guide (2004) states that the logic model is useful at various stages of programming. According to Fretchling (2007), utilization of the logic model to collect outcome results is advantageous, as it "becomes a map that guides others who might want to replicate the project or adapt it to other situations" (2007, p.17). Born out of the theoretical underpinnings of program theory, logic modeling is simply another avenue to conceptualize program or intervention research evaluation.

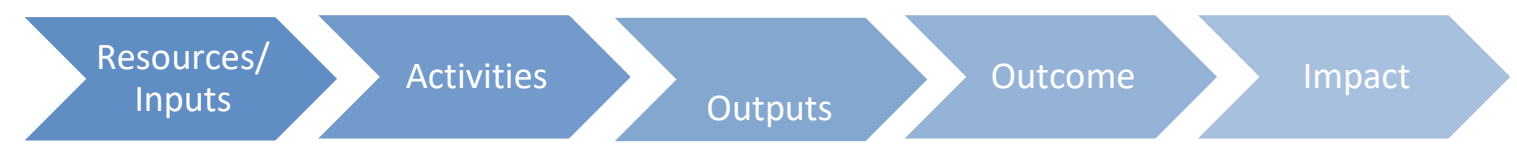

Figure 2. The basic logic model. (W.K. Kellogg Foundation, 2004)

The term "theory" has a broad translation. As Fretchling (2007) suggests, program theory can be research-based and include practitioner experience. The primary focus of this study is mental health providers' self-efficacy in assessing risk and managing suicidal behaviors. A primary construct from Social Cognitive Theory, assumes that all participants will have beliefs (cognitions) regarding their own self-efficacy and competence prior to and throughout training, as well as into the future. In order to assess competence, it is important to assess the beliefs about the provider's past and present learning experiences, including their self-efficacy, which is associated with the overall belief of competence and intention to act or behave in a certain way 
(Bandura, 1977, 1986). Various constructs of self-efficacy, mastery, vicarious experiences, social persuasion, and physiological and emotional arousal provide context to the logic model's input, activities, outputs and outcomes. Ultimately, this study will explore whether a training provided in a short and easily comprehensible format, aimed to develop skills for suicide risk assessment and management of suicidal behaviors, will predict an increase in self-efficacy after the conclusion of the training. The assumptions from Self-Efficacy Theory and the logic model provide the underlying foundation and construction of the proposed model and can be seen

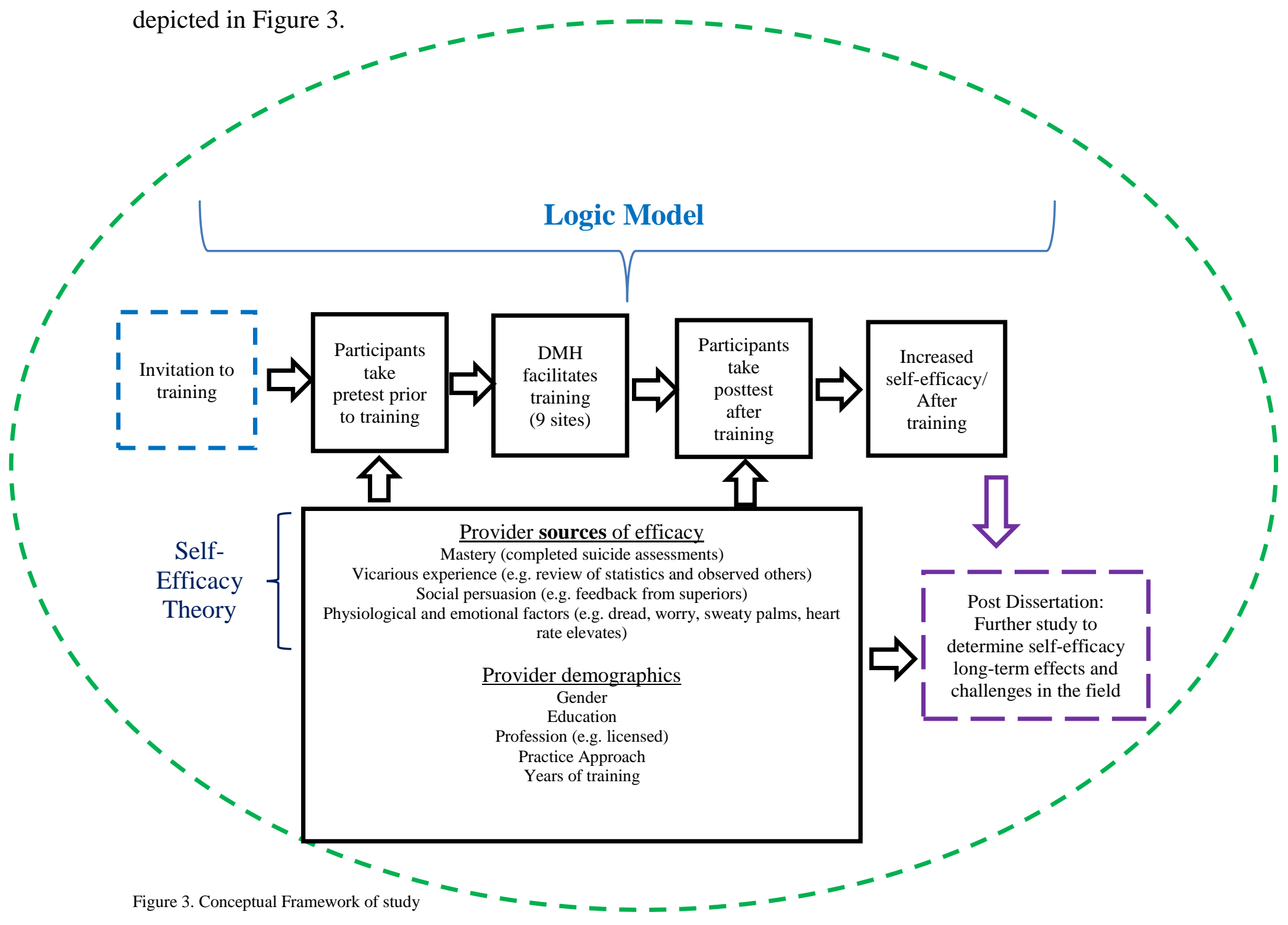


The review of the literature indicates that further research is needed in the area risk assessment and management of suicidal clients (Graham et al., 2011, Linehan et al, 2012 Schmitz et al., 2012). In the systematic review by Pisani et al. (2011), conclusive evidence supports the urgency of evaluating the impact that training has on services provided and outcomes achieved by the providers. Sufficient evidence can be found that self-efficacy and competence is necessary in order to effectively assess and manage an individual's suicidal behaviors (Cramer et al., 2013; Feldman \& Freedenthal, 2006; Mann et al., 2005; Oordt et al., 2009; Rudd et al., 2008; Schmitz et al., 2012).

Undeniably, research is scant on self-efficacy as it pertains to suicide assessments. Science is starting to prove that empirically based skills taught in short continuing educational trainings can change the perception of self-efficacy with possible sustainable changes up to six to 10 months following a training (McNiel, et al., 2008, Oordt, Jobes, Fonsca, \& Schmidt, 2009). Researchers are developing measures to target self-efficacy in suicide risk assessment (Douglas \& Morris, 2015; Harned, et al., 2016; McNiel et al., 2008; Oordt et al., 2009; Smith et al., 2014). Exploring which sources of self-efficacy afford providers an increased perception in his or her capacity to execute the tasks of a suicide risk assessment can contribute to the current knowledge base and provide insight into how to increase a provider's self-efficacy in suicide risk assessment, which hopefully, will impact the clinical decisions made in the management process. 


\section{Chapter Three: Research Questions, Method \& Design}

As noted in Chapter 2, there is a need for research to understand self-efficacy in suicide risk assessment and management of suicidal behaviors. Research posits efficacy is the overarching construct that influences behavior and performance which leads to competence of the task (Bandura, 1986). To further understand the perspectives of mental health providers, this study incorporates a training intervention using Bandura's Self-Efficacy Theory and a logic model for the evaluative approach. Outputs from the logic model will be employed to investigate how training impacts service providers' self-efficacy in suicide assessment and management of suicidal behaviors, as well as explore which factors of general self-efficacy predict higher selfefficacy in assessment and management of suicide. The following includes research questions along with their respective hypotheses, and methodology.

\section{Research Questions}

The overall aim of the research is to examine the outcome of suicide self-efficacy in risk assessment and management after training. For the purposes of this study, primary data collection was utilized to answer several questions. Based on the empirical research and assumptions of theory, the following hypotheses guided the quantitative analysis:

R1 (pre and post): How does the standardized suicide risk assessment and management training change a participant's overall self-efficacy in suicide assessment and management of suicide following the training?

Hypothesis 1: There is a mean difference in the participant's overall self-efficacy between before and after the training. 
R1b (pre and post): How does the standardized suicide risk assessment and management training change a participant's self-efficacy in the tasks of suicide assessment and management of suicidal behaviors (general assessment, high risk assessment, suicide history assessment, and management of suicidal assessment)?

Hypothesis $1 \mathrm{~b}$ : There are mean differences in general assessment, high risk assessment, suicide history assessment, and management of suicidal assessment before and after the training.

R2 (post only): How are demographics, characteristics of service providers, general selfefficacy, and sources of mastery associated with self-efficacy in suicide assessment?

Hypothesis 2: After the training, participants with higher self-efficacy in suicide assessment tasks are more likely to hold graduate degrees, have practiced in the field longer than two years, and perceive higher general self-efficacy and sources of efficacy.

R3 (post only): How are general efficacy and sources of efficacy (mastery, vicarious experience, social persuasion, physiological/emotional arousal) associated with the tasks of suicide assessment (general assessment, assessment of high risk and suicide history, management of suicidal behaviors) when controlling for demographic variables, characteristics of service providers, general self-efficacy, and sources of mastery?

Hypothesis 1: Compared to vicarious experience, social persuasion and physiological/emotional arousal, mastery and general self-efficacy are stronger in predicting higher efficacy in suicide assessment, assessment of high risk and suicide history. 
Hypothesis 2: Physiological/emotional arousal is stronger in predicting a decrease in efficacy in management of suicidal behaviors when compared with general self-efficacy, mastery, vicarious experience, and social persuasion.

\section{Methodology}

As discussed in Chapter 2, this study will be guided by Self-Efficacy Theory and logic modeling. The constructs of a logic model are: inputs, activities, outputs, outcomes, and impact. For this study the inputs, activities and outputs will be used. Future studies based on the findings of this study will be used to determine outcomes and impact. A brief summary of the questions surrounding the development of this logic model will be provided. This will then lead to the research design of the proposed study.

LRAMP logic model. Below are the five questions and corresponding answers developed from information gathered during a discussion with the developer of this intervention (training). A flowchart summarizing the steps in the logic model that were specifically designed for the Linehan Risk Assessment and Management Training directly follows.

1. What is the problem that is addressed by the LRAMP training? Linehan and colleagues (Harned et al., 2017; Linehan et al., 2012) developed the LRAMP to address clinicians' fears of intervening with suicide individuals. Dialectical Behavioral therapists have been using this tool for decades (Linehan, 1993) and it has been used in many clinical trials in the paper-based format (Harned et al., 2017). Low cost, empirically-supported training has not been readily available in the state of Missouri. Training in risk assessment and management of suicidal clients is expected for many licensed professionals. The Department of Mental Health has the capacity, availability of highly skilled trainers, and the fiscal means to address the gap of suicide 
risk assessment and management of suicidal behaviors using evidenced-based protocols. This training supports the National Suicide Prevention guidelines and the core behavioral competencies of suicide assessment (Suicide Prevention Resource Center, 2017).

2. Why address this issue? The review of the literature indicates that a provider's perceptions and practice of risk assessment and management of suicidal clients is favorably changed when properly trained (Oordt et al., 2009; Smith et al., 2014). Regehr et al. (2015) found a variation in risk assessment despite high rates of confidence. The conclusion from this study, as many others mentioned, speaks to the need for ongoing training and understanding of the provider's perspective in the area of risk assessment and management of suicidal clients.

3. What are the desired results from this training? The training should increase mental health providers' efficacy to assess and manage suicidal clients in outpatient settings. Training should also increase skills in assessment and management of suicidal clients and decrease client hospitalizations over time with the use of the LRAMP assessment tool.

4. Why will this training work? Several other studies have reported an increase in efficacy in brief didactic trainings (Fallucco et al., 2012; McNiel et al., 2008; Oordt et al., 2009; Pisani et al., 2012). Oordt et al. (2009) found brief and professional training overall showed an increase in provider efficacy. In a systematic review of workshop education the authors determined trainings are efficacious for transferring knowledge and shifting perceptions (Pisani et al. (2011).

5. What could influence the outcome? Outcomes could be influenced by the provider's beliefs about suicidal clients, fears of liability, and unwillingness to manage a suicidal client within a community setting (Linehan et al., 2012). The training program has little control over the preconceived beliefs of the provider thus the provider's personal and professional life all could influence the program outcomes. 
The following flowchart summarizes the training using the logic model as seen in W.K.

\section{Kellogg Foundation model guide (2004).}

Table 1. Logic Model for study

\section{Linehan Risk Assessment and Training Logic Model}

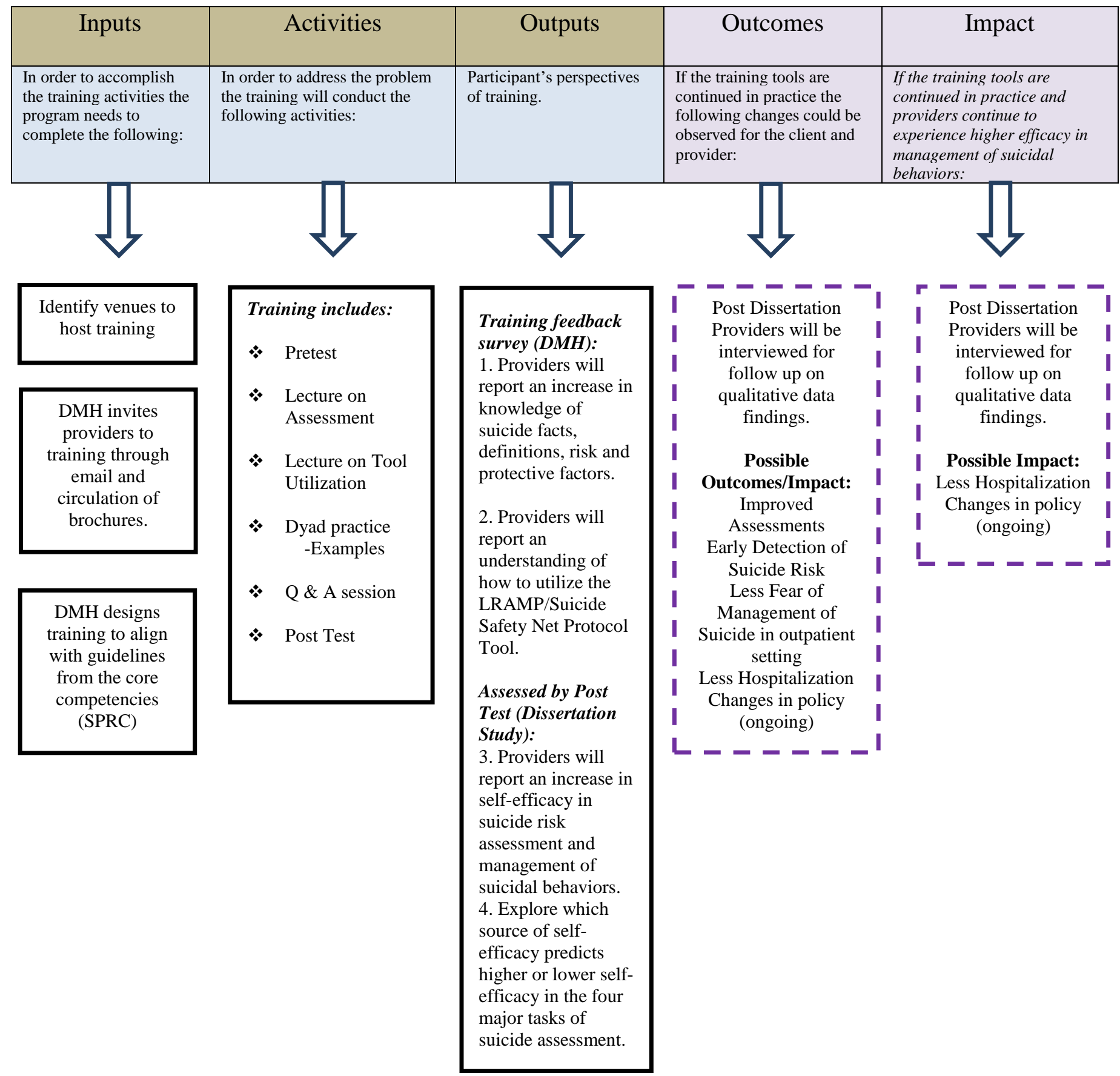




\section{Research Design}

For this study, a one group, pretest-posttest design involving quantitative hypothesis testing was utilized. Figure 5 illustrates how quantitative data was collected prior to the intervention (training) with study participants. Training was conducted for 6.5 hours and facilitated by the Department of Mental Health. Immediately after the training a posttest was conducted to collect quantitative data again from participants.
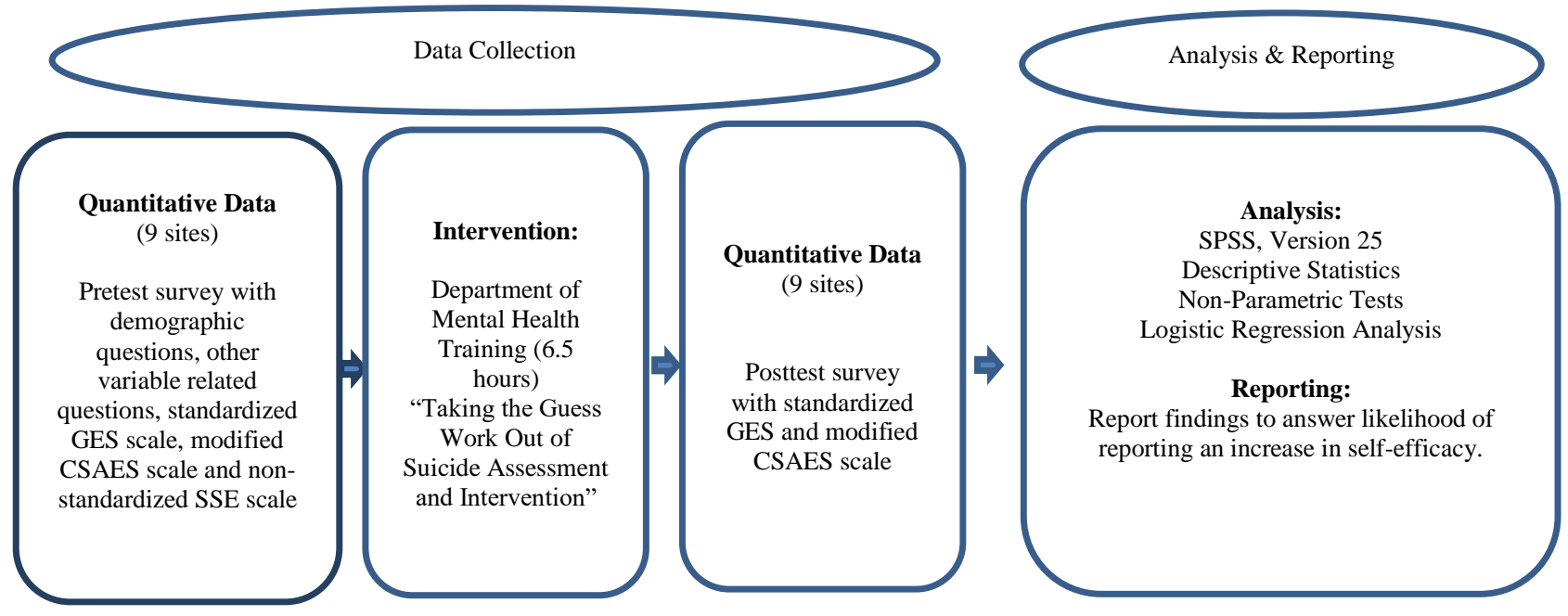

Figure 4: Research Design

\section{Setting}

Recruitment for this study occurred throughout Missouri. The training sites were located in the central, south and north regions of Missouri. Nine sites were identified, and the training was funded by the Missouri Department of Mental Health. The sites had easy parking access, large group space, and visual equipment conducive for training. There was no cost to the participant to attend the training. 


\section{Participants}

The target population for this study was mental health providers Missouri. The sampling frame included licensed as well as non-licensed professionals. Nonprobability purposive sampling was used to identify research participants. Exclusion criteria was anyone who is not currently practicing in the field. All other participants were eligible to participate in this study. A statistical power analysis was performed for sample size estimation and determined 300 participants would detect correlations .016 with a power of $>80 \%$ (Cohen, 1992). For this study, this researcher was able to sample above the proposed sample $(\mathrm{N}=300)$ and had $\mathrm{N}=340$ in the final sample.

\section{Measurement}

A survey instrument was used for this study to measure the dependent variable of general self-efficacy in suicide assessment and management of suicidal behaviors, as well as the four tasks of suicide risk assessment: general suicide assessment, assessment of high risk, assessment of suicide history, and management of suicidal behaviors. The instrument is a combination of the General Self-Efficacy Scale (Schwarzer \& Jerusalem, 1995), an adapted version of the Counselor Suicide Assessment Efficacy Survey (CSAES), and questions developed by the researcher based on the sources of self-efficacy and Self-Efficacy Theory (Bandura, 1986).

Dependent Variables in this Study. Table 2 provides a summary of how each dependent variable was operationalized, measured, and coded for statistical analysis. Internal consistency reliability for the variables are provided.

Counselor Efficacy in Suicide Assessment and Intervention. To measure efficacy in suicide assessment and intervention the Counselor Suicide Assessment and Efficacy Survey (CSAES) was used. This 25-item test was created by Douglas and Morris (2014). The 
developers of the survey used Bandura's work on self-efficacy and his recommendations for assessment construction to develop the instrument (Bandura, 1986, 2005; Douglas and Morris, 2014). The original intent for the survey was to create a measure of self-efficacy to assess specific tasks of suicide risk assessment. Douglas and Morris (2014), included items in the instrument based on general assessment questions (e.g. inquiring about thoughts or plans of suicide), risk factors and warning signs described by NIMH and AAS, personal characteristics which elevate risk (higher risk of suicide), history of suicide thoughts, plans or attempts, and intervention with the client (management of the suicidal behaviors).

For purposes of this study the scale was adapted and only used 18 items and reduced the Likert scale from 5 to 4 to align with the other instruments used in the study. The items not used from the original measurement were items specific to students in training and which was not this study targeted audience. The overall adapted measure was used to assess a general self-efficacy in suicide assessment and management of suicidal behaviors, as well as the certain tasks within this process (e.g. general assessment, assessment of high risk, assessment of suicide history, and management of suicidal behaviors). The Cronbach's alpha for this entire instrument was .95 indicating a high level of internal consistency. A limitation of this measure was modification of the instrument, however, all questions kept in the adjusted version were intact from their original design. The tasks above were included as dependent variables and are described as follows.

Suicide Assessment (task). One task related to suicide risk assessment is the basic inquiry about one's thoughts and plans. In order to ensure proper intervention with a client, providers need to be aware of their current state and intention. To measure this task, items 1 through 4 of the CSAES were developed into a composite score for general suicide assessment. The minimum score of eight indicated a low self-efficacy, with sixteen as the maximum score 
and indicative of higher self-efficacy in the task. This construct, "general suicide assessment," had a good level of internal consistency, as determined by a Cronbach's alpha of .865 .

Assessment of high risk (task). As a part of suicide risk assessment, a provider should explore personal characteristics which point to an elevation of risk (Centers for Disease Control and Prevention, 2018; American Association of Suicidology 2018). High risk characteristics can lead providers to appropriate intervention and management efforts. To measure this task, items 7-12 from the CSAES were utilized. Douglas and Morris (2014) included risk factors such as substance use, sexual abuse, history of mental illness, self-esteem, and acceptance of sexuality. Clearly the items from this standardized instrument do not incorporate all risk factors, which is a limitation to the construction of this composite. To test for reliability, the Cronbach alpha test was used and it was determined to have a high level of internal consistency, a .905.

Assessment of suicide history (task). Understanding a client's history of suicide is imperative to the overall general assessment of suicide risk. For providers to adequately formulize risk, they need to capture current and past states of their individual client and compare their current risk with past history (Douglas \& Morris, 2014; Pisani, Murrie, Silverman, 2015). This can shed light on foreseeable management strategies, which could decrease risks. One limitation from those developed items is there were no questions regarding past history of ideations, but one could assume this may be encountered in the question of "past attempts." To measure this task, items 13-15 were utilized from the CSAES. The Cronbach alpha indicated high internal consistency, $\alpha=.905$.

Management of suicidal behaviors (task). The National Strategy for Suicide Prevention (2012) specifies core competencies of suicide risk assessments should include assessing for the management of suicidal behaviors. Management of suicidal behaviors allows for the client to 
continue daily living in their natural environment, versus hospitalization for every episode of suicidal behavior. Douglas and Morris (2015) included three items in their standardized instrument to address this task. Those items, 16-18, were included in this study survey. The questions address a participant's ability to manage their client's suicide thoughts and the ability to take action for clients who present with moderate or imminent risk of suicide. To test for reliability, the Cronbach alpha test was used and it was determined to have a good level of internal consistency, $\alpha=.889$. 
Table 2: Operationalization and Measurement of Dependent Variables

\begin{tabular}{|c|c|c|c|c|c|}
\hline $\begin{array}{l}\text { Dependent } \\
\text { Variables }\end{array}$ & Variable & Item Description & Measure & Coding & Reliability \\
\hline \multirow[t]{2}{*}{ Full Scale } & $\begin{array}{l}\text { Counselor Efficacy in } \\
\text { Suicide Assessment and } \\
\text { Intervention }\end{array}$ & $\begin{array}{l}\text { Participant's belief in } \\
\text { their ability to perform } \\
\text { the task of asking } \\
\text { specific suicide } \\
\text { assessment and } \\
\text { management questions } \\
\text { of their clients. }\end{array}$ & $\begin{array}{l}\text { The CSAES (Douglas \& } \\
\text { Wachter Morris, 2015) a 25- } \\
\text { item scale. For purposes of } \\
\text { this study, the scale was } \\
\text { adapted and only } 18 \text { items } \\
\text { were used from the CSAES } \\
\text { and used to depict a general } \\
\text { belief of one's ability to } \\
\text { assess for suicide and } \\
\text { manage suicidal behaviors } \\
\text { on a } 4 \text { point Likert True } \\
\text { Scale from } 1 \text { (Not True) to } 4 \\
\text { (Exactly True) }\end{array}$ & $\begin{array}{l}\text { Theoretical range: } \\
\text { continuous } \\
\text { measure } 18-72 \text {. } \\
\text { minimum } 18= \\
\text { low self-efficacy } \\
\text { related to suicide } \\
\text { assessment and } \\
\text { maximum } 72= \\
\text { high self-efficacy } \\
\text { related to suicide } \\
\text { assessment. }\end{array}$ & $\begin{array}{c}\text { Cronbach } \\
\text { alpha } \\
.949\end{array}$ \\
\hline & $\begin{array}{l}\text { General Suicide } \\
\text { Assessment }\end{array}$ & $\begin{array}{l}\text { General suicide } \\
\text { assessment questions }\end{array}$ & $\begin{array}{l}\text { Questions 1-4 from the } \\
\text { CSAES instrument. }\end{array}$ & $\begin{array}{l}\text { Composite range: } \\
\text { continuous } \\
\text { measure with } \\
\text { minimum score of } \\
8=\text { low efficacy in } \\
\text { general suicide } \\
\text { assessment and } \\
\text { maximum score } \\
\text { of } 16=\text { high } \\
\text { efficacy in general } \\
\text { suicide } \\
\text { assessment. }\end{array}$ & $\begin{array}{c}\text { Cronbach } \\
\text { Alpha } \\
.865\end{array}$ \\
\hline \multirow[t]{3}{*}{$\begin{array}{l}\text { Tasks of } \\
\text { Suicide } \\
\text { assessment }\end{array}$} & High Risk Assessment & $\begin{array}{l}\text { High risk assessment } \\
\text { questions }\end{array}$ & $\begin{array}{l}\text { Questions } 7-12 \text { from the } \\
\text { CSAES instrument }\end{array}$ & $\begin{array}{l}\text { Composite range: } \\
\text { continuous } \\
\text { measure with } \\
\text { minimum score of } \\
6=\text { low efficacy in } \\
\text { high risk } \\
\text { assessment and } \\
\text { maximum score } \\
\text { of } 24=\text { high } \\
\text { efficacy in high } \\
\text { risk assessment. }\end{array}$ & $\begin{array}{c}\text { Cronbach } \\
\text { Alpha } \\
.881\end{array}$ \\
\hline & Suicide History & $\begin{array}{l}\text { Suicide history } \\
\text { assessment questions }\end{array}$ & $\begin{array}{l}\text { Questions } 13-15 \text { from the } \\
\text { CSAES instrument }\end{array}$ & $\begin{array}{l}\text { Composite range: } \\
\text { continuous } \\
\text { measure with } \\
\text { minimum score of } \\
3=\text { low efficacy in } \\
\text { suicide history } \\
\text { and maximum } \\
\text { score of } 12=\text { high } \\
\text { efficacy in suicide } \\
\text { history. }\end{array}$ & $\begin{array}{c}\text { Cronbach } \\
\text { Alpha } \\
.905\end{array}$ \\
\hline & $\begin{array}{l}\text { Management of suicidal } \\
\text { behaviors }\end{array}$ & $\begin{array}{l}\text { Management of } \\
\text { suicidal behaviors. }\end{array}$ & $\begin{array}{l}\text { Questions } 16-18 \text { from the } \\
\text { CSAES instrument }\end{array}$ & $\begin{array}{l}\text { Composite range: } \\
\text { continuous } \\
\text { measure with } \\
\text { minimum score of } \\
8=\text { low efficacy in } \\
\text { management of } \\
\text { suicidal behaviors } \\
\text { and maximum } \\
\text { score of } 20=\text { high } \\
\text { efficacy in } \\
\text { management of } \\
\text { suicidal } \\
\text { behaviors. }\end{array}$ & $\begin{array}{c}\text { Cronbach } \\
\text { Alpha } \\
.889\end{array}$ \\
\hline
\end{tabular}


Independent Variables. Table 3 provides a summary of how each independent variable was operationalized, measured and coded for statistical analysis. Reliability for the variables is provided.

General self-efficacy. To measure self-efficacy, the General Self-Efficacy Scale (GSE) was used. This 10-item test was created by Schwarzer \& Jerusalem (1995). The original intent for the survey was to assess a general sense of perceived self-efficacy. It was intended for an adult audience and indicates anyone under the age of 12 should not be tested. This test is selfadministered and takes approximately 4 minutes to complete. The responses are on a 4-point Likert scale and the final composite score ranged from 10 to 40 . The constructs of the selfefficacy scale were designed to identify successful coping and imply an internal-stable attribution. As Bandura (1986) points out, self-efficacy is an operative construct that relates to behavior. Therefore, this test is relevant to clinical practice and behavior change. The Cronbach's alpha for this test is .76. A limitation of this measure is that, while suitable for a broad range of applications, it does not identify specific behavior changes.

Provider sources of efficacy. While general self-efficacy is a global summary of perceived capability, four sources or antecedents of experience are used to develop the selfefficacy construct: mastery (routine experience), vicarious experience (modeling \& review of literature), social persuasion (feedback) and physiological and emotional arousal (Bandura, 1977; Gist \& Mitchell, 1992). As such, those experiences are suggested predictors of this study. Due to limited standardized measures to assess for mastery, vicarious experience, social persuasion, and physiological and emotional arousal related specifically to suicide risk assessment and management, this researcher created a measure without standardization for this dissertation 
study. Using guidelines from Bandura $(1986,2006)$ on creating a scale for self-efficacy and question formatting from the Douglas and Morris study (2015), four constructs were developed to capture the four sources of self-efficacy as they relate to suicide assessment and management of suicidal behaviors. The scale comprised of 14 items and each construct was tested for reliability. Content of questions were developed from the behavioral core competencies from the Suicide Prevention Resource Center, which developed those competencies outlined in the National Strategy for Suicide Prevention (2012). Since the instrument was not psychometrically tested, it could have reduced the validity of the findings.

Mastery. Literature suggests that mental health providers are commonly the professionals who encounter suicidal clients. It is suggested that $83 \%$ of individuals who die by suicide have encountered a health or mental health professional up to one year prior to their death (Andersen, Andersen, Rosholm \& Gram, 2000; Luoma, Martin \& Pearson, 2002). Mastery, as Bandura (1977) defines is learning through personal experience. Therefore, it is suggested that the longer one has practiced suicide assessments in the field, it is more probable their capability in conducting a suicide assessment will increase. For this construct, items one and two were used to develop a composite for mastery. The questions gauged a participant's routine facilitation of risk assessments and management of suicidal behaviors. To test for reliability, the Cronbach alpha test was used and it was determined to have an acceptable level of internal consistency, $\alpha=.785$.

Vicarious Experience. Vicarious experience, while somewhat similar to mastery, includes learning from observing or having a "model" to illustrate a certain task (Bandura, 1977; Strecher, Devellis, Beck, \& Rosenstock, 1986). In this case, it is predicted that providers who have had an opportunity to observe risk assessments by other professionals and routinely review 
suicide risk and protective factors and statistics of suicide, will be more likely to have higher efficacy of suicide risk assessment. For this construct, items three through seven were used to develop a composite for vicarious experience. To test for reliability, the Cronbach alpha test was used and it was determined to have a good level of internal consistency, $\alpha=.813$.

Social persuasion. Social persuasion is widely used to increase the likelihood that people will be able to cope successfully with difficult tasks (Bandura, 1977; Strecher, Devellis, Beck \& Rosenstock, 1986). Social persuasion often is in the form of persuasion or verbal encouragement from a peer or employer. Items for this construct were taken from items eight and nine on the non-standardized instrument. Content for the questions were centered on feedback given to the participants from other professionals regarding their capabilities in risk assessment and management. Cronbach alpha for this construct, $\alpha=.888$, illustrated good internal consistency. Physiological and emotional factors. The fourth determinant of self-efficacy is how an individual is aroused during taxing situations (Bandura, 1977). Individuals will typically rely on their physiological state to determine whether they will proceed with a particular experience. One might assume in the case of suicide risk assessment and management, where a client's life is in question, it would be important to see how significant this particular predictor may have on provider's belief of their capabilities in the area of suicide assessment (Linehan, 2012; Rudd \& Joiner, 1988). Research suggests perhaps the most common negative experience in risk assessment is the fear of liability for individuals who take their own lives (Linehan, 2012). To capture this phenomenon, physiological and emotional factors were measured using items nine through fourteen from the non-standardized instrument. For this construct, it had a good level of internal consistency, as determined by a Cronbach's alpha of $\alpha=.820$. 
Table 3: Operationalization and Measurement of Independent Variables

\begin{tabular}{|c|c|c|c|c|c|}
\hline $\begin{array}{l}\text { Independent } \\
\text { Variables }\end{array}$ & Variable & Item Description & Measure & Coding & Reliability \\
\hline \multirow[t]{3}{*}{ Full Scale } & General Efficacy & $\begin{array}{l}\text { Self-reported degree } \\
\text { of general self-efficacy }\end{array}$ & $\begin{array}{l}\text { The GSE (Schwarzer \& } \\
\text { Jerusalem, 1995) a } 10 \text {-item } \\
\text { scale. The GSE measures } \\
\text { general self-efficacy. The } \\
10 \text { items are measured } \\
\text { using a } 4 \text { point Likert True } \\
\text { Scale from } 1 \text { (Not True) to } 4 \\
\text { (Exactly True) }\end{array}$ & $\begin{array}{l}\text { Composite range: } \\
\text { Continuous measure } \\
10=\text { extremely low } \\
\text { general self-efficacy to } \\
40=\text { high general self- } \\
\text { efficacy. }\end{array}$ & $\begin{array}{c}\text { Cronbach } \\
\text { Alpha } \\
.889\end{array}$ \\
\hline & Mastery & $\begin{array}{l}\text { Self-reported degree } \\
\text { of routinely conducting } \\
\text { and managing suicide } \\
\text { clients }\end{array}$ & $\begin{array}{l}2 \text { questions on the survey } \\
\text { were used to measure } \\
\text { mastery. The questions } \\
\text { were developed from the } \\
\text { SPRC } 24 \text { core } \\
\text { competencies. The } 2 \text { items } \\
\text { are measured using a } 4 \\
\text { point Likert True Scale from } \\
1 \text { (Not True to } 4 \text { (Exactly } \\
\text { true) }\end{array}$ & $\begin{array}{l}\text { Composite range: } \\
\text { Continuous measure } 2 \\
=\text { little mastery to } 8= \\
\text { extreme mastery in } \\
\text { suicide assessment } \\
\text { and management of } \\
\text { suicidal behaviors. }\end{array}$ & $\begin{array}{c}\text { Cronbach } \\
\text { Alpha } \\
.785\end{array}$ \\
\hline & Vicarious Experience & $\begin{array}{l}\text { Self-reported degree } \\
\text { of routinely reviewing } \\
\text { risk/protective factors, } \\
\text { suicide statistics and } \\
\text { routinely observing } \\
\text { professionals conduct } \\
\text { a suicide assessment } \\
\text { and managing suicide } \\
\text { clients }\end{array}$ & $\begin{array}{l}5 \text { questions on the survey } \\
\text { were used to measure } \\
\text { vicarious experience. The } \\
\text { questions were developed } \\
\text { from the SPRC } 24 \text { core } \\
\text { competencies. The } 5 \text { items } \\
\text { are measured using a } 4 \\
\text { point Likert True Scale from } \\
1 \text { (Not True to } 4 \text { (Exactly } \\
\text { true) }\end{array}$ & $\begin{array}{l}\text { Composite range: } \\
\text { Continuous measure } 5 \\
=\text { not true they have } \\
\text { had vicarious } \\
\text { experiences to } 20= \\
\text { exactly true they have } \\
\text { had vicarious } \\
\text { experiences in suicide } \\
\text { assessment and } \\
\text { management of } \\
\text { suicidal clients. }\end{array}$ & $\begin{array}{c}\text { Cronbach } \\
\text { Alpha } \\
.813\end{array}$ \\
\hline \multirow{2}{*}{$\begin{array}{l}\text { Sources of } \\
\text { Self-Efficacy }\end{array}$} & Social persuasion & $\begin{array}{l}\text { Self-reported degree } \\
\text { of routinely receiving } \\
\text { feedback from } \\
\text { professionals of } \\
\text { capabilities for risk } \\
\text { assessment and } \\
\text { management of } \\
\text { suicidal behaviors. }\end{array}$ & $\begin{array}{l}2 \text { questions on the survey } \\
\text { were used to measure } \\
\text { social persuasion. The } \\
\text { questions were developed } \\
\text { from the SPRC } 24 \text { core } \\
\text { competencies. The } 2 \text { items } \\
\text { are measured using a } 4 \\
\text { point Likert True Scale from } \\
1 \text { (Not True to } 4 \text { (Exactly } \\
\text { true) }\end{array}$ & $\begin{array}{l}\text { Composite range: } \\
\text { Continuous measure } 2 \\
\text { = not true they have } \\
\text { had social persuasion } \\
\text { to } 8=\text { exactly true they } \\
\text { have had social } \\
\text { persuasion that can } \\
\text { provide a suicide } \\
\text { assessment and } \\
\text { management to } \\
\text { suicidal clients. }\end{array}$ & $\begin{array}{c}\text { Cronbach } \\
\text { Alpha } \\
.888\end{array}$ \\
\hline & $\begin{array}{l}\text { Physiological/Emotional } \\
\text { Arousal }\end{array}$ & $\begin{array}{l}\text { Self-reported degree } \\
\text { of experiencing dread, } \\
\text { worry, fear of liability } \\
\text { and physiological } \\
\text { symptoms (e.g. } \\
\text { increased heart rate, } \\
\text { sweaty palms) }\end{array}$ & $\begin{array}{l}5 \text { questions on the survey } \\
\text { were used to measure } \\
\text { physiological experiences. } \\
\text { The questions were } \\
\text { developed from the review } \\
\text { of the literature of } \\
\text { physiological experiences } \\
\text { reported when conducting } \\
\text { a suicide assessment. The } 5 \\
\text { items are measured using a } \\
4 \text { point Likert True Scale } \\
\text { from } 1 \text { (Not True to } 4 \\
\text { (Exactly true) }\end{array}$ & $\begin{array}{l}\text { Composite Range: } \\
\text { Continuous measure } \\
5=\text { they do not have } \\
\text { physiological } \\
\text { experiences when } \\
\text { conducting a suicide } \\
\text { risk assessment to } 20= \\
\text { exactly true they have } \\
\text { physiological } \\
\text { experiences when they } \\
\text { are conducting suicide } \\
\text { risk assessments. }\end{array}$ & $\begin{array}{c}\text { Cronbach } \\
\text { Alpha } \\
.820\end{array}$ \\
\hline
\end{tabular}




\section{Data Collection}

Data collection. Data collection took place between November 2016 and January 2018. There are a total of nine trainings hosted by the Missouri Department of Mental Health (DMH). All data was collected from hard copies of the pre/posttest.

Procedures. DMH sent out an email invitation letter (Appendix A) to the participants who were eligible to register for the training. The letter briefly described the proposed study and gave the participants an opportunity to contact either Dr. Reitz or myself if they had questions prior to the training. Once participants arrived to the training, they were asked to complete a document, consenting to the study (Appendix B). To assist in this process, there were individuals from DMH and this researcher at the check in desk to assist anyone in reading or understanding any portion of the consent documentation. This researcher was available if anyone needed assistance reading or understanding the research questionnaires or training feedback documents. All eligible participants who consented to the study were then given a self-report pre-test questionnaire (Appendix C) before the training began. Once those were completed, they were collected by the researcher. Immediately following the training, the participants were given the self-report posttest questionnaire (Appendix D) and were instructed to return them back to the researcher at the checkout desk. To ensure anonymity, each participant used the last two digits of their last name and last five digits of their cell phone on each questionnaire to enable matching of the pre- and post-test. The consent to the study included follow-up for the future, which originally had been proposed for this dissertation study. However, the magnitude of such a study far surpassed the scope of a dissertation and therefore was set for future studies. Participants were voluntarily asked for a preferred email address and phone numbers, which have 
been kept in a separate secure file for such future studies. Included in the training materials was a training feedback document (Appendix E). Each participant was asked to fill this out and return at check out.

The Department of Mental Health provided the training at no cost to the participants, and participants received $6 \mathrm{CEU}$ credits. In order to receive the CEU credits, they had to return the training feedback form.

\section{Intervention (Training)}

The development of the intervention (training) was guided by social learning theories and brought together by the trainer's expertise and training through Behavioral Tech Institute. The intention of the training was to provide information on suicide risk and protective factors, statistics, research, Linehan Risk Assessment and Management Protocol, assessment of suicide risk, and treatment planning or management of suicidal clients. The trainer utilized various methods to instruct the participants (e.g. didactic, visual and experiential) throughout the training. The content agenda can be found in Appendix F.

\section{Analytic Strategy}

The overall analysis was conducted using SPSS Software, Version 25 (IBM Corporation, 2017). The data was analyzed for missing data. The data missing was a small amount: $4 \%$ of the values. Most of the missing data was found in the independent variables: $3 \%$. To prevent compromising the statistical power of this study, the missing data for the dependent variables (1\%) were replaced by the mean for the entire series (Saunders, Howell, Spitznagel, Dore, Proctor \& Pescarino, 2006; van Buuren, 2012). Background characteristics of the participants 
attending the training and baseline data were analyzed using univariate methods including means, standard deviations, frequencies, and percentages where appropriate. Inferential statistics were used to answer Research Question One, hypothesis 1 and $1 \mathrm{~b}$. The $t$-test was used to assess the differences in self-efficacy between the pre-training and post training. The Wilcoxon Signed Rank Test was used for significance at $p<.05$.

A Spearman's rank order correlation was run to generate findings for Research Question Two, assessing the relationship of the predictor variables and dependent variables after training. Logistic regression was used to answer Research Question Three. A binominal regression was run on the demographic variables and each dependent variable generating the first model and another regression adding the five independent variables to illustrate model two. The final model includes the best fit model for the data. For purposes of the logistic regression median, cut off scores were used to dichotomize the variables because the distribution of the composite variables were skewed. Further discussion can be found in the results section of Chapter 4.

Table 4

Data Analysis

\begin{tabular}{|c|c|}
\hline Research Question & Data Analysis \\
\hline $\begin{array}{l}\text { 1A. How does a standardized suicide risk assessment and } \\
\text { management training change a participant's self-efficacy in } \\
\text { the suicide assessment and management of suicide? } \\
\text { 1B. How does the standardized suicide risk assessment } \\
\text { training change a participant's self-efficacy in the tasks of } \\
\text { suicide assessment? }\end{array}$ & $\begin{array}{l}\text { - Paired samples t test conducted to determined mean } \\
\text { differences }\end{array}$ \\
\hline $\begin{array}{l}\text { 2. What is the relationship among the variables after the } \\
\text { training? }\end{array}$ & $\begin{array}{l}\text { - Correlation conducted for dependent variables and } \\
\text { independent variables in order to examine } \\
\text { associations. }\end{array}$ \\
\hline $\begin{array}{l}\text { 3. How are general self-efficacy, sources of efficacy } \\
\text { (mastery, vicarious experience, social persuasion, } \\
\text { physiological/emotional arousal) associated with the self- } \\
\text { efficacy of tasks of suicide assessment (general assessment, } \\
\text { assessment of high risk and suicide history, management of } \\
\text { suicidal behaviors), when controlling for demographic } \\
\text { variables? }\end{array}$ & $\begin{array}{l}\text { Logistic Regression conducted to determine the } \\
\text { maximum likelihood of having higher self-efficacy } \\
\text { in suicide assessment tasks. }\end{array}$ \\
\hline
\end{tabular}


In summary, this chapter provided a summary of the proposed study, the research questions, research design, data collection procedures and plan for data analysis. The quasiexperimental design utilized the pre-posttests to create an understanding of the topic of this study. 


\section{CHAPTER FOUR: RESULTS}

Informed by the Self-Efficacy Theory, this study explored the perspectives Missouri mental health providers have on their efficacy in conducting suicide risk assessment and management of suicidal clients. Data was gathered from participants across the state of Missouri. Three hundred and forty individuals participated in the training "Taking the Guess Work Out: Risk Assessment and Management of Suicide" sponsored by the Missouri Department of Mental Health. All data was collected in a face-to-face setting. Quantitative data was collected in the form of hard copy surveys. In this chapter, a description of the sample is presented followed by the results of the analyses utilized to answer the three research questions.

\section{Pre-Analysis and Description of Sample}

As reported in Table 5, the mean age of the participants was 39 years old. Participants had, on average, five years of work experience in their professional roles. The majority of the participants were female $(n=289,85 \%)$ and identified as White/Caucasian $(n=280,85 \%)$. Over half worked in the capacity as a licensed professional $(n=182,54 \%)$, and slightly less than half $(n=132,41 \%)$ used behavioral approaches in their practice with clients.

Table 5

Demographic and Background Characteristics of Participants

\begin{tabular}{lcc}
\hline \multicolumn{1}{c}{ Variable } & Mean & Standard Deviation \\
\hline Age $(\mathrm{n}=338)$ & 39.45 & 12.20 \\
Months working in the field $(\mathrm{n}=300)$ & 61.66 & 86.63 \\
& (approx. 5 years) & \\
\hline
\end{tabular}




\begin{tabular}{|c|c|c|}
\hline & $\mathbf{N}$ & $\%$ \\
\hline \multicolumn{3}{|l|}{$\operatorname{Sex}(n=338)$} \\
\hline Females & 289 & 85.50 \\
\hline Males & 49 & 14.50 \\
\hline \multicolumn{3}{|l|}{ Race/ethnicity (n=329) } \\
\hline Caucasian/White & 280 & 85.10 \\
\hline African American/Black & 22 & 6.70 \\
\hline Hispanic/Latino & 5 & 1.50 \\
\hline Asian & 6 & 1.80 \\
\hline Biracial & 13 & 4.00 \\
\hline Other & 3 & .90 \\
\hline \multicolumn{3}{|l|}{ Education $(n=340)$} \\
\hline High School Diploma & 6 & 1.80 \\
\hline Some College & 8 & 2.40 \\
\hline Bachelor's Degree & 38 & 11.20 \\
\hline Master's Degree & 273 & 80.30 \\
\hline Doctorate & 15 & 4.40 \\
\hline \multicolumn{3}{|l|}{ Occupation $(\mathrm{n}=334)$} \\
\hline Licensed Professional & 182 & 54.50 \\
\hline Provisional Licensed Professional & 69 & 20.70 \\
\hline Substance Abuse Counselors & 6 & 1.80 \\
\hline Support Specialists & 42 & 12.60 \\
\hline School Professional & 4 & 1.20 \\
\hline Nurse & 5 & 1.50 \\
\hline Administrator & 8 & 2.40 \\
\hline Intern & 13 & 3.90 \\
\hline Other professional & 5 & 1.50 \\
\hline
\end{tabular}

Primary Practice Approach ( $\mathrm{n}=323)$

Cognitive Behavioral Therapy 


$\begin{array}{lcc}\text { Psychodynamic Therapy } & 10 & 3.10 \\ \text { Dialectical Behavioral Therapy } & 66 & 20.40 \\ \text { Humanistic } & 41 & 12.70 \\ \text { Medical Practice } & 7 & 2.20 \\ \text { Community Practice } & 15 & 4.60 \\ \text { Eye Movement Desensitization \& Reprocessing } & 8 & 2.50 \\ \text { Therapy } & & 4.00 \\ \text { Other } & 13 & \end{array}$

Location of Practice $(n=339)$

$\begin{array}{lll}\text { Rural (under 50,000) } & 102 & 30.10\end{array}$

$\begin{array}{lll}\text { Urban (over 50,000) } & 224 & 66.10\end{array}$

$\begin{array}{lll}\text { Not Currently Practicing } & 13 & 3.80\end{array}$

Table 6 provides further information about participants and their experiences working with suicidal clients. A majority of the participants indicated they had prior experience working with suicidal clients $(n=295,88 \%)$. Most participants indicated there was no fear of liability working with suicidal clients $(n=327,98 \%)$. This finding is inconsistent with the literature (Feldman \& Freedenthal, 2006; Harned et al., 2016; Jobes, 2017; Jobes \& Berman, 1993) and will be discussed in Chapter five. Out of 331 participants, there was almost an even split between those who had referred clients to the hospital within the last three months for suicidal behaviors and those who had not $(n=166,50 \%$; $n=165,49 \%)$. 
Table 6

Participant Experience with suicidal clients

\begin{tabular}{|c|c|c|}
\hline Variable & $\mathbf{N}$ & $\%$ \\
\hline \multicolumn{3}{|c|}{$\begin{array}{l}\text { Experience working with suicidal client } \\
(\mathrm{n}=334)\end{array}$} \\
\hline Yes & 295 & 88.30 \\
\hline No & 39 & 11.70 \\
\hline \multicolumn{3}{|c|}{ Frequency of seeing suicidal clients $(n=326)$} \\
\hline Daily & 57 & 17.50 \\
\hline Weekly & 110 & 33.70 \\
\hline Monthly & 60 & 18.40 \\
\hline A few times a year & 83 & 25.50 \\
\hline Never & 16 & 4.90 \\
\hline \multicolumn{3}{|c|}{$\begin{array}{l}\text { Fear liability working with suicidal clients } \\
(\mathrm{n}=333)\end{array}$} \\
\hline Yes & 6 & 1.80 \\
\hline No & 327 & 98.20 \\
\hline \multicolumn{3}{|c|}{$\begin{array}{l}\text { Client died by suicide while in provider care } \\
(\mathrm{n}=324)\end{array}$} \\
\hline Yes & 41 & 12.70 \\
\hline No & 283 & 87.30 \\
\hline \multicolumn{3}{|c|}{$\begin{array}{l}\text { Referred client to the hospital in last } 3 \\
\text { months for suicidal behavior }(\mathrm{n}=331)\end{array}$} \\
\hline Yes & 166 & 50.20 \\
\hline No & 165 & 49.80 \\
\hline
\end{tabular}

In Table 7, further information is provided to capture the participants experience in prior suicide assessment and management training. Nearly all participants $(n=279,82 \%)$ had some training in suicide assessment prior to attending the training and over half had prior training in management of suicidal clients $(n=199,61 \%)$. The mean average of years since their last training on suicide risk assessment was 1.4 years and 1.3 years for training in management of suicide. A majority of participants $(n=290,87 \%)$ were not required to attend this training. 
Table 7

Participants experience with previous training in suicide risk assessment and management of suicidal behaviors

\begin{tabular}{|c|c|c|}
\hline Variable & $\mathbf{N}$ & $\%$ \\
\hline \multicolumn{3}{|l|}{$\begin{array}{l}\text { Prior training in risk assessment of } \\
\text { suicide }(n=339)\end{array}$} \\
\hline Yes & 279 & 82.30 \\
\hline No & 60 & 17.70 \\
\hline \multicolumn{3}{|l|}{$\begin{array}{l}\text { Prior training in management of suicide } \\
(\mathrm{n}=327)\end{array}$} \\
\hline Yes & 199 & 60.90 \\
\hline No & 128 & 39.10 \\
\hline \multicolumn{3}{|l|}{$\begin{array}{l}\text { Were you required to attend today's } \\
\text { training }(n=334)\end{array}$} \\
\hline \multirow{3}{*}{$\begin{array}{l}\text { Yes } \\
\text { No }\end{array}$} & 44 & 13.20 \\
\hline & 290 & 86.80 \\
\hline & Mean & Standard Deviation \\
\hline $\begin{array}{l}\text { How many months received last } \\
\text { training in risk assessment of suicide } \\
(\mathrm{n}=238)\end{array}$ & $\begin{array}{c}17.10 \\
\text { (approx.. } 1.4 \text { years) }\end{array}$ & 27.17 \\
\hline $\begin{array}{l}\text { How many months received last } \\
\text { training in management of suicide } \\
(\mathrm{n}=150)\end{array}$ & $\begin{array}{c}15.00 \\
\text { (approx.. } 1.3 \text { years) }\end{array}$ & 19.23 \\
\hline
\end{tabular}

Table 8 provides additional information about each of the subscales and the overall measure of self-reported self-efficacy in suicide assessment and management of suicidal clients at pretest and posttest and the difference scores. On average after training, participants' selfefficacy in conducting a suicide assessment $(M=65.78, \mathrm{SD} 6.83)$ was higher than participants' self-efficacy at the beginning of the training $(\mathrm{M}=58.07, \mathrm{SD}=9.04)$. 
Table 8

Descriptive Statistics for Counselor Suicide Assessment Efficacy $(n=340)$

\begin{tabular}{|c|c|c|c|c|}
\hline Variable & Minimum & Maximum & Mean & SD \\
\hline \multicolumn{5}{|l|}{ Pre-Test } \\
\hline Self-Efficacy in suicide assessment & 18 & 72 & 58.07 & 9.04 \\
\hline \multicolumn{5}{|l|}{ Post-Test } \\
\hline Self-Efficacy in suicide assessment & 40 & 72 & 65.78 & 6.83 \\
\hline Difference score: post -pre & & & 7.71 & 7.35 \\
\hline \multicolumn{5}{|l|}{ Pre-Test Assessment tasks } \\
\hline General suicide assessment & 4 & 16 & 13.07 & 2.23 \\
\hline Assessment of High Risk & 6 & 24 & 19.64 & 3.05 \\
\hline Assessment of Suicide History & 3 & 12 & 10.14 & 1.80 \\
\hline Management of suicide & 5 & 20 & 15.23 & 3.09 \\
\hline \multicolumn{5}{|l|}{ Post-Test Assessment tasks } \\
\hline General suicide assessment & 8 & 16 & 14.81 & 1.61 \\
\hline Assessment of High Risk & 13 & 24 & 21.90 & 2.40 \\
\hline Assessment of Suicide History & 6 & 12 & 11.28 & 1.27 \\
\hline Management of suicide & 8 & 20 & 17.80 & 2.35 \\
\hline \multicolumn{5}{|l|}{ Difference score: post minus pre } \\
\hline General suicide assessment & & & 1.74 & 1.94 \\
\hline Assessment of High Risk & & & 2.26 & 2.52 \\
\hline Assessment of Suicide History & & & 1.13 & 1.55 \\
\hline Management of suicide & & & 2.57 & 2.71 \\
\hline
\end{tabular}

To calculate the differences scores, pretest scores were subtracted from posttest scores. Changes in efficacy in general suicide assessment ranged from -3 to 8 , and on average, scores increased by 1.74 points $(\mathrm{SD}=1.94)$. Changes in assessment of high risk ranged from -4 to 12 , and on average, scores increased by $2.26(\mathrm{SD}=2.52)$. Assessment of suicide history ranged from -4 to 6 , with a 1.13 increase in points $(S D=1.55)$. Finally, pretest scores for management of suicide ranged from -7 to 10 , and on average, scores increased by 2.57 ( $\mathrm{SD}=2.71$ ).

Pretest and posttest scores were used to answer Research Question One: How does a standardized suicide risk assessment and management training change a participant's selfefficacy in suicide assessment and management of suicide? Post-test scores were used to evaluate Research Question Two: What is the relationship among the study variables? Finally, 
posttest scores of the constructs of suicide assessment and management of suicide were used in the logistic regression model to answer Research Question Three: Which variable predicts higher self-efficacy in suicide assessment and management of suicide after the training?

\section{Research Question One}

Research Question One was: How does a standardized suicide risk assessment and management training change a participant's self-efficacy in suicide assessment and management of suicide? The author hypothesized that following the training, Taking the Guess Work Out: Risk Assessment and Management of Suicide, participants would report a significantly more favorable perception of their self-efficacy in assessment and management of suicidal clients.

The paired samples $t$-test (Table 9) was used to assess the differences in participants' self-efficacy on pretests and posttests. Prior to the analysis, the data was pre-analyzed to test for normality. The difference scores for the pre and posttest were not normally distributed as assessed by the Shapiro-Wilks test $(\mathrm{p}=.000)$ therefore the Wilcoxon Signed Ranks test was conducted for the $Z$ value for significance. Outlier labeling, and box plots were used to identify outliers (Hoagln \& Iglewicz, 1987). Three outliers were detected yet were not more than 1.5 box lengths from the edge, and after careful inspection of their values, did not reveal to be extreme, therefore those were kept in the analysis. As $t$-tests are vigorous to violations of normality, it is not anticipated any of the results are invalidated.

Cohen's d was used to calculate the effect size for the paired samples $t$-test (Cohen, 1992). These results suggest training had a large effect on participants' report for the overall measure of self-efficacy in suicide assessment and management of suicide $(\mathrm{d}=.96)$. 
Table 9

Results of the $t$-test for overall self-efficacy in suicide assessment and management of suicide

\begin{tabular}{|c|c|c|c|c|c|c|c|c|c|}
\hline & \multicolumn{3}{|c|}{ Pre } & \multicolumn{3}{|c|}{ Post } & \multirow[t]{2}{*}{$\begin{array}{l}95 \% \text { CI For } \\
\text { Mean } \\
\text { Difference }\end{array}$} & \multirow[b]{2}{*}{$Z+$} & \multirow[b]{2}{*}{$\mathrm{df}$} \\
\hline & $\mathrm{M}$ & SD & $\mathrm{n}$ & $\mathrm{M}$ & $\mathrm{SD}$ & $\mathrm{n}$ & & & \\
\hline $\begin{array}{l}\text { Self-Efficacy in } \\
\text { suicide } \\
\text { Assessment and } \\
\text { management of } \\
\text { suicide }\end{array}$ & 58.07 & 9.04 & 340 & 65.78 & 6.83 & 340 & $-8.50,-6.93$ & $-14.02 *$ & 339 \\
\hline
\end{tabular}

To further examine the differences, Research Question 1b, how does the standardized suicide risk assessment and management training change a participant's self-efficacy in the tasks of suicide assessment and management of suicidal behaviors, was analyzed using a paired samples $t$-test (Table 10). Prior to the running the $t$-test, the data was pre-analyzed to test for normality. For all four constructs the data was not normally distributed, therefore the Wilcoxon Signed Rank test was used for the $Z$ value for significance. Outlier labeling and box plots were used to identify outliers (Hoagln \& Iglewicz, 1987). For general assessment of suicide, three outliers were detected that were more than 1.5 box-lengths from the edge of the box in a boxplot. For the assessment of high risk, four outliers were detected that were more than 1.5 box-lengths from the edge of the box in a boxplot. Assessment of suicide history and management of suicide revealed no outliers in the data as assessed by inspection of a boxplot for values greater than 1.5 box-lengths from the edge of the box. For those constructs with outliers, further inspection of those values did not reveal those as extreme, therefore they were kept in the analysis. As previously mentioned, $t$-tests are vigorous to violations of normality; it is not anticipated any of the results are invalidated. The effect size was determined by Cohen's $d$. The results for the 
subscales of the measure were general suicide assessment $(\mathrm{d}=.60)$, assessment of high risk $(\mathrm{d}=$ $.83)$ assessment of suicide history $(\mathrm{d}=.73)$ and management of suicide $(\mathrm{d}=.94)$.

Table 10

Results of t-test for Tasks of Suicide Assessment and Management of Suicide

\begin{tabular}{|c|c|c|c|c|c|c|c|c|c|}
\hline & \multicolumn{3}{|c|}{ Pre } & \multicolumn{3}{|c|}{ Post } & $\begin{array}{l}\text { 95\% Cl For } \\
\text { Mean } \\
\text { Difference }\end{array}$ & \multirow[b]{2}{*}{$Z+$} & \multirow[b]{2}{*}{$\mathrm{df}$} \\
\hline & $\mathrm{M}$ & SD & $\mathrm{n}$ & $\mathrm{M}$ & SD & $\mathrm{n}$ & & & \\
\hline General Assessment & 13.07 & 2.24 & 340 & 14.81 & 3.40 & 340 & $-1.95,-1.54$ & $-12.46 * *$ & 339 \\
\hline High Risk Assessment & 19.64 & 3.01 & 340 & 21.90 & 2.40 & 340 & $-2.53,-1.99$ & $-12.88 * *$ & 339 \\
\hline $\begin{array}{l}\text { Suicide History } \\
\text { Assessment }\end{array}$ & 10.14 & 1.81 & 340 & 11.28 & 1.27 & 340 & $-1.30,-.968$ & $-10.69 * *$ & 339 \\
\hline $\begin{array}{l}\text { Management of } \\
\text { suicidal behaviors }\end{array}$ & 15.23 & 3.09 & 340 & 17.80 & 2.35 & 340 & $-2.86,-2.28$ & $-12.96 * *$ & 339 \\
\hline
\end{tabular}

+Wilcoxon Signed Rank Test

$* p<0.5, * * p<0.01$

Research question one summary. Research Question One served as one of the primary questions in this study. The results revealed that training has a significant influence on one's self-efficacy in conducting suicide assessments and managing suicide behaviors. In Chapter five the differences in self-efficacy related to the training is discussed in more detail.

\section{Research Question Two}

Research Question Two was: What is the relationship among the variables after the training? The hypothesis was that higher self-efficacy in suicide assessment tasks is strongly associated with participants who hold graduate degrees, have practiced in the field longer than two years, and perceive higher self-efficacy, and sources of efficacy after training. A nonparametric bivariate correlation test was performed to measure the strength and direction of association among the variables, and to detect possible multicollinearity between the predictor 
variables and outcome variables (Table 11). Preliminary analysis showed the relationship to be monotonic, as assessed by the visual inspection of the scatterplot. Since there were some correlations above .6 among the predictors, further assessment to determine multicollinearity was conducted. Multicollinearity was further assessed by examining the variance of inflation factor (VIF) and tolerance values. VIF values are further discussed below as they relate to the logistic regression models presented in Research Question Three.

Significant indicators on the four dependent variables were explained using the Spearman's correlation test $\left(\mathrm{r}_{\mathrm{s}}\right)$. First, for general suicide assessment, correlation results revealed a positive association with education $\left(r_{s}=.131, \leq .05\right)$, profession $\left(r_{s}=.205, \leq .05\right)$, years of practice in the field $\left(r_{s}=.175, \leq .01\right)$, general self-efficacy $\left(r_{s}=.227, \leq .01\right)$, mastery $\left(r_{s}=.161\right.$, $\leq .01)$, vicarious experience $\left(r_{s}=.139, \leq .05\right)$ and social persuasion $\left(r_{s}=.156, \leq .05\right)$. For assessment of high risk, correlation results indicated a positive association with years of practice in the field $\left(r_{s}=.176, \leq .01\right)$, general self-efficacy $\left(r_{s}=.181, \leq .01\right)$ and mastery $\left(r_{s}=.160, \leq .01\right)$, vicarious experience $\left(r_{s}=.114, \leq .05\right)$. Assessment of suicide history was significantly related to gender $\left(r_{s}=.123, \leq .05\right)$, education $\left(r_{s}=.123, \leq .05\right)$, profession $\left(r_{s}=.198, \leq .01\right)$, years of practice in the field $\left(r_{s}=.168, \leq .01\right)$, general self-efficacy $\left(r_{s}=.252, \leq .01\right)$, mastery $\left(r_{s}=.206, \leq .01\right)$, vicarious experience $\left(r_{s}=.117, \leq .05\right)$ and social persuasion $\left(r_{s}=.117, \leq .05\right)$. Lastly, management of suicide behaviors was significantly associated with years practicing in the field $\left(r_{s}=.174, \leq .01\right)$, general self-efficacy $\left(r_{s}=.171, \leq .01\right)$, mastery $\left(r_{s}=.213, \leq .01\right)$ and social persuasion $\left(r_{s}=.171, \leq .01\right)$.

Research question two summary. A Spearman's rank-order correlation was run to the relationship of the predictor variables and their relationship to the four dependent variables. 
Among the four dependent variables there were predictors, which were not statistically significant (see Table 11). Significant predictors on the four dependent variables were explained. 
Table 11

Bivariate Correlations Variables

Demographics

1. Gender

2. Race $^{\mathrm{b}}$

3. Education ${ }^{\mathrm{c}}$

4. Profession $^{d}$

5. Practice Approach

6. Years practicing ${ }^{f}$

Predictor Variables:

7. General Efficacy

8. Mastery

9. Vicarious Experience

10. Social persuasion

11. Physiological and Emotional Arousal

Outcomes:

12. General suicide assessment

13. Assessment of high risk factors

.022

$.227^{*}$

$$
.161^{* *}
$$

.156

4. Assessment of suicide history

15. Management of suicide

$\begin{array}{llllllll}.006 & .004 & -.004 & .024 & -.019 & .174^{* *} & .171^{* *} & .213^{* *}\end{array}$

\section{$.099 \quad .171^{* *} \quad-.043$}

Note: ${ }^{a}$ Reference group: male, ${ }^{b}$ Reference group: non-white; ${ }^{\mathrm{c}}$ Reference group: bachelor's
behavioral practice approach, ${ }^{\mathrm{f}}$ Reference group: Two or less years of practice in the field. $*_{\mathrm{p}}<0.05$ level (2-tailed), **p $<0.01$ level (2-tailed) 


\section{Research Question Three}

Research Question Three was: How are general efficacy and sources of efficacy (mastery, vicarious experience, social persuasion, physiological/emotional arousal) associated with the tasks of suicide assessment (general assessment, assessment of high risk and suicide history, management of suicidal behaviors), when controlling for demographic variables (gender, race, education, occupation, practice approach, years of practice in the field)? Prior to running a logistic regression, the data was analyzed to determine if assumptions were met. Since the data had independent variables, the assumption of linearity did not need to be conducted (Box \& Tidwell, 1962). The data was analyzed for outliers using case diagnostics, ZResid, which revealed no values greater than 2.5 , therefore all the cases were kept in the analysis.

One limitation of logistic regression is the sensitivity to variables that have very high correlations to each other. Tabachnick and Fidell (2013) indicate variables that are highly collinear often generate large standard errors and inflated regression estimates. To observe the collinearity between the variables in the models the calculation of tolerance and variance, inflation factor (VIF) values were used. Predictors in Model 1 of the following regression analysis revealed that VIF values ranged from a low 1.02 to high 2.34. Tolerance values ranged from .64 to .99. Durbin-Watson test shows highest value of .70, which indicates the assumption of independence of errors is defendable. VIF and tolerance values further suggest multicollinearity was not a problem.

Predictors in Model 2 of the following regression analysis, Table 12, revealed that VIF values ranged from a low 1.02 to high 2.27. Tolerance values ranged from .44 to 97 . Durbin- 
Watson test shows a highest value of two, but it still indicates the absence of autocorrelation because it is not close to zero (positive autocorrelation) or four (negative autocorrelation).

For the likelihood of higher self-efficacy in general suicide assessment, gender, profession, practice approach, and years of practice were included in the final model (Table 12, Model 1). A binomial logistic regression was performed to ascertain the effects of the demographic variables on the maximum likelihood that participants had higher self-efficacy in general suicide assessment. To test the null hypothesis that the data fit the specified model, the Hosmer and Lemeshow Goodness-of-Fit test was conducted, $x^{2}(4, \mathrm{~N}=305)=7.390, p=.389$, and the null hypothesis was retained. This meant the predicated probabilities did not deviate from the probabilities in such a way that was not aligned with the prediction of the binary distribution and the model was adequate for analysis. The logistic regression model was statistically significant, $\chi 2(4)=153.406, p<.0005$. The model explained $52 \%\left(\right.$ Nagelkerke $\left.\mathrm{R}^{2}\right)$ of the variance in self-efficacy in general suicide assessment and correctly classified $81 \%$ of cases. Of the four predictor variables, three were statistically significant: gender, profession, and years of practice (as shown in Table 12). For general suicide assessment, females were 2.41 times more likely to score higher suicide self-efficacy than males. Participants who reported they were licensed counselors were 2.71 times more likely to score higher suicide self-efficacy than noncounselors. For those participants who used a cognitive behavioral approach in their practice, they were .57 less likely of scoring a higher level of self-efficacy than participants with a noncognitive behavioral approach. Those participants who had over two years of practice were 2.13 times more likely to score higher self-efficacy in general suicide assessment, whereas those with ten years or more of practice they were to 3.07 times more likely to score higher in general suicide assessment efficacy. 
In the Model 2, a multiple logistic regression was performed to include the additional predictors, general self-efficacy and sources of self-efficacy, on the maximum likelihood that participants had higher self-efficacy in general suicide assessment. The Hosmer and Lemeshow Goodness-of-Fit test was conducted to test model fit. Out of all the predictor variables, general self-efficacy and mastery remained in the final model as indicated by Hosmer and Lemeshow Goodness of fit test, $x^{2}(7, \mathrm{~N}=305)=3.557 . p=.895$. The logistic regression model was statistically significant, $\chi 2(7)=176.054, p<.0005$. The model explained 59\% (Nagelkerke $\left.\mathrm{R}^{2}\right)$ of the variance in self-efficacy in general suicide assessment and correctly classified $83 \%$ of cases. For the final Model 2, out of the two predictor variables, only one resulted in statistical significance, general self-efficacy. Despite the addition of the predictor variables, (e.g. ges and sources of selfefficacy) several demographic variables remained significant. Females were $2.14(p=.033)$ times more likely than to score higher than males in self-efficacy in general assessment, and licensed counselors were 4.44 ( $p=.001)$ more likely to score higher than non-licensed counselors. Participants who used a cognitive-behavioral approach were $.48(p=.024)$ times less likely to score higher self-efficacy in general suicide assessment than those who used a non-cognitive behavioral approach. This result was surprising and will be discussed further in Chapter 5 . Participants who had practiced ten years or more had 3.37 more odds than those with two or less years of practice to score higher self-efficacy in general suicide assessment. Participants with a graduate degree or higher did not remain in Model 1, yet was statistically significant in Model 2. Those participants had .29 fewer odds to score higher self-efficacy in general suicide assessment than those with a bachelor degree or less. In addition, those participants with higher general selfefficacy were 3.93 times more likely to score higher general suicide assessment efficacy. 
Table 12

Summary of Logistic Regression of High Self-Efficacy in General Suicide Assessment based on Gender, Profession, Practice Approach and Years of Practice, Education, General SelfEfficacy and Sources of Mastery

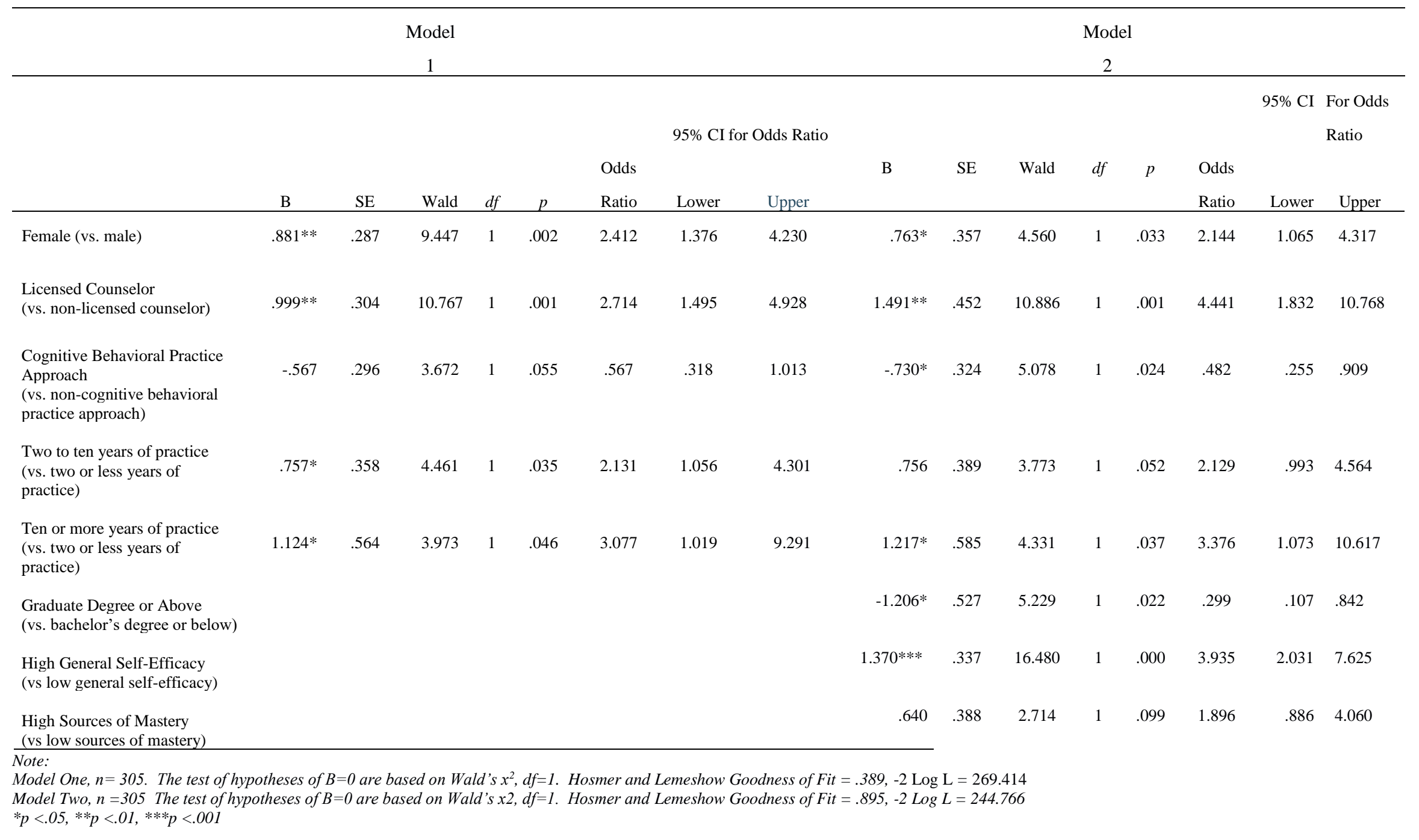


Table, 13, Model 1 illustrates the results of a logistic regression for the likelihood of higher self-efficacy in assessment of high risk based on the demographic variables. Model 1 passed the Hosmer and Lemeshow Goodness-of-Fit test, $x^{2}(4, \mathrm{~N}=305)=1.200, p=.878$. The model was statistically significant, $\chi 2(4)=29.803, p<.0005$. The model explained $12 \%$ (Nagelkerke $\mathrm{R}^{2}$ ) of the variance in self-efficacy in assessment of high risk and correctly classified $61 \%$ of the cases. Of the demographic variables remaining in the model, only two were statistically significant, profession and ten years or more of practice (Table 13). Results indicate participants who were licensed counselors were 2.40 times more likely to score higher self-efficacy in the assessment of high risk than non-counselors. Participants who practiced ten years or more in the field were 3.67 times more likely to score higher self-efficacy in assessment of high-risk factors than those who practiced two years or less.

For Model 2 (Table13) the predicting variables, general efficacy and sources of selfefficacy, were added to the model. The binominal logistic regression was performed to determine the effects of those variables. The model was a good fit according to the Hosmer and Lemeshow Goodness-of-Fit test, $x^{2}(5, \mathrm{~N}=305)=1.136, p=.992$. The logistic regression model was statistically significant, $\chi 2(5)=44.710 \mathrm{p}<.0005$. The model explained $18 \%$ (Nagelkerke $\mathrm{R}^{2}$ ) of the variance in self-efficacy in assessment of high risk and correctly classified $65 \%$ of the cases. With the addition of the predictor variables, several demographic variables remained significant including: education, profession and years of practice. For those participants who had a graduate degree or above, they had .35 times fewer odds of scoring higher self-efficacy than participants with a bachelor's degree or less education. Participants who were licensed counselor were 3.47 times more likely to score higher suicide self-efficacy than non-licensed 
counselors. Participants who have been practicing for ten years or more in the field were 3.63 times more likely to score with higher efficacy in assessment for high risk than those who have two years or less years of practice. Out of the five predictor variables, only general self-efficacy and sources of mastery remained in the model. Out of those two predictor variables, both were statistically significant. For those participants who scored as having higher general self-efficacy, they were 3.31 times more likely to score higher efficacy in assessment of high risk. Participants who scored as having higher sources of mastery in suicide assessments, their odds to score higher efficacy in assessment of high risk were .43 times more likely than those with lower sources of mastery. 
Table 13

Summary of Logistic Regression of High Self-Efficacy in Assessment of High Risk based on Education, Profession, Years of Practice, General Self-Efficacy and Sources of Mastery

\begin{tabular}{|c|c|c|c|c|c|c|c|c|c|c|c|c|c|c|c|c|}
\hline & & & Model & & & & & & & & & Mode & & & & \\
\hline & & & 1 & & & & & & & & & 2 & & & & \\
\hline & & & & & & & $95 \% \mathrm{C}$ & r Odds & & & & & & & $95 \% \mathrm{CI}$ & Odds \\
\hline & & & & & & & & & & & & & & & for & Ratio \\
\hline & & & & & & Odds & & & B & SE & Wald & $d f$ & $p$ & Odds & & \\
\hline & B & SE & Wald & $d f$ & $p$ & Ratio & Lower & Upper & & & & & & Ratio & Lower & Upper \\
\hline $\begin{array}{l}\text { Graduate degree or higher } \\
\text { (vs. bachelor's degree or } \\
\text { lower) }\end{array}$ & -.647 & .366 & 3.129 & 1 & .077 & .523 & .255 & 1.072 & $-1.042 *$ & .418 & 6.208 & 1 & .013 & .353 & .156 & .801 \\
\hline $\begin{array}{l}\text { Licensed Counselor } \\
\text { (vs. non-licensed counselor) }\end{array}$ & $.875^{*}$ & .371 & 5.559 & 1 & .018 & 2.398 & 1.159 & 4.960 & $1.247^{* * *}$ & .403 & 9.555 & 1 & .002 & 3.479 & 1.578 & 7.670 \\
\hline $\begin{array}{l}\text { Two to ten years of practice } \\
\text { (vs. two years or less of } \\
\text { practice) }\end{array}$ & .452 & .268 & 2.858 & 1 & .091 & 1.572 & .930 & 2.657 & .363 & .276 & 1.7333 & 1 & .188 & 1.438 & .837 & 2.469 \\
\hline $\begin{array}{l}\text { Ten or more years of practice } \\
\text { (vs. two years or less or } \\
\text { practice) }\end{array}$ & $1.300^{* *}$ & .424 & 9.422 & 1 & .002 & 3.670 & 1.600 & 8.420 & $1.289^{* * *}$ & .433 & 8.858 & 1 & .003 & 3.628 & 1.533 & 8.477 \\
\hline - & & & & & & & & & & & & & & & & \\
\hline $\begin{array}{l}\text { High General Self-Efficacy } \\
\text { (vs. low general self-efficacy) }\end{array}$ & & & & & & & & & $1.197 * * *$ & .271 & 19.452 & 1 & .000 & 3.311 & 1.945 & 5.638 \\
\hline - & & & & & & & & & & & & & & & & \\
\hline $\begin{array}{l}\text { High Sources of Mastery } \\
\text { (vs. low sources of mastery) }\end{array}$ & & & & & & & & & $.886^{* * *}$ & .317 & 7.806 & 1 & .005 & 2.427 & 1.303 & 4.519 \\
\hline
\end{tabular}


Results for the task of assessing suicide history can be found in Table 14. A multiple logistic regression was performed to determine the effects of the demographic variables, and only four out of the six demographic variables remained in the model. The Hosmer and Lemeshow goodness-of-fit test illustrates the model to be a good fit for the analysis, $x^{2}(2$, $\mathrm{N}=305)=.800, p=.977$. The logistic regression model was statistically significant, $\chi 2(4)=$ $81.744, p<.0005$. The model explained $31 \%\left(\right.$ Nagelkerke $\mathrm{R}^{2}$ ) of the variance in self-efficacy in assessment of high risk and correctly classified $73 \%$ of the cases. Out of the remaining demographic variables, only two were statistically significant, gender and profession (Table 14). For self-efficacy in assessment of suicide history, females are 1.97 times more likely to score higher suicide self-efficacy than males. It is important to note there were 289 females compared to 49 males in the study, which can impact the results. This will be discussed further in Chapter 5. Those participants who were licensed counselors had 2.92 times more odds to score higher suicide self-efficacy than non-licensed counselors.

Table 14, Model 2 depicts a logistic regression for the task of assessing suicide history, adding the five predictor variables. Out of the five predictors (general self-efficacy, mastery, vicarious experience, social persuasion and physiological/emotional arousal) only two remained in the final model as predictors of higher self-efficacy in this task. The results of the Hosmer and Lemeshow test showed the model was acceptable for analysis, $x^{2}(5, \mathrm{~N}=305)=4.681, p=.585$. The binominal logistic regression model was statistically significant, $\chi 2(5)=107.946, p<.0005$. The model explained $40 \%$ (Nagelkerke $\mathrm{R}^{2}$ ) of the variance in self-efficacy in assessment of suicide history and correctly classified $75 \%$ of the cases. Out of the five predictor variables only two were statistically significant (Model 2, Table 14). With the addition of the predictor variables several of the demographic variables remained significant (graduate degree and profession). In 
this model, participants who had a graduate degree or above had .23 fewer odds of scoring higher self-efficacy in assessing suicide history than participants with a bachelor's degree or less education. A discussion as to why this may be the case can be found in Chapter 5. Those participants who were licensed counselors were 3.23 times more likely to score higher suicide self-efficacy than non-licensed counselors. All those participants who scored with higher general self-efficacy were 3.11 times more likely to score higher efficacy in assessment of suicide history than those with a lower general self-efficacy score. For participants who had higher sources of mastery in suicide assessments were 2.31 more likely to score higher in efficacy of assessment of suicide history than those who scored lower. 
Table 14

Summary of Logistic Regression of High Self-Efficacy in Assessment of Suicide History based on Gender, Education, Profession, Years Practice, General Self-

Efficacy and Sources of Mastery

\begin{tabular}{|c|c|c|c|c|c|c|c|c|c|c|c|c|c|c|c|c|}
\hline \multirow{2}{*}{\multicolumn{9}{|c|}{$\begin{array}{c}\text { Model } \\
1\end{array}$}} & \multirow{2}{*}{\multicolumn{8}{|c|}{$\begin{array}{c}\text { Model } \\
2 \\
\end{array}$}} \\
\hline & & & & & & & & & & & & & & & & \\
\hline & \multirow[b]{3}{*}{$\mathrm{B}$} & \multirow[b]{3}{*}{ SE } & \multirow[b]{3}{*}{ Wald } & \multirow[b]{3}{*}{$d f$} & \multirow[b]{3}{*}{$p$} & \multirow{3}{*}{$\begin{array}{l}\text { Odds } \\
\text { Ratio } \\
\end{array}$} & \multirow{2}{*}{\multicolumn{2}{|c|}{ 95\% CI for Odds Ratio }} & \multirow[b]{3}{*}{$\mathrm{B}$} & \multirow[b]{3}{*}{ SE } & \multirow[b]{3}{*}{ Wald } & \multirow[b]{3}{*}{$d f$} & \multirow[b]{3}{*}{$p$} & \multirow{3}{*}{$\begin{array}{l}\text { Odds } \\
\text { Ratio } \\
\end{array}$} & \multirow{3}{*}{$\begin{array}{l}95 \% \mathrm{CI} \\
\text { Lower } \\
\end{array}$} & \multirow{3}{*}{$\begin{array}{l}\text { For Odds } \\
\text { Ratio } \\
\text { Upper } \\
\end{array}$} \\
\hline & & & & & & & & & & & & & & & & \\
\hline & & & & & & & Lower & Upper & & & & & & & & \\
\hline Female (vs. male) & $.676^{*}$ & .283 & 5.728 & 1 & .017 & 1.967 & 1.130 & 3.423 & .394 & .313 & 1.579 & 1 & .209 & 1.482 & .802 & 2.740 \\
\hline $\begin{array}{l}\text { Graduate degree or } \\
\text { higher (vs. bachelor or } \\
\text { less) }\end{array}$ & -.760 & .421 & 3.254 & 1 & .071 & .468 & .205 & 1.068 & $-1.477 * *$ & .482 & 9.383 & 1 & .002 & .228 & .089 & .587 \\
\hline $\begin{array}{l}\text { Licensed Counselor } \\
\text { (vs. non-licensed } \\
\text { counselor) }\end{array}$ & $1.074 * *$ & .381 & 7.959 & 1 & .005 & 2.928 & 1.388 & 6.176 & $1.172 * *$ & .409 & 8.215 & 1 & .004 & 3.228 & 1.448 & 7.193 \\
\hline $\begin{array}{l}\text { Two to ten years of } \\
\text { practice } \\
\text { (vs. two or less years of } \\
\text { practice) }\end{array}$ & .495 & .302 & 2.684 & 1 & .101 & 1.641 & .907 & 2.967 & .363 & .317 & 1.311 & 1 & .252 & 1.438 & .772 & 2.679 \\
\hline $\begin{array}{l}\text { Ten or more years of } \\
\text { practice } \\
\text { (vs. two or less years of } \\
\text { practice ) }\end{array}$ & .857 & .452 & 3.599 & 1 & .058 & 2.355 & .972 & 5.707 & .862 & .472 & 3.333 & 1 & .068 & 2.367 & .939 & 5.972 \\
\hline $\begin{array}{l}\text { High General Self- } \\
\text { Efficacy } \\
\text { (vs, low general-self- } \\
\text { efficacy) }\end{array}$ & & & & & & & & & $1.134 * * *$ & .279 & 16.505 & 1 & .000 & 3.107 & 1.798 & 5.368 \\
\hline $\begin{array}{l}\text { High Sources of Mastery } \\
\text { (vs low sources of mastery) }\end{array}$ & & & & & & & & & $.837 *$ & .323 & 6.723 & 1 & .010 & 2.308 & 1.227 & 4.344 \\
\hline
\end{tabular}


As shown in Table 15, Model 1 reports on the final task of suicide assessment, management of suicidal behaviors. Model 1 explores which of the six demographic variables has the maximum likelihood to predict higher self-efficacy in this task. The Hosmer and Lemeshow Goodness-of-Fit test was conducted and the model passed the test, $x 2(2, \mathrm{~N}=305)$ $=.090, p=.956$. The logistic regression model was statistically significant, $\chi 2(2)=9.970, p<.01$. The model explained $31 \%$ (Nagelkerke $\mathrm{R}^{2}$ ) of the variance in self-efficacy in management of suicide behaviors and correctly classified $58 \%$ of the cases. Of the demographic variables, two were statistically significant, education and ten or more years of practice (Table 15, Model 1). For those participants who had a graduate degree or above, they had .69 fewer odds of scoring higher self-efficacy in management of suicide behaviors than participants with a bachelor's degree or less education. Those participants who had ten years or more in the field were 2.71 times more likely to score higher self-efficacy management of suicide behaviors than those with two years or less in the field.

Model 2 (Table 15) reports on the additional predictor variables and includes the demographic variables found in Model 1. The Hosmer and Lemeshow Test indicated a good fit for the analysis, $x^{2}(5, \mathrm{~N}=305)=3.407, p=.845$. The logistic regression model was statistically significant, $\chi 2(5)=37.654, p<.0005$. The model explained $15 \%\left(\right.$ Nagelkerke $\left.\mathrm{R}^{2}\right)$ of the variance in self-efficacy in management of suicide behaviors and correctly classified $63 \%$ of the cases. Of the predictor variables two were statistically significant and several of the demographic variables remained significant (education and years of practice). For those participants who had a graduate degree or above, they had .41 times fewer odds of scoring higher self-efficacy in management of suicide behaviors than participants with a bachelor's degree or less education. Participants who practiced ten years or more in the field were 2.89 times more likely to score 
higher self-efficacy in management of suicide behaviors. In addition, those who had higher sources of mastery in suicide assessments were 3.18 times more likely to score higher efficacy in management of suicidal behaviors. Those who reported higher physiological and emotional arousal had .49 fewer odds of scoring higher self-efficacy in management of suicidal behaviors than participants who had lower sources of physiological and emotional arousal. This means participants who indicated they experienced stress, worry thoughts, and dread when managing suicidal clients were less likely to score higher in self-efficacy in management of suicidal behaviors. 
Table 15

Summary of Logistic Regression of High Self-Efficacy in Management of Suicide Behaviors based on Education, and Years of Practice, General Self-Efficacy, Sources of Mastery and Physiological and Emotional Arousal

\begin{tabular}{cccc}
\hline Model & Model \\
2 & 2 \\
\hline
\end{tabular}

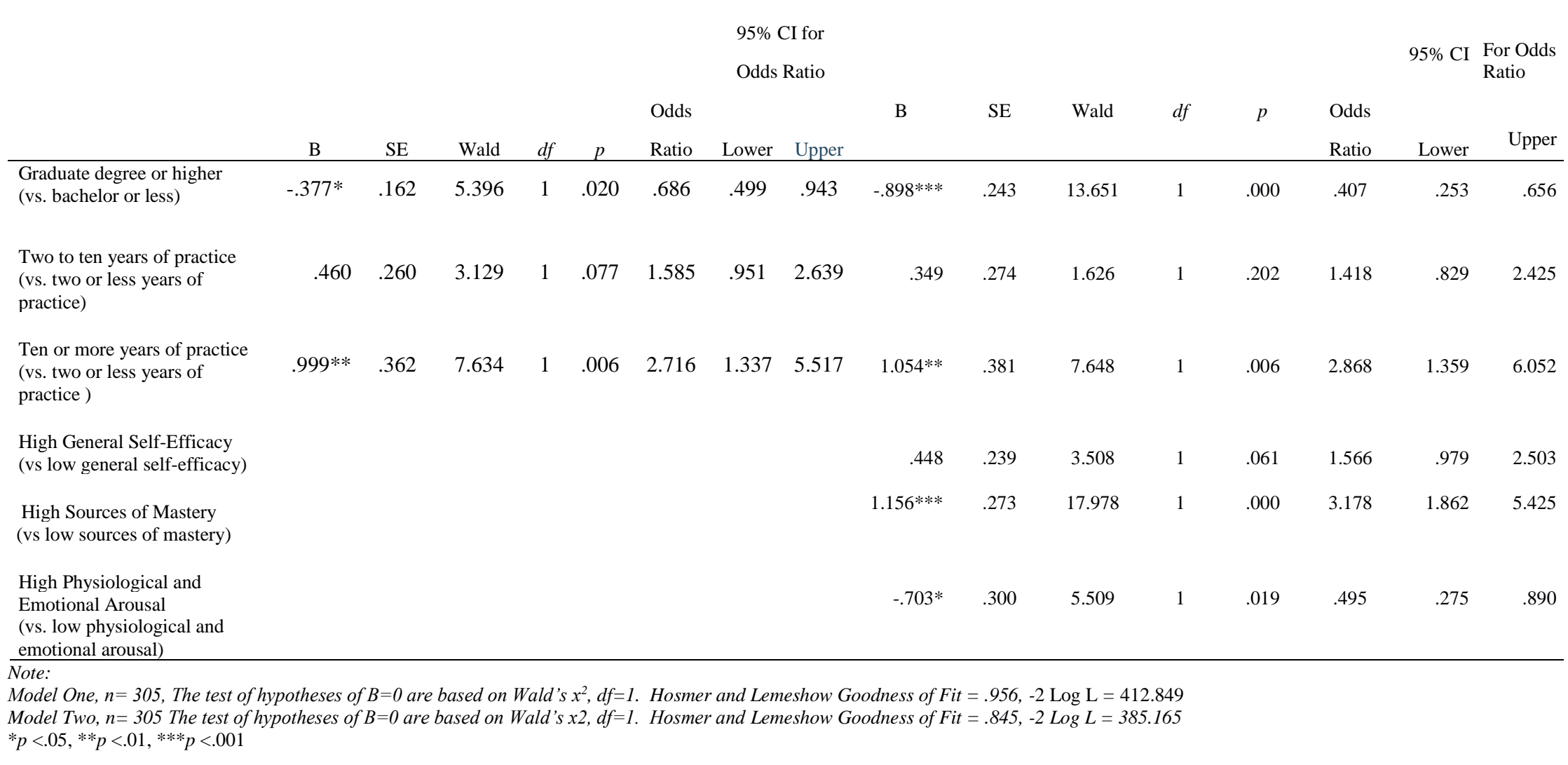


Research question three summary. Research question three served as one of the primary questions in this study. The results shed light on which demographic factors predict higher self-efficacy in the primary tasks of suicide assessment, as well as explores which sources of self-efficacy give way to the maximum likelihood of higher self-efficacy in the four tasks of suicide assessment. Consistently throughout the analysis, participants who reported attainment of a graduate degree or beyond were less likely than their counterparts (bachelor's degree or below) to report higher efficacy in the four tasks of suicide assessment. This finding seems to be counterintuitive and is further discussed in Chapter five.

This chapter provided a description of the results of the statistical analysis for this study. Quantitative findings were used to answer all three research questions. Research Question One suggested that the training had a significant influence on self-efficacy in conducting suicide assessments and managing suicidal behaviors. Several of the demographic and predictor variables were associated with higher self-efficacy in suicide assessment tasks. Results of the regression analysis showed several demographic variables were more likely to predict higher self-efficacy in tasks of suicide assessment than others. For participants who reported a high level of general self-efficacy, they consistently were more likely to report higher self-efficacy than those who had lower general self-efficacy. Out of all the sources of self-efficacy, mastery frequently was shown to predict higher selfefficacy in suicide assessment tasks than other sources of self-efficacy. Discussion of the findings, implications and limitations are discussed in Chapter 5. 


\section{CHAPTER FIVE: DISCUSSION}

In this chapter, a discussion of the findings as they relate to the literature will be discussed for each research question. Implications will be considered within a context that is meaningful to providers, in particular social work practioners, policymakers and future research. Limitations are addressed, and recommendations are made for future research, followed by concluding remarks.

\section{Discussion of findings}

Descriptive data. Most providers in this study were female which was consistent with other studies (Jacobson et al., 2012; Kleespies et al., 1993; Scheerder, Reynolds, Andriessen \& Van Audenhove, 2010; Harned et al., 2017). Most of the sample selfidentified as White which is reflective of Missouri's geographical location (U.S. Census Bureau, 2018). The sample collected was a diverse set of participants practicing in various settings such as schools, community mental health organizations, hospitals, and graduate training programs. The most common practice approach reported by participants was cognitive behavioral therapy which is an evidenced based practice often used in mental health settings since the 70's (Beck, 1976, 2016). Other practice approaches included, dialectical behavior therapy, psychodynamic, humanistic, eye movement desensitization and reprocessing and motivational interviewing.

Research question one. Recent studies indicate training in suicide assessment and management has had an impact on participant's knowledge and skills (Harned, et al., 2017; McNeil, et al., 2008; Oordt et al, 2009, Schmitz et al, 2012). Not as widely known is the 
association of training on self-efficacy in suicide assessment and training (Harned et al, 2017). The hypothesis for this research question was there would be a difference in selfefficacy based on pre-posttest scores. Results indicated there was a significant increase in participant's self-efficacy in suicide assessment and management post intervention. The positive findings support other results from other studies where post suicide training interventions have shown an increase in participant's confidence (Harned, et al., 2017; Oordt, et al, 2009).

Self-efficacy theory suggests individuals judge their capacity for challenging tasks based on their perceptions of knowledge, skills and strategies (Bandura, 1986). Since this training included suicide terminology, statistics, risk/protective factors and intervention strategies it is reasonable, based on self-efficacy theory, that the participants would initially report higher self-efficacy post intervention. In addition, this training had time set aside to role play using the assessment tool which Bandura notes that practice increases selfefficacy (1986). Practice can increase how one perceives their ability to use any given tool or instrument for suicide assessment (Bandura, 1977). Thus, incorporating experiential learning opportunities would be a valuable component to include for future trainings or workshops.

When exploring self-efficacy in suicide assessment and management of suicidal behaviors, it has been suggested to examine specific constructs of suicide assessment tasks (Douglas \& Morris, 2015). Taking this recommendation, the original items from the CSAES were used to test each construct (general suicide assessment, assessment of high risk and suicide history, and management of suicidal behaviors). Based on the results higher self-efficacy was perceived for all four suicide tasks post training. The significant 
increase is indicative participants perceived they were more capable post training to perform the suicide assessment tasks. These findings develop a foundation in which to explore further.

Research question two. Results from the analysis revealed several demographic and predictor variables were strongly associated with higher scores of self-efficacy, in particular suicide assessment tasks. A primary finding was that participants who had graduate degrees, a license to practice, more than two years of field practice, higher levels of self-efficacy, higher sources of mastery, vicarious experience or social persuasion, also reported higher efficacy in general suicide assessment tasks. Meaning those who reported one or more of those characteristics displayed stronger efficacy in asking questions about whether a client wanted to kill themselves or not. This aligns with Bandura's theory; individuals who report they have practiced or have been coached and encouraged to perform are more likely to perceive they can execute the task. However, there is also some question of whether this merely had to do with the nature of the task alone. For instance, asking "do you want to kill yourself or have you had thoughts of killing yourself" are often standard intake questions and are a requirement of accreditation for most organizations. Therefore, it would make sense licensed professionals, who are already assigned to frequently conduct a suicide assessment within their organizations would be more comfortable with the general suicide assessment task (basic questions referenced above) versus those who are not frequently assigned to this task; bachelor level, or non-degreed professionals.

Assessing high risk characteristics is a part of the suicide assessment task process and is crucial in determining next steps for provider and client. A strong relationship was 
found in the study between participants who reported two or more years of practice, higher general self-efficacy, mastery or vicarious experience. It is suspected that this task can be increasingly difficult as it begins to unfold whether a client is at imminent danger or not. When a given task begins to become more intimidating, perception of efficacy begins to decrease (Bandura, 1986). This stronger relationship between years of practice and sources of efficacy can assist administrative personnel in determining who might be their best provider for thoroughly assessing a client who presents at imminent risk.

As discussed in Chapter One, there are many "types" of mental health professionals, yet all need to be able to increase safety, reduce risk and promote wellness (Zero Suicide, 2019). Gathering complete information about the past, recent and present can assist in this process. From this study, there was a strong positive relationship between the gender of the participant, educational and professional background, and experience in the field, higher general self-efficacy, mastery, vicarious experience, and social persuasion. Familiarity with managing clients with suicide behaviors is an expectation of the Suicide Prevention and Resource Center core competencies for mental health professionals (2008) and the National Strategy for Suicide Prevention (2012). Findings from this study suggest a strong relationship between higher efficacy in management of suicidal behaviors and participants who report two or more years of practice in the field, high general selfefficacy, high mastery, and sources of social persuasion. Social persuasion is the verbal encouragement, coaching and evaluative feedback given to an individual from someone suggesting the individual is capable of performing a certain task (Bandura, 1986). One possible reason social persuasion is positively correlated with higher efficacy in management of suicidal behaviors is the relationship of social persuasion to general 
practice experience. As mentioned, the likelihood of mental health providers encountering a suicidal client is far greater than any other profession. It would be reasonable to presume participants who have had experience in the field have been provided some coaching as well as evaluative feedback on how they intervene with clients. In my experience as a mental health clinician and administrator, it is common for providers to receive not only constructive criticism but positive feedback on their performance as a practioner. Social persuasion did not correlate with any other task therefore further inquiry into this finding may be useful to establish administrative and supervisory procedures that include regular coaching and feedback to the provider specifically in management of suicidal clients.

Findings from this portion of the study suggests that practice experience, training and/or repeating the task to increase mastery have the strongest relationship to tasks of suicide assessment and can strengthen perception of their abilities. Thus, having a positive impact on participants' willingness to perhaps engage in working with suicidal individuals. Providers who come into their professional careers already with a strong perception they can complete difficult tasks (general self-efficacy) are associated with those providers who demonstrate higher efficacy in suicide assessment. To further comprehend the association between the variables and predict which are more likely to increase the odds of higher selfefficacy a regression analysis was utilized.

Research question three. Perceived self-efficacy is a strong predictor of behavior (Bandura, 1997; Moran, Hoy \& Hoy, 1998) and depending on individuals' perception it can result in whether they perform a task effectively and consistently. Research question three aimed to examine which demographic and predictor variable related to higher selfefficacy in suicide assessment tasks. 
General assessment of suicide task. This task is a common and routine practice within health professions which typically includes questions that indicate whether the state of the client requires further assessment (e.g. "Have you had thoughts of suicide"). Among the participant background variables, being female, licensed and having at least two or more years in practice predicted higher odds of reporting higher self-efficacy in general suicide assessment. The results are not surprising given that most of the participants were female (85\%) and licensed (73\%). With the addition of the predictor variables, gender, licensure, and ten more years of practice did remain significant. Interestingly, practice approach was found to be significant and yet resulted in a negative relationship. As discussed in chapter one, some practice approaches incorporate the routine use of suicide assessment and management strategies as a part of their protocol. Dialectical behavior therapy is one of those approaches. The author initially suspected since DBT providers are typically trained and readily use the LRAMP, they would report higher self-efficacy in suicide assessment and management of suicidal behaviors. Unfortunately, only 19\% of the sample reported using DBT as their primary approach which prevented a comparison of DBT approaches to all other practice approaches. Considering this limitation, practice approaches for this study were categorized into cognitive-behavioral approaches and noncognitive approaches. This resulted in $65 \%$ of the sample using a CBT approach with their clients. Although, cognitive behavioral therapy is an evidenced-based framework used in practice to treat clients who are suicidal (Alonzo \& Gearing, 2017; Handley, et al., 2013) there is not necessarily a strong emphasis in training on suicide assessment and management of suicide behaviors as dialectical behavior therapy has included in its training regime (Linehan, et al., 2012). 
Amidst all five predictor variables, only one indicated higher odds of predicting high self-efficacy in the general suicide assessment task. Participants with a strong perception of general self-efficacy were more likely than all other participants to report they were more likely to believe they were capable of this task. According to Bandura (1977), self-efficacy is the belief that an individual can act on novel or difficult tasks. Assessing life and death of a client is generally a stressful task (Linehan et al., 2012), therefore it would make sense that participants who perceive they are generally capable of handling difficult situations would report higher efficacy in asking clients about their suicide state.

Assessment of high risk. Assessment of high risk summons a degree of personal information from a client (e.g. sexuality, history of mental illness). Risk factors are characteristics associated with suicide yet are not direct causes (CDC, 2018) and assists the assessor in determining risk state (e.g. imminent risk). This task is a critical step in the suicide assessment process and should not be overlooked. Participants who were professionally licensed and had practiced ten years or more depicted higher odds in perceiving they were capable of this task than all other participants. It seemed likely this would be the case just based on the sheer number of licensed professionals attending the training. However, while professionals with more years of practice had higher odds of perceived efficacy in assessing high risk, this is a small percentage of participants, indicating most participants sensed they were not as likely to feel capable in this area of suicide assessment. This insinuates it could be advantageous to further focus training, for inexperienced professionals, on risk factors as they relate to elevating suicide risk. After adding predictor variables to the analysis, graduate level participants proved to be 
significant yet not in the direction one might expect. Surprisingly, graduate professionals reported less odds of predicting higher efficacy in the task of assessing high risk. Since this finding is consistent with all four suicide assessment tasks, a discussion pertaining to those results follows the interpretation of all four areas of assessment. Out of all five of the predictor variables, two were significant in predicting the likelihood of higher self-efficacy in the assessment of high-risk characteristics of clients. General self-efficacy and mastery prove higher odds than any other sources of efficacy. As previously mentioned the task of assessing high risk can be awkward and stressful. Participants who perceive themselves as already capable of difficult tasks and readily reporting high mastery in suicide assessment reasonably might ascertain they can assess high risk. This is an important factor to consider when contemplating whom should be thoroughly assessing an individual who demonstrates thoughts of suicide, especially since this task is needed to formulate risk (SPRC, 2008). It would seem logical most organizations would want their most capable provider's assessing high suicide risk factors to mitigate potential risk to the organization, provider or and client.

Assessment of suicide history. The results of this study showed that being female and having a license were characteristics which predicted higher odds of self-efficacy in the task of assessing client's history of suicide. This result does not imply gender or professional status has solid bearing on self-efficacy; this was not tested in the current study. Once the predictor variables were included in the analysis, gender was no longer significant.

Two predictor variables demonstrated an increase in the odds of expressing higher self-efficacy in assessing suicide history, general self-efficacy and mastery. Both of those 
variables, according to self-efficacy theory are powerful sources of self-efficacy (van der Bijl \& Shortridge-Baggett, 2001). Since providers with low general self-efficacy (ges) and sources of mastery had less odds than those who reported higher ges and sources of mastery, of believing they were capable of this task, it might be prudent for administrators and supervisors to pay particular attention to this area of suicide assessment by regularly checking with their less experienced providers on how they are assessing for suicide history and using this information for formulation of risk.

Management of suicide behaviors. Douglas \& Morris (2015) took special care to develop items on the CSAES to reflect levels of difficulty in suicide assessment. By far the most difficult task is to manage a client who is reporting thoughts of suicide (Harned et al, 2016; Jacobson et al., 2012; Keleespies et al., 1993; Linehan et al., 2012). Among all the demographic characteristics used in this study, experienced providers (e.g. over ten years of experience) were the only participants who reported higher odds of perceived efficacy in managing suicidal behaviors. Conversely, participants who did not have experience, were less likely to report ability to manage suicidal clients. This is concerning since previous research mentioned in chapter one posits most mental health professionals are highly likely to encounter suicidal clients. This suggests time spent with less experienced professionals to develop their skills in managing suicidal behaviors would be a favorable component to the induction into practice. With the additional predictor variables, experience still maintained significance. Higher source of mastery, so those repeated opportunities to practice managing suicidal behaviors, were also indicative of higher efficacy in managing suicidal behaviors. According to self-efficacy theory, practicing is the most important source of self-efficacy (Bandura, 1977). Failure in a task can decrease self-efficacy 
especially when it occurs early in the learning process yet individuals who are certain (mastery) of their capacities will attribute failure as situational versus internally doubting their capacity of the task (van der Bijl \& Shortridge-Baggett, 2001). An implication of this finding, points to increasing a provider's opportunity to regularly engage in managing suicidal client's behaviors within the context of their practice. Unless the client is at imminent risk this might mean instead of immediately removing a client from someone's case load or hospitalizing the client, providers should, with proper supervision, continue to intervene and apply management techniques to ensure client safety. Managing most suicidal behaviors in an outpatient setting can be critical to suicide prevention since it is known suicide risk peaks in periods after hospital discharge (Kessler et al., 2014; Qin \& Nordentoft, 2005). Clinical oversight of clients can prove challenging. Jobes (2012) suggests significant misunderstanding in risk management is one of the primary concerns of providers. This may mean that organizations must provide ample opportunities for providers to have support when they intervene and manage their client's suicidal behaviors. Support may present differently based on provider but should include regular consultation with another provider, frequent check in with clients external supports (e.g. family or friends), decreased caseloads if working with numerous suicidal clients, perhaps additional credit towards billable services for the week if a provider sees a client more than once during a week, and frequent encouragement to engage in self-care practices in order to alleviate stress and anxiety.

One perplexing finding from this study was participants who had earned a graduate degree and above reported they were less likely to perceive higher self-efficacy in all four suicide assessment tasks. After contemplating this finding, there are a few suggestions as to 
why this may be the case. Typically, most providers who acquire a bachelor's degree or some college will be persons whose responsibilities are most likely different than graduate degreed participants. Since the responsibilities are vastly different, the bachelor degreed individuals may have reported the likelihood that training increased their self-efficacy because they believe they can do their best in the assessment process yet also have the safety net of turning it over to a higher degreed individual to be thoroughly reviewed and determine next steps. Therefore, bachelor level participants might score higher efficacy because they are not able to make the final call on assessments. Whereas, the graduate degreed individual may be less likely to have anyone to consult before making a final call on a client's risk of suicide thus impacting their sense of efficacy. This coincides with selfefficacy theory, where Bandura (1986) indicates social persuasion enables triumph over adverse tasks. For graduate degreed individuals' sources of persuasion may not exist or be limited since they are just expected to make those final decisions as a part of their role in the organization.

One could also argue that graduate level individuals are the primary resources to manage suicidal clients. While providers who have earned a bachelor level or below may be asked to check in with the individual client, they are not normally the primary provider who will intervene when someone is suicidal. Many organizations hire bachelor leveled individuals for positions like a case manager or group facilitator. Both of those positions require some supportive interventions with clients yet do not encourage ongoing therapeutic interventions, such as regular assessment and treatment of suicidal behaviors. Typically, it is the graduate leveled individuals providing direct care (e.g. therapy) and regularly intervening with suicidal clients. It is possible to contend that during this training 
study as the skill level increased for graduate leveled participants, the seriousness of working with suicidal individuals may have set in; thus, decreasing the level of comfort of managing suicidal behaviors. Meaning once participants learned what was involved in effectively and realistically managing a client, which was a training module, their perception in their capability of handling those tasks might have declined. Finally, it appears in each model there are other predictors which relate to experience in particular mastery and with general self-efficacy (how confident of a person are you generally). In the literature it indicates that professional degrees (social work and counseling psychology) do not have programs which have risk assessment and management as a part of the core curriculum, so this might contribute to why education is less of a predictor than experience (Bongar \& Harmatz, 1989; Feldman \& Freedenthal, 2006; Jacobson et al., 2004; Jacobson et al, 2012). The findings may mean education is not actually a reliable predictor of whether you have high suicide self-efficacy or not when it comes to suicide assessment task.

Because of these findings, it could be implied possessing certain characteristics and sources of efficacy can help increase the likelihood a provider will perceive they are capable in handling suicide assessment tasks. Although there were some perplexing findings, in general findings point to some solid implications for practice, policy and research.

\section{Implications}

Social Work Practice. Poverty, mental health, serious physical health conditions, prolonged stress, childhood abuse and neglect are all known health, environmental and 
historical factors known to increase the chance of suicide (AFSP, 2018). Those are the common maladies where social workers are employed to intervene and assist clients in developing strategies to overcome those challenges. Thus, it is nearly impossible for a social worker in the field to not encounter clients experiencing suicide. This means social workers need to be prepared to not only assess for risk but manage client's suicide behaviors. A part of being "prepared", can in part be explained by whether one perceives they are capable (self-efficacy) of accomplishing a task. Often social workers are put into positions where they must perform tasks under stressful conditions (long work hours, high caseloads, clients with severe mental and physical conditions) all of which rightfully impact their ability to perceive they are capable of intervening. Awareness into the interplay of self-efficacy, as it relates to suicide assessments tasks, can help individual social work providers develop strategies to increase their mastery in a task, frequently seek out feedback directly related to their observed capability of the task, or decrease their worry about a task by preventively seeking out mentorship or counseling to have someone to process their work with suicidal clients. Additionally, directly examining sources of selfefficacy can point social work educators and supervisors to where they should implement professional development opportunities. For social workers who are in supervision or a mentorship, attending to their subjective appraisal of their practice would be useful. Ensuring their self-messaging is accurate and reflective of their capabilities versus sending a self-disparaging message which leaves them less apt to perceive they are capable. Since it has been proven in other reports and supported by the results of this study, efficacy can be altered by training, it would benefit social work academic training programs to increase their education in this area. Suggesting both bachelor and graduate level programs include 
specific courses in suicide assessment and management of suicidal clients as well as frequent opportunities to practice prior to graduation and entering the field.

While it is uncertain exactly how many social workers have had a client die by suicide (Feldman \& Freedenthal, 2006) some studies suggest one third of all social workers encounter a death by suicide in their professional careers (Jacobson et al, 2004; Heller, 2017). Bandura (1986) explains that physiological and emotional arousal can have a negative impact on an individual's self-efficacy. The loss of a client's life to suicide can in fact have a major impact on a social workers future ability to make clinically appropriate decisions. In addition, lack of practice (mastery) in suicide assessments can also lead to poor outcomes for providers who serve clients with suicidal behaviors (Feldman \& Freendenthal, 2006). Therefore, it seems reasonable mental health professionals should have opportunities to observe and practice suicide assessments prior to engaging in this task solely on their own. However, from professional experience, this is not always the case. Often immediately after beginning employment, social workers are stuck into positions where they will encounter someone at risk with little to no proper practice or organizational training. Thus, increasing the likelihood of experiencing distress (Deutsch, 1984). Adequate preparation, support and helping social work professionals become aware of their levels of arousal in the face of challenges, like suicide assessments, should be a top priority for medical and mental health organizations.

Policy. In 2018, Missouri House Bill 1719 was passed by the legislature. This bill includes a requirement for all health care professionals to complete a two-hour suicide prevention training as a condition of licensing. In response, the Missouri Division of Professional Registration for social workers (2018) implemented a 2-hour requirement 
requiring evidence of this training for licensure and renewal applications. Yet still this is not a requirement in every state (AFSP, 2016). A recent study by Jahn, Quinnett \& Ries (2016), suggests that suicide-focused training is critical. Therefore, research results, like the findings from this study, imply there is still working to be done in effectively supporting professionals, especially licensed professionals, in managing suicidal clients. It will be important as evidence unfolds to use the findings to adapt and enhance current policies which directly impact the state of suicide training required by law.

Also, as impactful is how organizational policy and procedures support professionals who have lost a client to suicide. Providers who have lost a client need extra support, coaching and feedback from their peers and employers to continue in their practice. Besides state or national requirements, organizations should examine their internal policies on suicide training. Developing internal processes which support the development of professionals in assessment and management would be beneficial for morale and retention. Improvement in these areas will require more research.

\section{Limitations}

This study had some limitations to take into consideration when interpreting the results. First, the participants were all volunteers which subjects the results to selection bias. While this study had a larger sample size, there was an undercoverage for certain members of the general population, males and participants who had less than a graduate degree as well as unlicensed professionals. Additionally, the study employed nonpurposive sampling which limits the generalizability of the research findings. Generally, in the social sciences, social desirability is often a threat (Lavrakas, 2008). For a study on 
self-efficacy, this could be particularly problematic since it would be assumed reporting high self-efficacy in conducting suicide assessments would be preferable among licensed professionals currently working in the field.

The thorough understanding of which sources of efficacy are associated with higher self-efficacy in suicide assessment tasks is limited by the cross-sectional design. To comprehend the total magnitude of training as it relates to provider self-efficacy, post intervention follows up at different points in time are preferred (Schmitz et al., 2012). Although the survey consisted of standardized measures for most of the instrument, for sources of self-efficacy, measures were created without standardization. Reliability of those measures, as determined by Cronbach alpha, depicted good to high levels of internal consistency. However, validity was a limitation. Due to time constraints in this study, this portion of the survey was not piloted or psychometrically tested which could reduce the validity of the findings. Despite the limitations, this study is an initial attempt to understand the predictors of self-efficacy as they related to suicide assessment and management of suicidal clients and can be an important step towards progressing the literature forward in this area.

One final limitation is the limitation of type of analysis. In behavioral science research often, participants will change as part of the course and often they might change for systematic reasons thus to improve this study it would have been beneficial to have a comparison group (Rubin \& Babbie, 2011). As previously mentioned self-efficacy is subjective and, in this study, there could have been numerous factors which might have influenced the participants self-report of their efficacy at this one point in time. While I was 
certainly attuned to this limitation, feasibility of developing a comparison group for this study was not prudent at the time it was developed.

Future Research. Improving training for mental health professionals is a logical means to prevent suicide and save lives (Harned, et al, 2016; Oordt, et al, 2009; Schmitz et al., 2012). While having clinical practice guidelines, especially those suggested by the national suicide prevention strategy, are beneficial they might not directly impact any changes in a provider's attitude or behavior (Freemantle et al., 2002; Worrall, Chaulk, \& Freake, 1997, Oordt et al, 2009). Therefore, it would be advantageous for research to continue to investigate factors that influence attitudes or behavioral changes when it pertains to suicide assessment and management of suicidal behaviors. To enhance understanding for the outputs of this study, the Department of Mental Health has approved for me to develop a qualitative study follow up with the participants. The logic model, as seen in Chapter 3, describes the follow up and potential impact on providers, clients and community. Since there has not been a plethora of systematic research of the effects of training, another suggestion would be to develop a longitudinal study to develop a robust understanding of the impact of training on providers' ability and how it improves competence. To my knowledge there are no studies which specifically examine sources of self-efficacy on suicide assessment tasks. Furthering this study to include a comparison group would be advantageous to provide additional knowledge to the growing suicide training literature. One limitation, as discussed below, is the lack of standardized measurements to examine sources of self-efficacy. Piloting and psychometrically testing such an instrument could add to the research in this area. As Pisani et al., (2011) point out, training/workshops transfer knowledge and can assist in shifting attitudes of providers. 
Furthering research in this area, can certainly continue to enhance the development of future trainings in suicide assessment.

This study aimed to examine which demographic characteristics of mental health professionals, general self-efficacy and sources of self-efficacy influenced stronger perception in efficacy in suicide assessment tasks. Informed by self-efficacy theory, results reveled training and specific sources of self-efficacy are strong predictors of an increased perception of capabilities to complete certain suicide assessment tasks. It clearly supports it is possible to favorably change provider perceptions related to self-efficacy through professional training (Oordt, 2009). While suicide assessment training studies have been conducted over time, limited studies report on the influence of self-efficacy as it relates to suicide assessment tasks. This study served to fill in some of the gaps and advance literature in this area. Results of this study suggest training does have an impact on provider's perceptions of their abilities in suicide assessment. 


\section{References}

Aarons, G. A., Glisson, C., Green, P. D., Hoagwood, K., Kelleher, K. J., Landsverk, J. A. \& Research Network on Youth Mental Health (2012). The organizational and social context of mental health services and clinician attitudes toward evidence-based practice: A United States national study. Implementation Science, 7(1), 56-72. doi: 10.1186/1748-5908-7-56.

American Association of Suicidology (2018). Retrieved March 1, 2018 from http://www.suicidology.org.

Alonzo, D., \& Gearing, R. E. (2017). Suicide assessment and treatment: Empirical and evidencebased practices. Springer Publishing Company.

Andersen, U. A., Andersen, M., Rosholm, J. U. \& Gram, L. F. (2000). Contacts to the health care system prior to suicide: A comprehensive analysis using registers for general and psychiatric hospital admissions, contacts to general practioners and practising specialists and drug prescriptions. Acta Psychiatrica Scandinavica, 102, 126-134. doi: 10.1034/j.1600-0447.2000.102002126.x.

Andrews, J. A. \& Lewinsohn, P. M. (1992). Suicidal attempts among older adolescents: Prevalence and co-occurrence with psychiatric disorders. Journal of the American Academy of Child \& Adolescent Psychiatry, 31(4), 655-662. doi:10.1097/00004583-199207000-00012.

Bagge, C. L., Glenn, C. R. \& Lee, H. (2013). Quantifying the impact of recent negative life events on suicide attempts. Journal of Abnormal Psychology, 122(2), 359-368. doi: 10.1037/a0030371. 
Bandura, A. (1977). Self-efficacy: Toward a unifying theory of behavioral change. American Psychological Association, 84(1), 191-215. doi:10.1037/0033295X.84.2.191.

Bandura, A. \& Simon, K. M. (1977). The role of proximal intentions in self-regulation of refractory behavior. Cognitive Therapy and Research, 1(3), 177-193.

Bandura, A. (1986). Social foundations of thoughts and actions: A social cognitive theory. Englewood, NJ: Prentice-Hall.

Bandura, A. (1986). The explanatory and predictive scope of self-efficacy theory. Journal of Social and Clinical Psychology, 4(3), 359-373.

Bandura, A. (1997). Self-efficacy: The exercise of control. Macmillan.

Bandura, A. (2001). Social Cognitive Theory: An Agentic Perspective. Annual Review of Psychology, 52(1), 1-26. doi:10.1146/annurev.psych.52.1.1.

Beck, A. T. (1979). Cognitive therapy and the emotional disorders. Penguin.

Beck, A.T. (2016). The Evolution of CBT in Community Mental Health. Retrieved from health/

https://beckinstitute.org/the-evolution-of-cbt-in-community-mental-

Beautrais, A. L., Joyce, P. R. \& Mulder, R. T. (1997). Precipitating factors and life events in serious suicide attempts among youths aged 13 through 24 year. Journal of the American Academy of Child and Adolescent Psychiatry, 36(11), 1543-1551. doi: 10.1016/S0890-8567(09)66563-1.

Behavioral Tech Institute. (1996). Linehan Suicide Safety Net. Retrieved on June 5, 2015 from http://behavioraltech.org/products/ssn.cfm. 
Betz, M., Sullivan, A., Manton, A., Espinola, J., Miller, I., Camargo, C. \& Boudreaux, E. (2013). Knowledge, attitudes, and practices of emergency department providers in the care of suicidal patients. Depression and Anxiety, 30(10), 1005-1012. doi: 10.1002/da.22071.

Boekaerts, M. (1991). Subjective competence, appraisals and self-assessment. Learning and Instruction, 1(1), 1-17.

Bongar, B. \& Harmatz, M. (1989). Graduate training in clinical psychology and the study of suicide. Professional Psychology: Research and Practice, 20(4), 209-213. doi: 10.1037/0735-7028.20.4.209.

Bongar, B., \& Harmatz, M. (1991). Clinical psychology graduate education in the study of suicide: Availability, resources, and importance. Suicide and Life-Threatening Behavior, 21(3), 231-244.

Bongar, B. (2002). The suicidal patient: Clinical and legal standards of care (2 $\left.{ }^{\text {nd }} \mathrm{Ed}\right)$, Washington, DC, US: American Psychological Association.

Boudreaux, E. \& Horowitz, L. (2104). Suicide risk screening and assessment: Designing instruments with dissemination in mind. American journal of preventive medicine. 47(3), S163-S169. doi.org/10.1016/j.amepre.2014.06.005

Box, G. E. P., \& Tidwell, P. W. (1962). Transformation of the independent variables. Technometrics, 4, 531-550.

Braun, V., \& Clarke, V. (2006). Using thematic analysis in psychology. Qualitative research in psychology, 32(2), 77-101.

Brent, D. A. (2001). Assessment and treatment of the youthful suicidal patient. Annals of the New York Academy of Sciences, 932(1), 106-131. 
Brent, D. A., Oquendo, M., Birmaher, B., Greenhill, L, Kolko, D., Stanley, B.,...Salazar, J.

O. (2002). Familiar pathways to early-onset suicide attempts: Risk for suicidal behavior in offspring of mood-disordered suicide attempters. Archives of general psychiatry, 59(9), 801-807. doi:10.1001/archpsyc.59.9.801.

Brown, G. K., Have, T. H., Henriques, G. R., Xie, S. X., Hollander, J. E., \& Beck, A. T. (2005). Cognitive therapy for the prevention of suicide attempts: A randomized controlled trial. Journal of American Medical Association, 294, pp. 563570.doi:10.1001/jama.294.5.563.

Burvill, P. W. (1998). Migrant suicide rates in Australia and in country of birth. Psychological Medicine, 28(1), 201-208. doi:10.1017/S0033291797005850.

Cavanagh, J. T. O., Carson, A. J., Sharpe, M. \& Lawrie, S. M. (2003). Psychological autopsy studies of suicide: a systematic review. Psychological Medicine, (3), 395405. doi:10.1017/S003329102006943.

Centers of Disease Control and Prevention. (2013). Retrieved on March 23, 2013 from http://www.cdc.gov.

Chandy, J. M., Blum, R. W., Resnick, M. D. (1997). Sexually abused male adolescents: How vulnerable are they? Journal of Child Sexual Abuse, 6(2), 1-16. doi:10.1300/J070v06n02_01.

Chemtob, C., Hamada, R., Bauer, G., Torigoe, R. \& Kinney, B. (1988). Patient suicide and impact on psychologists. Professional Psychology: Research and Practice, 19(4), 416-420.

Chen, G., Gully, S. M. \& Eden, D. (2001). Validation of a new general self-efficacy scale. Organizational Research Methods, 4(1), 62-83. 
Chowdhury, S., Endres, M., \& Lanis, T. W. (2002). Preparing students for success in team work environments: The importance of building confidence. Journal of Managerial Issues, 14(3), 346-359.

Cohen, J. (1988). Statistical power analysis for the behavioral sciences (2nd ed., pp. 567). Hillsdale, NJ: L. Erlbaum Associates

Cohen, J. (1992). A power primer. Psychological bulletin, 112(1), 155-159.

Commission on Accreditation of Rehabilitation (2016). Retrieved June 27, 2017 from http://www.carf.org/Resources/.

Conner, K. R., Houston, R. J., Swogger, M. T., Conwell, Y., You, S., He, H.,...Duberstein, P. R. (2012). Stressful life events and suicidal behavior in adults with alcohol use disorders: Role of event severity, timing and type. Drug and Alcohol Dependence, 120(1-3), 155-161. doi.org/10.1016/j.drugalcdep.2011.07.013.

Coombs, D. W., Miller, H. L., Alarcon, R., Herlihy, C. Lee, J. M. \& Morrison, D. P. (1992). Presuicide attempt communications between parasuicide and consulted caregivers. Suicide and Life-Threatening Behavior, 22(3), 289-302.

Cramer, R., Johnson, S. M., McLaughlin, J., Rausch, E., \& Conroy, M. A. (2013). Suicide risk assessment training for psychology doctoral programs: Core competencies and a framework for training. Training and Education in Professional Psychology, 7(1), 1-11. doi:10.1037/a0031836.

Cramer, R. J., Bryson, C. N., Eichorst, M. K., Keyes, L. N., \& Ridge, B. E. (2017). Conceptualization and Pilot Testing of a Core Competency-Based Training Workshop in Suicide Risk Assessment and Management: Notes From the Field. Journal of clinical psychology, 73(3), 233-238. 
Creswell, J. W., Plano, Clark, V. L., Gutmann, M. L. \& Hanson, W. E. (2003). Advanced mixed methods research designs. Handbook of mixed methods in social and behavioral research, 209-240.

Creswell, J. W. \& Plano Clark, V. L. (2011). Designing and conducting mixed methods research, $2^{\text {nd }}$ Ed. Thousand Oaks, CA: Sage Publications.

de Beurs, D. P., de Groot, M. H., de Keijser, J., Mokkenstorm, J., van Duijn, E., de Winter, R. \& Kerhof, Ad. J. F. M. (2015). The effect of an e-learning train-the-trainer programme on implementation of suicide guidelines in mental health care. Journal of Affective Disorders, 175, 446-453. dx.doi.org/10.1016/j.jad.2015.01.046.

Deutsch, C. J. (1984). Self-reported sources of stress among psychotherapists. Professional Psychology: Research and Practice, 15, 833-845.

Dexter-Mazza, E. \& Freeman, K. (2003). Graduate training and the treatment of suicidal clients: The student's perspective. Suicide and life-threatening behavior, 33(2), 211-218. doi: 10.1521/suli.33.2.211.22769.

Dictionary, M. W. S. C. (1996). Merriam-Webster. Incorporated, $10^{\text {th }}$ edition edition.

Dillion, T. W., Lending, D., Thaddeus, R. C. \& Blankenship, R. (2003). Nursing selfefficacy of an integrated clinical and administrative information system. Computers Informatics Nursing, 21(4), 198-205. 00024665-200307000-00010.

Duberstein, P. R., Conwell, Y., \& Caine, E. D. (1993). Interpersonal stressors, substance abuse, and suicide. The Journal of nervous and mental disease, 181(2), 80-85.

Durkheim, E. (1951). Suicide: A study in sociology. Routledge.

Elliot, A. J. \& Dweck, C. S. (2013). Handbook of competence and motivation. New York, NY: Guilford Press. 
Fallucco, E., Conlon, M., Gale, G., Constantino, J. \& Glowinski, A. (2011). Use of standardized patient paradigm to enhance a proficiency in risk assessment for adolescent depression and suicide. Journal of Adolescent Health, 51(1), 66-72. dx.doi.org/10.1016/j.jadohealth.2011.12.026.

Feldman, B. \& Freedenthal, S. (2006). Social work education in suicide intervention and prevention: An unmet need? Suicide and Life-Threatening Behavior, 36(4), 467480. doi: 10.1521/suli.2006.36.4.467.

Feltz, D., Short, S. \& Sullivan, P. (2008). Self-efficacy in sport: Research and strategies for working with athletes, teams and coaches. International Journal of Sports Science \& Coaching, 3(2), 293-295.

Fenwick, C. d., Vassilas, C. A., Carter, H. \& Haque, M.S. (2004). Training health professionals in the recognition, assessment and management of suicide risk. International Journal of Psychiatry in Clinical Practice, 8(2), 117-121. doi:10.1080/13651500410005658.

Fergusson, D. M., Woodward, L. J. \& Horwood, L. J. (2000). Risk factors and life processes associated with the onset of suicidal behavior during adolescence and early adulthood. Psychological Medicine, 30(1), 23-29. doi:10.1017/S003329179900135X.

Fowler, J. C. (2012). Suicide risk assessment in clinical practice: Pragmatic guidelines for imperfect assessments. Psychotherapy, 49(1), 81-90. doi: 10.1037/a0026148.

Fraser, S. L., Geoffroy, D., Chachamovich, E., \& Kirmayer, L. (2015). Changing rates of suicide ideation and attempts among Inuit youth: A gender-based analysis of risk and protective factors. Suicide and Life Threatening Behavior, 45(2), 141-156. 
Fretchtling, J. A. (2007). Logic modeling methods in program evaluation. San Francisco, CA: Joseey-Bass.

Gaynes, B. N., West, S.L., Ford, C. A., Frame, P., Klein, J., \& Lohr, K. N. (2004). Screening for suicide risk in adults: A summary of the evidence for the U.S. preventive services task force. Annals of Internal Medicine, 140(10), 822-835. doi:10.7326/0003-4819-140-10-200405180-00023.

Ghoncheh, R., Gould, M. S., Twisk, J. W., Kerkhof, A. J., \& Koot, H. M. (2016). Efficacy of adolescent suicide prevention e-learning modules for gatekeepers: a randomized controlled trial. JMIR mental health, 3(1), e8.

Gist, M. E. \& Mitchell, T. (1992). Self-efficacy: A theoretical analysis of its determinants and malleability. Academy of Management Review, 17(2), 183-211. doi: 10.5465/AMR.1992.4279530.

Goodstadt, M. (2014). The use of logic models in health promotion practice.pdf.

Gould, M., Munfakh, J., Kleinman, M. \& Lake, A. (2012). National suicide prevention lifeline: Enhancing mental health care for suicidal individuals and other people in crisis. Suicide and life-threatening behavior, 42(1), 22-35. doi:10.1111/j.1943278X.2011.00068.x.

Graham, R., Rudd, M. D., Bryan, C. (2011). Primary care provider's views regarding assessing and treating suicidal patients. Suicide and Life-Threatening Behavior, 41(6), 614-623. doi: 10.1111/j.1943-278X.2011.00058.x.

Handley, T. E., Kay-Lambkin, F. J., Baker, A. L., Lewin, T. J., Kelly, B. J., Inder, K. J., ... $\&$ and

Kavanagh, D. J. (2013). Incidental treatment effects of CBT on suicidal ideation 
hopelessness. Journal of affective disorders, 151(1), 275-283.

Harned, M. S., Lungu, A., Wilks, C. R., \& Linehan, M. M. (2016). Evaluating a multimedia tool for suicide risk assessment and management: the linehan suicide safety net. Journal of clinical psychology, 73(3), 308-318.

Harris, E. C., Barraclough, B. (1997). Suicide as an outcome for mental disorders: A meta- analysis. The British Journal of Psychiatry, 170(3, 205.228.

Harter S. (1982). The perceived competence scale for children. Wiley on behalf of the Society for Research in Child Development, 53(1), 87-97. doi:10.2307/1129640.

Hawgood, J. L., Krysinkska, K. E., Ide, N. \& Leo D. D. (2008). Is suicide prevention taught in medical schools? Medical Teacher, 30(3), 287-295. doi: 10.1080/01421590701753542.

Heller, N. R. (2017). The Limits and Possibilities of Risk Assessment: Lessons from

Suicide Prevention. In S. Stanford, E. Sharland, N.R. Heller \& J. Warner (Eds.), Beyond The Risk Paradigm in Mental Health Policy and Practice (71-83 ). New York: Red Globe Press.

Hoaglin, D. C., \& Iglewicz, B. (1987). Fine-tuning some resistant rules for outlier labeling. Journal of the American Statistical Association, 82(400), 1147-1149.

Hooper, L., Epstein, S., Weinfurt, K., DeCoster, J., Qu, L., \& Hannah, N. (2012). Predictors of primary care physician's self-reported intention to conduct suicide risk assessments. The Journal of Behavioral Health Services and Research, 39(2), 103115. 
Hung, E., Binder, R., Fordwood, S., Hall, S., Cramer, R., McNiel, D. (2012). A method for evaluating competency in assessment and management of suicide risk. Academic Psychiatry, 36(1), 23-28. doi:10.1176/appi.ap.10110160.

Inman, D. J., Bascue, L. O., Kahn, W. J. \& Shaw, P. A. (1984). The relationship between suicide knowledge and suicide interviewing skill. Death Education, 8(2-3), 179- 184. doi.org/10.1080/07481188408252456.

Isaac, M., Elias, B., Katz, L., Belik, S., Deane, F., Enns, M., \& Sareen, J. (2009).

Gatekeeper training as a preventative intervention for suicide: A systematic review. $L a$ Revue canadienne de psychiatrie, 54(4), 260-268.

Jacobson, J. M., Ting, L., Sanders, S. \& Harrington, D. (2004). Prevalence of and reactions to fatal and nonfatal client suicidal behaviors: a national study of mental health social workers. Omega: Journal of Death and Dying, 49, 237-248.

Jacobson, J. M., Osteen, P. J., Sharpe, T. L. \& Pastoor, J. B. (2012). Randomized trial of suicide gatekeeper training for social work students. Research on Social Work Practice, doi: 1049731511436015.

Jahn, D. R., Quinnett, P., \& Ries, R. (2016). The influence of training and experience on mental health practitioners' comfort working with suicidal individuals. Professional Psychology: Research and Practice, 47(2), 130-138. https://doi.org/10.1037/pro0000070

Jerusalem, M., \& Schwarzer, R. (1992). Self-efficacy as a resource factor in stress appraisal processes. In R. Schwarzer (Ed.) Self-efficacy. Thought control of action (p. 195-213). Washington, D.C.: Hemisphere. 
Jobes, D. A. (2017). Clinical assessment and treatment of suicidal risk: A critique of contemporary care and CAMS as a possible remedy. Practice Innovations, 2(4), 207-220. https://doi.org/10.1037/pri0000054

Jobes, D. (2006). Managing suicidal risk: A collaborative approach. New York: Guilford Press.

Jobes, D. \& Berman, A. (1993). Suicide and malpractice liability: Assessing and revising policies, procedures and practice in outpatient settings. Professional Psychology: Research and Practice, 24(1), 91-99. doi:10.1037/0735-7028.24.1.91.

Joint Commission. (2018). Accreditation and Certification on Suicide Risks. Retrieved from https://www.jointcommission.org/issues/article.aspx.

Joint Commission. (2010a). Sentinel even alert: A follow-up report on preventing suicide. Focus on medical/surgical units and the emergency department. Retrieved from httP://www.jointcomissio.org/assets/1/18/SEA_46.pdf.

Kaplan, S. A. \& Garrett, K. E. (2005). The use of logic model by community based initiatives. Evaluation and Program Planning, 28(2), 167-172. doi.org/10.1016/j.evalprogplan.2004.09.002.

Kaslow, N. J., Sherry, A., Bethea, K., Wyckoff, S., Compton, M. T., Grall, J. B.,...Parker, R.

(2005). Social risk and protective factors for suicide attempts in low income African American men and women. Suicide and Life-Threatening Behavior, (35)4, 400-412. doi: 10.1521/suli.2005.35.4.400.

Kellogg, W. K. (2004). Logic Model Development Guide [Electronic Version]. Michigan: WK Kellogg Foundation. 
Kessler, R. C., Warner, C. H., Ivany, C., Petukhova, M. V., Rose, S., Bromet, E. J., ... \& Fullerton, C. S. (2015). Predicting suicides after psychiatric hospitalization in US Army soldiers: the Army Study to Assess Risk and Resilience in Service members (Army STARRS). JAMA psychiatry, 72(1), 49-57.

Kleespies, P., Penk. W., \& Forsyth, J. (1993). The stress of patient suicidal behavior during clinical training: Incidence, impact and recovery. Professional Psychology: Research and Practice, 24(3), 293-303. doi:10.1037/0735-7028.24.3.293.

Knesper, D. J., American Association of Suicidology, \& Suicide Prevention Resource Center. (2010) Continuity of care for suicide prevention and research: Suicide attempts and suicide deaths subsequent to discharge from the emergency

department or inpatient unit. Newton, MA: Education Development Center, Inc.

Kral, M. J., Links, P. S. \& Bergmans, Y. (2012). Suicide studies and the need for mixed methods. Journal of Mixed Methods Research, 6(3), 236-249. doi: $10.1177 / 1558689811423914$.

Lafferty, C. K. \& Mahoney, C. A. (2003). A framework for evaluating comprehensive community initiatives. Health Promotion Practice 4(1), 31-44. doi: $10.1177 / 1524839902238289$.

Lapierre, S., Erlangsen, A., Waern, M., De Leo, D., Oyama, H., Scocco, P.,...Quinnett, P. (2011). A systematic review of elderly suicide prevention programs. The Journal of Crisis Intervention and Suicide Prevention, 32(2), 88-98. doi:10.1027/0227-5910/a000076.

Le Deist, F. D. \& Winterton, J. (2005). What is competence? Human Resource Development International, 8(1), 27-46. doi: 10.1080/1367886042000338227. 
Lent, R. W., Cinamon, R. G., Bryan, N. A., Jezzi, M. M., Martin, H. \& Lim, R. (2009). Perceived sources of change in trainees' self-efficacy beliefs. Psychotherapy: Theory, Research, Practice \& Training, 46(3), 317-327.

Lewinsohn, P. M., Rohde, P. \& Seeley, J. R. (1993). Psychosocial characteristics of adolescents with a history of suicide attempts. Journal of the American Academy of Child \& Adolescent Psychiatry, 32(1), 60-68. doi:10.1097/00004583-19930100000009.

Liebling-Boccio, D., \& Jennings, H. (2013). The current status of graduate training in suicide risk assessment. Psychology in the School, 50 (1), 72-86.

Linehan, M. (1993). Cognitive-behavioral treatment of borderline personality disorder. New York, NY: Guildford Press.

Linehan, M.M. (2009) University of Washington Risk Assessment Action Protocol: UWRAMP, University of WA, Unpublished Work.

Linehan, M., Comtois, K., Ward-Ciesielski, E. (2012). Assessing and managing risk with suicidal individuals. Cognitive and behavioral practice, 19(2), 218-232.

Linehan, M. Cognitive-behavioral treatment of borderline personality disorder.New York: Guilford Press.

Linehan, M. M., Korslund, K. E., Harned, M. S., Gallop, R. J., Lungu, A., Neacsiu, A. D., ... \& Murray-Gregory, A. M. (2015). Dialectical behavior therapy for high suicide risk in individuals with borderline personality disorder: a randomized clinical trial and component analysis. JAMA psychiatry, 72(5), 475-482.

London, P. (1986). Major issues in psychotherapy integration. International Journal of Eclectic Psychotherapy, 5(3), 211-216. 
Luoma, J. B., Martin, C .E. \& Person, J. L. (2002). Contact with mental health and primary care providers before suicide: A review of the evidence. American Journal of Psychiatry, 159(6), 909-916. doi:10.1176/appi.ajp.159.6.909.

Lustig, J. L., Ozer, E. M., Adams, S. H., Wibbelsman, C. J., Fuster, C. D., Bonar, R. W. \& Irwin, C. E. (2001). Improving the delivery of adolescent clinical preventive services through skills-based learning. Pediatrics, 107(5), 1100-1107. doi: 10.1542/peds.107.5.1100.

Luszcynska, A., Gutierrez-Dona, B. \& Schwarzer, R. (2005). General self-efficacy in various domains of human functioning: Evidence from five countries. International Journal of Psychology, 40(2), 80-89.

Mackelprang, J., Karle, J., Reihl, K. \& Cash, R. (2014). Suicide intervention skills:

Graduate training and exposure to suicide among psychology trainees. Training and education in professional psychology, 8(2), 135 - 142.

Mann, J. J., Apter, A., Bertolote, J. Beautrais, A., Currier, D., Haas, A.,... \&Hendin, H. (2005). Suicide prevention strategies: A systematic review. JAMA, 294(16), 20642074. doi: 10.1001/jama.294.16.2064.

McAdams III, C. R., \& Foster, V. A. (2000). Client Suicide: Its Frequency and Impact on Counselors. Journal of Mental Health Counseling, 22(2).

McLaughlin, J. A. \& Jordan, G. B. (1999). Logic models: a tool for telling your programs performance story. Evaluation and Program Planning, 22(1), 65-72. doi.org/10.1016/S0149-7189(98)00042-1. 
McLean, J., Maxwell, M., Platt, S., Harris, F. M. \& Jepson, R. (2008). Risk and protective factors for suicide and suicidal behavior. A literature review.

McMain, S. F., Guimond, T., Barnhart, R., Habinski, L., \& Streiner, D. L. (2017). A randomized trial of brief dialectical behaviour therapy skills training in suicidal patients suffering from borderline disorder. Acta Psychiatrica Scandinavica, 135(2), $138-148$.

McNiel, D. E., Fordwood, S., Weaver, C. M., Chamberlain, J. R., Hall, St. E. \& Binder, R.

L. (2008). Effects of training on suicide risk assessment. Psychiatric Services, 59(12), 1462-1465. doi:10.1176/ps.2008.59.12.1462.

Mertler \& Vannatta, R. (2010). Advanced and Multivariate Statistical Methods, ${ }^{\text {th }}$ Ed. California: Pyrezak Publishing.

Millar, A., Simeone, R. S. \& Carnevale, J. T. (2001). Logic models: a system tool for performance management. Evaluation and Program Planning, 24(1), 73-81. doi.org/10.1016/S0149-7189(00)00048-3.

Molnar, B. E., Berkman, L. F. \& Buka, S.L. (2001). Psychopathology, childhood sexual abuse and other childhood adversities: Relative links to subsequent suicidal behavior in the US. Psychological Medicine, 31(6), 965-977. doi.org/10.1017/S0033291701004329.

Moody, C. \& Smith, N. G. (2013). Suicide protective factors among trans adults. Archives of Sexual Behavior, 42(5), 739-752. doi:10.1007/s10508-013-0099-8.

National Action Alliance for Suicide Prevention (2013). Retrieved March 1, 2013 from http://actionallianceforsuicideprevention.org/resources. 
National Association of Social Workers (NASW). (2014). Code of ethics of the National Association of Social Workers: Ethical principles. Washington, D.D.: Author. Retrieved on July 8, 2014 from http://www.socialwrkers.org/cod.asp/National.

National Institute of Mental Health (2013). Retrieved March 1, 2013 from https://www.nimh.nih.gov/index.shtml.

Neimeyer, R. A. (2000). Suicide and hastened death: Toward a training agenda for counseling psychology. The Counseling Psychologist, 28(4), 551-560. doi:10.1177/0011000000284005

Neimeyer, R. A., Fortner, B. \& Melby, D. (2001). Personal and professional factors and suicide intervention skills. Suicide and Life-Threatening Behavior, 31(1), 71-82. 10.1521/suli.31.1.71.21307.

Nock, M. K., Hwang, I., Sampson, N. A. \& Kessler, R. C. (2010). Mental disorders, comorbidity and suicidal behavior: Results from the national comorbidity survey replication. Molecular Psychiatry, 15(8), 868-876. doi: 10.1038/mp.2009.29.

Nock, M. K., Borges, G., \& Ono, Y. (Eds.) (2012). Suicide: Global Perspectives from the WHO World Mental Health Surveys. New York: Cambridge University Press.

Nock, M. K., Deming, C. A., Fullerton, C. S., Gilman, S. E., Goldenberg, M., Kessler, R. C., ...\& Schoenbaum, M. (2013). Suicide among soldiers: a review of psychosocial risk and protective factors. Psychiatry, 76(2), 97-125.

Orlinsky, D. Y. \& Howard, K. (1986). Process and outcome in psychotherapy. In S.L. Garfield \& A. E. Bergin (Eds.), Handbook of psychopathology and behavior change (pp. 311-383). New York: Wiley. 
Oordt, M., Jobes, D., Fonseca, V., \& Schmidt, S. (2009). Training mental health professionals to assess and manage suicidal behavior: Can provider confidence and practice behaviors be altered? Suicide and life-threatening behavior, 39(1), 21-32. doi: 10.1521/suli.2009.39.1.21.

Osteen, P., Frey, J. \& Ko, J. (2014). Advancing training to identify, intervene, and follow up with individuals at risk for suicide through research. American journal of preventive medicine, 47(3), S216-S221.

Ozer, E. M., Adams, S. H., Lustig, J. L., Gee, S., Garber, A. K., Gardner, L. R.,....Irwin, C. E. (2005). Increasing the screening and counseling of adolescents for risky health behaviors: a primary care intervention. Pediatrics, 115(4), 960-968. doi: 10.1542/peds.2004-0520

Page, A., Morrell, S., \& Taylor, R. (2002). Suicide and political regime in New South Wales and Australia during the 20th century. Journal of Epidemiology \& Community Health, 56(10), 766-772.

Palmer, S. (2008). Suicide: Definitions, statistics, and interventions at the international level. In S. Palmer (ED.) Suicide: Strategies and interventions for reduction and prevention. (PP. 11-26). London and New York: Routledge.

Palmieri, G., Forghieri, M., Ferrari, Sl., Pingani, L., Coppola, P., Colombini, N.,....Neimeyer, R. A. (2008). Suicide intervention skills in health professionals: A multidisciplinary comparison. Archives of Suicide Research, 12(3), 232-237. doi: 10.1080/13811110802101047.

Pajares, F. (2002). Gender and perceived self-efficacy in self-regulated learning. Theory Into Practice, 41(2), 116-125. 
Pedhazur, E. J. \& Schmelkin, L. P. (2013). Measurement, design and analysis: An integrated approach. New York, NY: Psychology Press.

Petrovich, A. (2004). Using self-efficacy theory in social work teaching. Journal of Social Work Education, 40(3), 429-443.

Pisani, A. R., Cross, W. F. \& Gould, M. S. (2011). The assessment and management of suicide risk: State of workshop education. Suicide and Life-Threatening Behavior, 41(3), 255-276. doi: 10.1111/j.1943-278X.2011.00026.x.

Pope, K. S. \& Tabachnik, B. G. (1993). Therapist's anger, fear and sexual feelings: National survey of therapist responses, client characteristics, critical, formal complaints, and training. Professional Psychology: Research and Practice, 24, $142-152$.

Office of the Surgeon General, National Action Alliance for Suicide Prevention. National strategy for suicide prevention: goals and objectives for action, 2012 [Internet]. Washington (DC) : Department of Health and Human Services ; 2012 Retrieved from: https://www.surgeongeneral.gov/library/reports/national-strategy-suicideprevention/index.html 655-679. 10.1002/j.2168-9830.2011.tb00031.x.

Qi, X., Tong, S., Hu, W. (2009). Preliminary spatiotemporal analysis of the association between socio-environmental factors and suicide. Environmental Health, 8(1), 4658. doi:10.1186/1476-069X-8-46.

Question, Persuade, Refer Institute. (2014). Retrieved on June 5, 2014 from https://www.qprinstitute.com/. 
Qin, P., \& Nordentoft, M. (2005). Suicide risk in relation to psychiatric hospitalization:

evidence based on longitudinal registers. Archives of general psychiatry, 62(4), 427432.

Quinnett, P. (2010). Suicide risk assessment competency certification examination. Retrieved June 23, 2014, from http://courses.qprinstitute.com/

Ramberg, I. L. \& Wasserman, D. (2003). The roles of knowledge and supervision in work with suicidal patients. Nordic Journal of Psychiatry, 57(5), 365-371. doi: 10.1080/08039480310002705.

Regehr, C., Bogo, M., LeBlanc, V. R., Baird, S., Paterson, J. \& Birze, A. (2015). Suicide risk assessment: Clinician's confidence in their professional judgment. Jo9urnal of Loss and Trauma, O(0), 1-17. doi: 10.1080/15325024.2015.1072012

Roggenbaum, S., Annette, C. \& Leblanc, A. (20120. Suicide assessment and prevention during and after emergency commitment. Community Mental Health, 48, 741-745.

Roy, A., Segal, N. L., Centerwall, B. S., \& Robinette, C. (1991). Suicide in twins. Archives of General Psychiatry, 48(1), 29-32. doi:10.1001/archpsyc.1991.0181025003 1003.

Roy, A., Segal, N. L. \& Sarchiapone, M. (1995). Attempted suicide among living co-twins of twin suicide victims. The American journal of psychiatry, 152(7), 1075-1076.

Rubin, A., \& Babbie, E. (2011). Research methods for social work. USA: Brooks/Cole, Cengage Learning.

Rudd, M. D., Joiner, T. \& Rajad, M. H. (1996). Relationships among suicide ideators, attempters, and multiple attempters in a young-adult sample. Journal of Abnormal Psychology, 105(4), 541-550. doi:10.1037/0021-843X.105.4.541. 
Rudd, M. D. \& Joiner, T. (1998). The assessment, management and treatment of suicidality: Toward clinically informed and balanced standards of care. Clinical Psychology: Science and Practice, 5(2), 135-150.

Rudd, M.D., Cukrowicz, K. \& Bryan, C. (2008). Core competencies in suicide risk assessment and management: Implications for supervision. Training and Education in Professional Psychology, 2(4), 219-228. doi: 10.1037/1931-3918.2.4.219.

Rutz, W., Knorring, V. L., Walinder, J. (1989). Frequency of suicide on Gotland after systematic postgraduate education of general practioners. Acta Psychiatrica Scandinavica, 802), 151-154.

Saunders, J. A., Morrow-Howell, N., Spitznagel, E., Doré, P., Proctor, E. K., \& Pescarino, R. (2006). Imputing missing data: A comparison of methods for social work researchers. Social work research, 30(1), 19-31.

Schaffer, A., Flint, A. J., Smith, E., Rothschild, A. J., Mulsant, B. H., Szanto, K.,...\& Meyers, $\quad$ B. S. (2008). Correlates of suicidality among patients with psychotic depression. $\quad$ Suicide and Life Threatening Behavior, 38(4), 403-414. doi:

10.1521/suli.2008.38.4.403.

Schlock, R. L. \& Bonham, G. S. (2003). Measuring outcomes and managing for results. Evaluation and Program Planning, 26(3), 229-235.

Scheerder, G., Reynders, A., Andriessen, K. \& Van Audenhove, C. (2010). Suicide intervention skills and related factors in community and health professionals. Suicide and Life-Threatening Behavior, 40(2), 115-124. doi:

10.1521/suli.2010.40.2.115 
Schmitz, W., Allen, M., Feldman, B., Gutin, N., Jahn, D., Kleespies, P.,..\&Simpson, S. (2012). Preventing suicide through improved training in suicide risk assessment and care: An American Association of Suicidology Task Force report addressing serious gaps in US mental health training. Suicide and life-threating behavior, 42(3), 292304. doi:10.1111/j.1943-278X.2012.00090.x.

Scholz, U., Dona, B. G., Sud, S. \& Schwarzer, R. (2002). Is general self-efficacy a universal construct? Psychometric findings from 25 countries. European Journal of Psychological Assessment, 18(3), 242-251. doi: 10.1027//1015-5759.18.3.242.

Schwarzer, R. (Ed) (1992). Self-efficacy: Thought control of action. Washington, D.C.: Hemisphere.

Schwarzer, R., \& Jerusalem, M. (1995). Generalized Self-Efficacy scale. In J. Weinman, S. Wright, \& M. Johnston, Measures in health psychology: A user's portfolio. Causal and control beliefs (pp. 35-37). Windsor, UK: NFER-NELSON.

Shaw, M., Dorling, D. \& Smith, G. D. (2002). Mortality and political climate: How suicide rates have risen during periods of conservative government, 1901-2000. Journal of Epidemiology and Community Health, 56(10), 723-725. doi:

10.1136/jech.56.10.723.

Sherer, M., Maddux, J. E., Mercandante, B., Prentice-Dunn, S., Jacobs, B. \& Rogers, R. W. (1982). The self-efficacy scale: construction and validation. Psychological Reports, 51(2), 663-671.

Smith, A., Silva, C., Covington, D. \& Joiner, Jr. T. (2014). An assessment of suiciderelated knowledge and skills among health professionals. Health psychology, 33(2), 110-119. doi.org/10.1037/a0031062. 
Statham, D. J., Heath, A. C., Madden, P. A., Bucholz, K. K., Bierut, L., Dinwiddie, S. H.,...\& Martin, N. G. (1988). Suicidal behavior: An epidemiological and genetic study. Psychological Medicine, 28(04), 839-855.

Strecher, V. J., DeVellis, B. M., Becker, M. H. \& Rosenstock, I. M. (1986). The role of self-efficacy in achieving health behavior change. Health Education and Behavior, 13(1), 73-92.

Stanley, B. \& Brown, G. K. (2012). Safety planning intervention: A brief intervention to mitigate suicide risk. Cognitive and Behavioral Practice, 19, 256-264. doi:10.1016/j.cbpra.2011.01.001.

Sue, V. M. \& Ritter, L. A. (2012). Conducting online surveys. Los Angeles, CA: Sage Publications.

Suicide Prevention Resource Center. (2011). Assessing and managing suicide risk: Core competencies for mental health professionals. Retrieved on June 27, 2015, from http://www.sprc.org/traininginstitute/amsr/clincomp.asp.

Suicide Prevention Resource Center \& Suicide Prevention Action Network USA. (2010). Charting the future of suicide prevention: A 2010 progress review of the national strategy and recommendations for the decade ahead. Retrieved June 27, 2015, from http://www.ncbi.nlm.nih.gov/books/NBK44281/pdf/TOC.pdf.

Szanto, K., Kalmar, S. Hendin, H., Rihmer, Z. \& Mann, J. (2007). A suicide prevention program in a region with a very high suicide rate. Archives of General Psychiatry, 64(8), 914-920. doi: 10.1001/archpsyc.64.8.914.

Tabachnick, B. G., \& Fidell, L. S. (2014). Using multivariate statistics (6th ed.). Essex, UK: Pearson. 
Taliaferro, L. A., \& Muehlenkamp, J. L. (2014). Risk and protective factors that distinguish adolescents who attempt suicide from those who only consider suicide in the past year. Suicide and Life-Threatening Behavior, 44(1), 6-22. doi: 10.1111/sltb.12046

Tang, M., Addison, K. D., LaSure-Bryant, D., Norman, R., O’Connell, W. \& StewartSicking, J. A. (2004). Factors that influence self-efficacy of counseling students: An exploratory study. Counselor Education and Supervision, 44(1), 70-80. doi: 10.1002/j.1556-6978.2004.tb01861.x.

Taylor, E. A. \& Stansfeld, S. A. (1984). Children who poison themselves: A clinical comparison with psychiatric controls. The British Journal of Psychiatry, 145(2)), 127-135. doi:10.1192/bjp.145.2.127.

Ting, L., Jacobson, J. M. \& Sanders, S. (2008). Available supports and coping behaviors of mental health social workers following fatal and nonfatal client suicidal behavior. Social Work, 53(3), 211-221. doi: 10.1093/sw/53.3.211.

Too, L. S., Milner, A., Bugeja, L. \& McClure, R. (2014). The socio-environmental determinants of railway suicide: A systematic review. BMC Public Health, 14(1), 20-31. doi:10.1186/1471-2458-14-403.

Trochim, W. M. K. \& Donnelly, J. P. (2008). The Research Methods Knowledge Base. $3^{\text {rd }}$ (Ed.). Atomic Dog. Mason, OH: Cengage Learning.

Tschannen-Moran, M., Hoy, A. W. \& Hoy, W. K. (1998). Teacher efficacy: Its meaning and measure. Review of Educational Research, 68(2), 202-248. doi:10.2307/1170754.

U.S Census Bureau (n.d.). Factfinder search. Accessed http://factfinder.census.gov/faces/nav/jsf/pages/index.xhtml 
United States Bureau of Labor Statistics. (2014). Occupational Outlook Handbook - Social Workers. Retrieved on July 8, 2014 from http://www.bls.gov/ooh/community-andsocial-service/social-workers.htm.

United States Department of Health and Human Services. (2001). National strategy for suicide prevention: Goals and objectives for action. Rockville, MD: Department of Health and Human Services.

Unutzer, J., Schoenbaum, M., Druss, B. G., \& Katon, W. J. (2006). Transforming mental health care at the interface with general medicine: Report for the Presidents Commission. Psychiatric Services, 57(1), 37-47. doi:10.1176/appi.ps.57.1.37.

U.S. Public Health Service. (1999). The surgeon general's call to action to prevent suicide. Retrieved on March 23, 2013 from http://www.surgeongeneral.gov/library/reports/national-strategy-suicideprevention/full_report-rev.pdf.

van Buuren, S. (2012). Flexible Imputation of Missing Data, First Edition. New York: Chapman and Hall/CRC.

van der Bijl, J. J. \& Shortridge-Baggett, L. M. (2001). The theory and measurement of the self-efficacy construct. Research and Theory for Nursing Practice, 15(3), 189-207.

Walsh, J. (2010). Theories for Direct Social Work Practice. Connecticut: Cengage Learning.

Wenzel, A., Brown G. K. \& Beck, A. (2009). Cognitive therapy for suicidal patients. Washington D.C.: American Psychological Association. 
Westman, J., Sundquist, J., Johansson, L. M., Johansson, S. E. \& Sundquist, K. (2006). Country of birth and suicide: A follow-up study of a national cohort in Sweden. Archives of Suicide Research, 10(3), 239-248. doi: 10.1080/13811110600582471.

Wharff, E. A., Ross, A. M., Lambert, S. (2014). Field note-developing suicide risk assessment training for hospital social workers: An academic-community partnership. Journal of Social Work Education, 50(1), 184-190.

doi:10.1080/10437797.2014.856249

Wagler, R. (2011). The impact of vicarious experiences and field experience classroom characteristics on preservice elementary science teaching efficacy. Electronic Journal of Science Education, 15(2), 1-28.

Wise, J. B. \& Trunnell, E. P. (2001). The influence of sources of self-efficacy upon efficacy strength. Journal of Sport \& Exercise Psychology, 23, 268-280.

Wolitzky- Taylor, K., Ruggiero, K., McCart, M., Smith, D., Hanson, R., Resnick, H., ...Kilpatrick, D. (2010). Has Adolescent Suicidality Decreased in the United States? Data from Two National Samples of Adolescents Interviewed in 1995 and 2005. Journal of Clinical Child and Adolescent Psychology, 39(1), 64-76.

World Health Organization. (2013). Retrieved on March 25, 2013 from http://www.who.int/mental_health/prevention/suicide/suicideprevent/en/.

Wurst, F., Mueller, S., Petitjean, S., Euler, S., Thon, N., Wiesbeck, G. \& Wolfersdorf, M. (2010). Patient suicide: A survey of therapist's reactions, Suicide and lifethreatening behavior, 40(4), 328-336. doi:10.1521/suli.2010.40.4.328 
Yeh, Y.C., Huang, L. Y. \& Yeh, Y. L. (2011). Knowledge management in blended learning: Effects on professional development in creativity instruction. Computers and Education, 56(1), 146-156. doi.org/10.1016/j.compedu.2010.08.011.

Zero Suicide (2019). Retrieved March 1, 2019 from https://zerosuicide.sprc.org/ 


\section{정 \\ School of Social Work University of Missouri}

Dear Colleague:

You are cordially invited to the training "Taking the Guess Work Out: Risk Assessment and Management of Suicide". I wanted to let you know that I am conducting research to evaluate the impact of this training on your beliefs about self-efficacy and confidence in your ability to deliver the assessment and manage the suicidal client in your clinical practice. I would greatly value your feedback if you are willing to provide it. However, your participation is completely voluntary. If you choose to participate, this would involve you completing a brief pretest and posttest on the day of the training, and 3 and 6 months after the training. I am also seeking any participate who would like to participate in a focus group to discuss candidly the factors that influence confidence and competence in delivering suicidal assessments in the workplace. All the data you provide will be kept confidential.

If you have any questions about this research or about the upcoming training, please do not hesitate to contact me. In addition, you may contact the Department of Mental Health at (573) 298-1722 and speak with Dr. Ronda Reitz.

Thanks in advance for your consideration to participate in the study and we will see you soon!

Respectfully,

Rebekah Freese, MSW, LCSW

Doctoral Candidate

University of Missouri - School of Social Work 


\section{Appendix B: Consent to participate}

You are being asked to participate in a research study. The purpose of this research is to explore the perceptions of mental health providers on the impact of this training on their self-efficacy in assessing suicide risk and managing the suicidal individual.

The training program is being sponsored by the Department of Mental Health under the direction of, Dr. Ronda Reitz, Ph.D. Dr. Reitz is the Director of Dialectical Behavior Therapy Programming for the State of Missouri. The training is absolutely free to all participants.

The research study is being directed by Rebekah A. Freese, MSW, LCSW, a social work doctoral candidate, under the supervision of Professor Mansoo Yu, PhD. School of Social Work, and University of Missouri.

\section{By agreeing to participate, I understand that:}

a. This study seeks to increase the understanding of the impact of training in risk assessment and management of suicidal clients from a mental health provider's point of view.

b. My part in this research will be to complete a demographic data sheet, pre/posttest as well as a posttest 3 months from the initial training.

c. It may take up to 20 minutes to answer the questions.

d. Participation is voluntary. I am free to discontinue my participation at any time.

e. I will provide my email address for the posttest to be sent electronically after the training (e.g. 3 months post training). Posttest will be conducted by Qualtrics and will remain anonymous. Email addresses collected at the time of the training will be gathered and kept separately from the surveys.

f. To protect my identity the survey's and demographic component are free of any identifying information. The survey is anonymous.

g. I understand that I will be asked if I would like to voluntarily participate in individual interviews and by doing so will release my phone number for future contact. I am free to discontinue my participation at any time. (please initial here if you are willing to participate in this portion of the study).

h. (If applicable) If I voluntarily released my phone number to the researcher then $\mathbf{I}$ agree to be contacted by phone to arrange future interviews to discuss findings from this study. I understand the individual interview will assist the researcher in further explaining and understanding the perceptions of providers' self-efficacy in suicide risk assessment and management of suicidal clients. willing to participate in this portion of the study). (please initial here if you are

i. I understand I can also skip questions that I do not wish to answer. If I don't want to take part, there will be no penalty or loss of any benefits to which are otherwise entitled.

j. I understand the survey asks only about your professional experiences and does not contain embarrassing questions. However, your privacy is important to us. The survey is anonymous and is kept separate from any contact information you provide to us. All information you provide us will be kept on a password-protected computer in a locked office at the University Of Missouri School Of Social Work.

k. There is no cost to you for being in this study. 
1. There is no compensation to you for being in this study.

$\mathrm{m}$. If you agree to take part in this study, you may not experience a direct benefit from it. You may experience a loss of privacy if you provide contact information and it is inadvertently released. I cannot guarantee that your contact information will never be inadvertently released; however, we take extensive measures to prevent this from happening. There are no reasonably foreseeable risks. You may experience some discomfort when taking the survey or participating in the training or interviews. The foreseeable discomfort would be regarding any personal, family or client experience you have had with suicidal behaviors. Since this study and training are completely voluntary, you may stop your participation at any time. This investigator is a license professional and can assist you with any discomfort and/or resources to help support you.

This study has been approved by the MU campus Institutional Review Board (IRB) at the University of Missouri Columbia (project \#2005305). I understand that I can contact the IRB office at 483 McReynolds Hall, Columbia, MO 65211, telephone: (573)882-9585.

If I have any additional questions, I can contact Rebekah A. Freese, MSW, LCSW, Doctoral Candidate: 721 Clark Hall, University of Missouri-School of Social Work, Columbia, MO 65211 or at 573-884-8276. I can email her at freesera@missouri.edu. Dr. Mansoo Yu can be reached at: yuma@missouri.edu. 


\section{Appendix C: Pretest}

\section{LRAMP Participant Questionnaire (PRETEST)}

Participant's initials \& last five digits of cell phone (e.g. RF3-2717):

\section{The following are a few questions about you and your professional practice.}

Age:

Gender:

Racial/Ethnic Identity

What is your highest level of education?

$\square$ High School Diploma

$\square$ Bachelor's Degree

$\square$ Master's Degree

$\square$ Doctorate

$\square$ Other (describe)

Are you currently a student in higher education? $\square$ Yes $\square$ No

If yes, please indicate your anticipated degree (e.g. social work)

What is your profession?

$\square$ Licensed Professional Counselor

$\square$ Psychologist

$\square$ Licensed Master Social Worker

$\square$ Licensed Clinical Social Worker

$\square$ Psychiatrist

$\square$ Other (please describe)

Please describe any special certifications (e.g. NAFC - Certified Forensic Counselor).

What is your primary therapy practice orientation?

$\square$ Cognitive Behavioral Therapy

$\square$ Behavior Therapy

$\square$ Psychodynamic

$\square$ Dialectical Behavioral Therapy

$\square$ Humanistic

$\square$ Other (please describe)

How many years have you been practicing in the mental health field? 
How would you describe the area where you currently practice?

$\square$ Rural

$\square$ Urban (area of 50,000 or more people)

$\square$ I am not currently practicing in the field

$\square$ Other (please describe)

What is your agencies/place of practice zip code?

In the last 6 months, have you been in private practice? $\square$ Yes $\square$ No

Have you ever worked with a suicidal client at your practice? $\square$ Yes $\square$ No

If yes, how many?

Have you ever avoided seeing a client whom you suspected was suicidal due to fear of liability? Yes $\square$ No

Have you ever had a client complete suicide while under your care? $\square$ Yes $\square$ No

If yes, how many?

When did this last occur?

last month $\square$ last 6 months $\square$ last year $\square$ over a year ago

How often do you interact with suicidal clients in your practice?

$\square$ Daily
$\square$ Weekly
$\square$ Monthly
$\square$ A few times a year
$\square$ Never

In the past 3 months before this training, have you referred any of your client's to the hospital? $\square$ Yes No

If yes, how many clients?

Do you know anyone in your circle of friends or family that have completed suicide?

$\square$ Yes

No

If yes, how many?

When did this last occur?

$\square$ last month $\square$ last 6 months $\square$ last year $\square$ over a year ago

Did you receive training in risk assessment of suicide prior to this training?

$\square$ Yes

$\square$ No

If you answered yes, where did you receive your most recent training?

\begin{tabular}{ll}
$\square$ Graduate School & $\square$ Place of Employment \\
\hline$\square$ Online Training & $\square$ Training in the community \\
\hline$\square$ Other (please describe) &
\end{tabular}


If you answered yes, how many days, months or years ago was your training? (e.g. 10 days)

Did you receive training in management of suicide prior to this training?

$\square$ Yes

$\square$ No

If you answered yes, where did you receive your most recent training?

$\square$ Graduate School $\square$ Place of Employment

$\square$ Online Training $\square$ Training in the community

$\square$ Other (please describe)

If you answered yes, how many days, months or years ago was your training? (e.g. 10 days)

If you have had prior training, what best describes your most recent training?

$\square$ Lecture $\quad \square$ Workshop $\quad \square$ Required Reading $\quad \square$ Seminar $\square$ Online

Training

$\square$ Other (please describe)

Were you as a part of your job required to attend today's training?

$\square$ Yes

$\square$ No 


\section{Counselor Suicide Assessment Efficacy Survey (CSAES)}

(Adapted from Douglas, K. A. \& Morris, C.A., 2015)

Directions: There are a number of factors that can make conducting a risk assessment and management of suicide difficult for a provider. Below are several warning signs and risks a provider will face when conducting a suicide risk assessment or managing suicidal behaviors. Please read each statement and circle the corresponding level of your belief in your ability to perform the following tasks using the following scale.

\begin{tabular}{|c|c|c|c|c|}
\hline & Not True & Hardly True & $\begin{array}{l}\text { Moderately } \\
\text { True }\end{array}$ & Exactly True \\
\hline $\begin{array}{l}\text { I can effectively inquire if a client has } \\
\text { had thoughts of killing oneself. }\end{array}$ & 1 & 2 & 3 & 4 \\
\hline I can effectively assess hopelessness & 1 & 2 & 3 & 4 \\
\hline $\begin{array}{l}\text { I can effectively assess whether a } \\
\text { client has means to carry out a plan. }\end{array}$ & 1 & 2 & 3 & 4 \\
\hline $\begin{array}{l}\text { I can effectively inquire whether a } \\
\text { client has a suicide plan. }\end{array}$ & 1 & 2 & 3 & 4 \\
\hline $\begin{array}{l}\text { I can effective manage a client who } \\
\text { has a history of making suicidal } \\
\text { threats. }\end{array}$ & 1 & 2 & 3 & 4 \\
\hline $\begin{array}{l}\text { I can effectively manage a client who } \\
\text { has previously attempted suicide. }\end{array}$ & 1 & 2 & 3 & 4 \\
\hline $\begin{array}{l}\text { I am able to assess a client's level of } \\
\text { risk for a suicide attempt. }\end{array}$ & 1 & 2 & 3 & 4 \\
\hline $\begin{array}{l}\text { I can effectively ask a client about his } \\
\text { or her drug or alcohol abuse. }\end{array}$ & 1 & 2 & 3 & 4 \\
\hline $\begin{array}{l}\text { I can effectively ask a client about his } \\
\text { or her history of sexual abuse. }\end{array}$ & 1 & 2 & 3 & 4 \\
\hline $\begin{array}{l}\text { I can effectively ask a client about his } \\
\text { or her history of mental illness. }\end{array}$ & 1 & 2 & 3 & 4 \\
\hline $\begin{array}{l}\text { I can effectively ask a client questions } \\
\text { to assess whether he or she has low } \\
\text { self-esteem. }\end{array}$ & 1 & 2 & 3 & 4 \\
\hline $\begin{array}{l}\text { I can effectively assess a client's } \\
\text { acceptance of their sexuality. }\end{array}$ & 1 & 2 & 3 & 4 \\
\hline $\begin{array}{l}\text { I can effectively ask a client about his } \\
\text { or her previous suicide attempts. }\end{array}$ & 1 & 2 & 3 & 4 \\
\hline $\begin{array}{l}\text { I can effectively ask a client about his } \\
\text { or her personal history of self- } \\
\text { harming behavior. }\end{array}$ & 1 & 2 & 3 & 4 \\
\hline $\begin{array}{l}\text { I can effectively ask a client about his } \\
\text { or her family history of suicide. }\end{array}$ & 1 & 2 & 3 & 4 \\
\hline
\end{tabular}




\begin{tabular}{|l|c|c|c|c|}
\hline $\begin{array}{l}\text { I am able to manage a client if they } \\
\text { report suicidal thoughts. }\end{array}$ & 1 & 2 & 3 & 4 \\
\hline $\begin{array}{l}\text { I can appropriately take action when } \\
\text { a client is at moderate risk of suicide }\end{array}$ & 1 & 2 & 3 & 4 \\
\hline $\begin{array}{l}\text { I can appropriately take action when } \\
\text { a client is at imminent risk for } \\
\text { suicide. }\end{array}$ & 1 & 2 & 3 & 4 \\
\hline
\end{tabular}




\section{General Efficacy Scale}

(Adapted from Schwarzer, R. \& Jerusalem, M., 1995)

Directions: For each item listed below, please rate how true the following statements are about you in your professional practice.

\begin{tabular}{|c|c|c|c|c|}
\hline & Not True & Hardly True & Moderately True & Exactly True \\
\hline $\begin{array}{l}\text { 1. I can always manage to solve } \\
\text { difficult problems if I try hard } \\
\text { enough. }\end{array}$ & 1 & 2 & 3 & 4 \\
\hline $\begin{array}{l}\text { 2. If someone opposes me, I can } \\
\text { find the means and ways to get } \\
\text { what I want. }\end{array}$ & 1 & 2 & 3 & 4 \\
\hline $\begin{array}{l}\text { 3. It is easy for me to stick to my } \\
\text { aims and accomplish my goals. }\end{array}$ & 1 & 2 & 3 & 4 \\
\hline $\begin{array}{l}\text { 4. I am confident that I could } \\
\text { deal efficiently with unexpected } \\
\text { events. }\end{array}$ & 1 & 2 & 3 & 4 \\
\hline $\begin{array}{l}\text { 5. Thanks to my resourcefulness, } \\
\text { I know how to handle } \\
\text { unforeseen situations. }\end{array}$ & 1 & 2 & 3 & 4 \\
\hline $\begin{array}{l}\text { 6. I can solve most problems if I } \\
\text { invest the necessary effort. }\end{array}$ & 1 & 2 & 3 & 4 \\
\hline $\begin{array}{l}\text { 7. I can remain calm when facing } \\
\text { difficulties because I can rely on } \\
\text { my coping abilities. }\end{array}$ & 1 & 2 & 3 & 4 \\
\hline $\begin{array}{l}\text { 8. When I am confronted with a } \\
\text { problem, I can usually find } \\
\text { several solutions. }\end{array}$ & 1 & 2 & 3 & 4 \\
\hline $\begin{array}{l}\text { 9. If I am in trouble, I can usually } \\
\text { think of a solution. }\end{array}$ & 1 & 2 & 3 & 4 \\
\hline $\begin{array}{l}\text { 10. I can usually handle whatever } \\
\text { comes my way. }\end{array}$ & 1 & 2 & 3 & 4 \\
\hline
\end{tabular}


Directions: There are a number of sources that will influence an individual's self-efficacy and in particular suicide self-efficacy. The following statements pertain specifically to your past professional practice (your practice before this training).

\begin{tabular}{|c|c|c|c|c|}
\hline $\begin{array}{l}\text { In the past, as part of my } \\
\text { practice...... }\end{array}$ & Not True & Hardly True & $\begin{array}{l}\text { Moderately } \\
\text { True }\end{array}$ & Exactly True \\
\hline $\begin{array}{l}\text { I routinely conduct suicide risk } \\
\text { assessments. }\end{array}$ & 1 & 2 & 3 & 4 \\
\hline $\begin{array}{l}\text { I routinely manage client's } \\
\text { suicidal behaviors. }\end{array}$ & 1 & 2 & 3 & 4 \\
\hline $\begin{array}{l}\text { I routinely review suicide risk } \\
\text { factors. }\end{array}$ & 1 & 2 & 3 & 4 \\
\hline $\begin{array}{l}\text { I routinely review suicide } \\
\text { protective factors. }\end{array}$ & 1 & 2 & 3 & 4 \\
\hline $\begin{array}{l}\text { I routinely review suicide } \\
\text { statistics. }\end{array}$ & 1 & 2 & 3 & 4 \\
\hline $\begin{array}{l}\text { I routinely view video } \\
\text { examples of other provider's } \\
\text { conducting suicidal risk } \\
\text { assessments. }\end{array}$ & 1 & 2 & 3 & 4 \\
\hline $\begin{array}{l}\text { I routinely view video } \\
\text { examples of other provider's } \\
\text { managing suicidal behaviors. }\end{array}$ & 1 & 2 & 3 & 4 \\
\hline $\begin{array}{l}\text { I regularly receive feedback } \\
\text { from other professionals that I } \\
\text { am capable of conducting } \\
\text { suicide risk assessments. }\end{array}$ & 1 & 2 & 3 & 4 \\
\hline $\begin{array}{l}\text { I regularly receive feedback } \\
\text { from other professionals that I } \\
\text { am capable of managing a } \\
\text { client's suicidal behaviors. }\end{array}$ & 1 & 2 & 3 & 4 \\
\hline $\begin{array}{l}\text { I regularly experience feelings } \\
\text { of dread about conducting a } \\
\text { suicide risk assessment. }\end{array}$ & 1 & 2 & 3 & 4 \\
\hline $\begin{array}{l}\text { I regularly experience worry } \\
\text { thoughts about my clients } \\
\text { dying from suicide. }\end{array}$ & 1 & 2 & 3 & 4 \\
\hline $\begin{array}{l}\text { I regularly experience worry } \\
\text { thoughts that I will be liable } \\
\text { for my clients dying by suicide. }\end{array}$ & 1 & 2 & 3 & 4 \\
\hline $\begin{array}{l}\text { I regularly experience physical } \\
\text { symptoms of stress (e.g. hear } \\
\text { beating fast, increased } \\
\text { breathing rate, sweaty palms) } \\
\text { when assessing risk of suicide. }\end{array}$ & 1 & 2 & 3 & 4 \\
\hline
\end{tabular}




\begin{tabular}{|l|l|l|l|l|}
\hline $\begin{array}{l}\text { I regularly experience physical } \\
\text { symptoms of stress (e.g. hear } \\
\text { beating fast, increased }\end{array}$ & 1 & 2 & 3 & 4 \\
breathing rate, sweaty palms) \\
when managing client's risk of \\
suicide.
\end{tabular}

Thank you for taking time to complete this survey! 


\section{Appendix D: Post Test}

\section{LRAMP Participant Questionnaire (Post-Test Training) \\ Participant's initials \& last five digits of cell phone (e.g. RF3-2717): \\ Counselor Suicide Assessment Efficacy Survey (CSAES)}

(Adapted from Douglas, K. A. \& Morris, C.A., 2015)

Directions: There are a number of factors that can make conducting a risk assessment and management of suicide difficult for a provider. Below are several warning signs and risks a provider will face when conducting a suicide risk assessment or managing suicidal behaviors. Please read each statement and circle the corresponding level of your belief in your ability to perform the following tasks using the following scale.

\begin{tabular}{|l|c|c|c|c|}
\hline & Not True & Hardly True & $\begin{array}{l}\text { Moderately } \\
\text { True }\end{array}$ & Exactly True \\
\hline $\begin{array}{l}\text { I can effectively inquire if a } \\
\text { client has had thoughts of } \\
\text { killing oneself. }\end{array}$ & 1 & 2 & 3 & 4 \\
\hline $\begin{array}{l}\text { I can effectively assess } \\
\text { hopelessness }\end{array}$ & 1 & 2 & 3 & 4 \\
\hline $\begin{array}{l}\text { I can effectively assess } \\
\text { whether a client has means } \\
\text { to carry out a plan. }\end{array}$ & 1 & 2 & 3 & 4 \\
\hline $\begin{array}{l}\text { I can effectively inquire } \\
\text { whether a client has a } \\
\text { suicide plan. }\end{array}$ & 1 & 2 & 3 & 4 \\
\hline $\begin{array}{l}\text { I can effective manage a } \\
\text { client who has a history of } \\
\text { making suicidal threats. }\end{array}$ & 1 & 2 & 3 & 4 \\
\hline $\begin{array}{l}\text { I can effectively manage a } \\
\text { client who has previously } \\
\text { attempted suicide. }\end{array}$ & 1 & 2 & 3 & 4 \\
\hline $\begin{array}{l}\text { I am able to assess a client's } \\
\text { level of risk for a suicide } \\
\text { attempt. }\end{array}$ & 1 & 2 & 3 & 4 \\
\hline $\begin{array}{l}\text { I can effectively ask a client } \\
\text { about his or her drug or } \\
\text { alcohol abuse. }\end{array}$ & 1 & 2 & 3 & 4 \\
\hline $\begin{array}{l}\text { I can effectively ask a client } \\
\text { about his or her history of } \\
\text { sexual abuse. }\end{array}$ & 1 & 2 & 3 & 4 \\
\hline $\begin{array}{l}\text { I can effectively ask a client } \\
\text { about his or her history of } \\
\text { mental illness. }\end{array}$ & 1 & 2 & 3 & \\
\hline
\end{tabular}




\begin{tabular}{|l|l|l|l|l|}
\hline $\begin{array}{l}\text { I can effectively ask a client } \\
\text { questions to assess whether } \\
\text { he or she has low self- } \\
\text { esteem. }\end{array}$ & 1 & 2 & 3 & 4 \\
\hline $\begin{array}{l}\text { I can effectively assess a } \\
\text { client's acceptance of their } \\
\text { sexuality. }\end{array}$ & 1 & 2 & 3 & 4 \\
\hline $\begin{array}{l}\text { I can effectively ask a client } \\
\text { about his or her previous } \\
\text { suicide attempts. }\end{array}$ & 1 & 2 & 3 & 4 \\
\hline $\begin{array}{l}\text { I can effectively ask a client } \\
\text { about his or her personal } \\
\text { history of self-harming } \\
\text { behavior. }\end{array}$ & 1 & 2 & 3 & 4 \\
\hline $\begin{array}{l}\text { I can effectively ask a client } \\
\text { about his or her family } \\
\text { history of suicide. }\end{array}$ & 1 & 2 & 3 & 4 \\
\hline $\begin{array}{l}\text { I am able to manage a client } \\
\text { if they report suicidal } \\
\text { thoughts. }\end{array}$ & 1 & 2 & 3 & 4 \\
\hline $\begin{array}{l}\text { I can appropriately take } \\
\text { action when a client is at } \\
\text { moderate risk of suicide }\end{array}$ & 1 & 2 & 3 & \\
\hline $\begin{array}{l}\text { I can appropriately take } \\
\text { action when a client is at } \\
\text { imminent risk for suicide. }\end{array}$ & 1 & 2 & 3 & \\
\hline
\end{tabular}

General Efficacy Scale

(Adapted from Schwarzer, R. \& Jerusalem, M., 1995)

Directions: For each item listed below, please rate how true the following statements are about you in your professional practice.

\begin{tabular}{|l|c|c|c|c|}
\hline & Not True & Hardly True & Moderately True & $\begin{array}{l}\text { Exactly } \\
\text { True }\end{array}$ \\
\hline $\begin{array}{l}\text { 1. I can always manage to solve } \\
\text { difficult problems if I try hard } \\
\text { enough. }\end{array}$ & 1 & 2 & 3 & 4 \\
\hline $\begin{array}{l}\text { 2. If someone opposes me, I can } \\
\text { find the means and ways to get } \\
\text { what I want. }\end{array}$ & 1 & 2 & 3 & 4 \\
\hline $\begin{array}{l}\text { 3. It is easy for me to stick to my } \\
\text { aims and accomplish my goals. }\end{array}$ & 1 & 2 & 3 & 4 \\
\hline $\begin{array}{l}\text { 4. I am confident that I could } \\
\text { deal efficiently with unexpected } \\
\text { events. }\end{array}$ & 1 & 2 & 3 & 4 \\
\hline
\end{tabular}




\begin{tabular}{|l|c|c|c|c|}
\hline $\begin{array}{l}\text { 5. Thanks to my resourcefulness, } \\
\text { I know how to handle } \\
\text { unforeseen situations. }\end{array}$ & 1 & 2 & 3 & 4 \\
\hline $\begin{array}{l}6 . \text { I can solve most problems if I } \\
\text { invest the necessary effort. }\end{array}$ & 1 & 2 & 3 & 4 \\
\hline $\begin{array}{l}\text { 7. I can remain calm when facing } \\
\text { difficulties because I can rely on } \\
\text { my coping abilities. }\end{array}$ & 1 & 2 & 3 & 4 \\
\hline $\begin{array}{l}8 . \text { When I am confronted with a } \\
\text { problem, I can usually find } \\
\text { several solutions. }\end{array}$ & 1 & 2 & 3 & 4 \\
\hline $\begin{array}{l}\text { 9. If I am in trouble, I can usually } \\
\text { think of a solution. }\end{array}$ & 1 & 2 & 3 & 4 \\
\hline $\begin{array}{l}10 . \text { I can usually handle whatever } \\
\text { comes my way. }\end{array}$ & 1 & 2 & 3 & 4 \\
\hline
\end{tabular}


Appendix E: Training Feedback

Taking the Guess Work Out: Linehan Risk Assessment and Management of Suicide

ID\#:

The following are a few questions regarding the Training hosted by the Department of Mental Health: Taking the Guess Work Out: Linehan Risk Assessment and Management of Suicide.

\begin{tabular}{|l|l|l|l|l|l|}
\hline & $\begin{array}{l}\text { Strongly } \\
\text { Disagree }\end{array}$ & Disagree & Neutral & Agree & $\begin{array}{l}\text { Strong } \\
\text { Agree }\end{array}$ \\
\hline $\begin{array}{l}\text { 1. The objectives of the training were } \\
\text { clearly defined. }\end{array}$ & & & & & \\
\hline $\begin{array}{l}\text { 2. Participation and interaction were } \\
\text { encouraged. }\end{array}$ & & & & & \\
\hline $\begin{array}{l}\text { 3. The topics covered were relevant to } \\
\text { me. }\end{array}$ & & & & & \\
\hline $\begin{array}{l}\text { 4. The content was organized and easy } \\
\text { to follow. }\end{array}$ & & & & & \\
\hline $\begin{array}{l}\text { 5. The materials distributed were } \\
\text { helpful. }\end{array}$ & & & & & \\
\hline $\begin{array}{l}\text { 6. This training experience will be useful } \\
\text { to my work. }\end{array}$ & & & & & \\
\hline $\begin{array}{l}\text { 7. The trainer was knowledgeable about } \\
\text { the training topics. }\end{array}$ & & & & & \\
\hline 8. The trainer was well prepared. & & & & & \\
\hline 9. The training objectives were met. & & & & & \\
\hline $\begin{array}{l}\text { 10. The time allotted for the training } \\
\text { was sufficient. }\end{array}$ & & & & & \\
\hline $\begin{array}{l}\text { 11. The meeting room and facilities } \\
\text { were adequate and comfortable. }\end{array}$ & & & & & \\
\hline
\end{tabular}

12. What did you like most about the training?

13. What aspects of the training could be improved?

14. Please share any other comments:

THANK YOU FOR YOUR FEEDBACK! 
Appendix F: Agenda for Training

Taking the Guesswork Out of Suicide Assessment and Intervention Instructed by: Ronda Oswalt Reitz, PhD

Missouri Department of Mental Health

Agenda

8:00 am: $\quad$ Sign in/Pre-Test

8:30 am: $\quad$ Mindfulness Exercise

8:45 am: Overview of who attempts and how to assess suicide risk including long term factors

10:00 am: Break

10:15am: Assessing Short-Term/Imminent Risk

12:00: $\quad$ Lunch on your own

1:00 pm: Using the LRAMP to Assess Risk and Document Intervention (management)

2:15 pm: Break

2:30pm: $\quad$ General guidelines continued - completing assessment

4:30pm: Closing- Posttest 


\section{VITA}

Rebekah Ann Freese was born in Evansville, Indiana. Rebekah graduated from the University of Texas at Arlington with a Bachelor's Degree in Social Work. She worked for several years as a pediatric aids case manager for AIDS Outreach in Fort Worth, Texas and social worker at Mid-Missouri Mental Health Center before pursuing the Master of Social Work (MSW) Degree. Rebekah graduated from the University of Missouri - Columbia with the MSW Degree in 2000. Following graduation, Rebekah worked as a therapist in community mental health for Family Counseling Center for ten years. She became a clinical instructor for the University of Missouri - Columbia School of Social Work in 2008 and full-time faculty in 2011. Rebekah began her doctoral studies in 2012. Her research included activities related to suicide prevention and training for mental health providers. In April of 2019, Rebekah accepted a position as the Clinical Director of McCallum Place Eating Disorder Center in Saint Louis. Rebekah successfully defended her dissertation on May 7, 2019 and graduated from the University of Missouri in July of 2019. She plans to continue teaching and developing research. 